NIST

PUBLICATIONS

\title{
The Influence of Ignition Source on the Flaming Fire Hazard of Upholstered Furniture
}

Thomas G. Cleary

Thomas J. Ohlemiller

Kay M. Villa

Building and Fire Research Laboratory

Gaithersburg, Maryland 20899

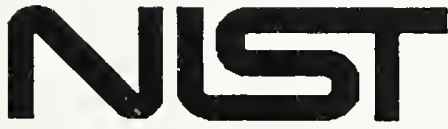

$-\mathrm{QC}$ d States Department of Commerce nology Administration

100 nal Institute of Standards and Technology

.056

4847

1992

C. 2 


$$
+
$$




\section{The Influence of Ignition Source on the Flaming Fire Hazard of Upholstered Furniture}

Thomas G. Cleary

Thomas J. Ohlemiller

Kay M. Villa

June 1992

Building and Fire Research Laboratory

National Institute of Standards and Technology

Gaithersburg, MD 20899

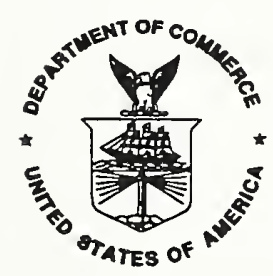

U.S. Department of Commerce

Barbara Hackman Franklin, Secretary

Technology Administration

Robert M. White, Under Secretary for Technology

National Institute of Standards and Technology

John W. Lyons, Director 

page

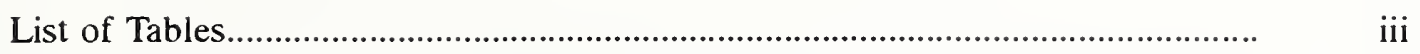

List of Figures........................................................................................ iv

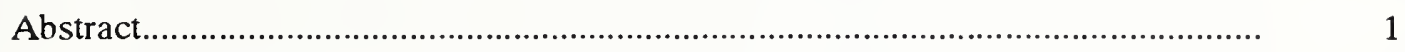

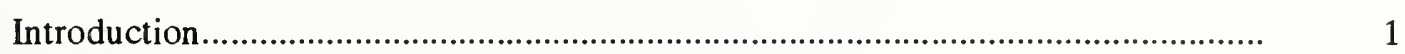

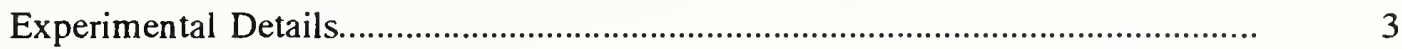

Upholstered Chairs............................................................................. 3

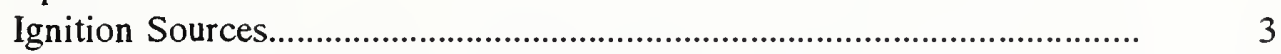

Test Apparatus................................................................................. 5

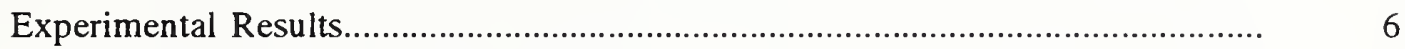



Observation of Ignition and Early Development....................................... 6

Peak Rate of Heat Release.................................................................... 8

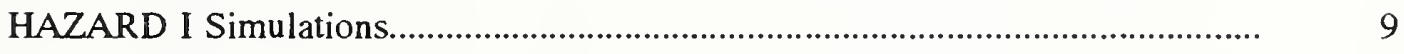

Analysis Procedure........................................................................... $\quad 10$

Results........................................................................................... 10

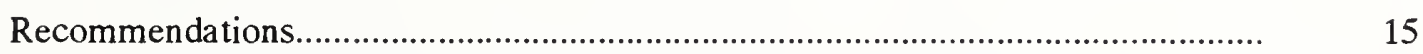

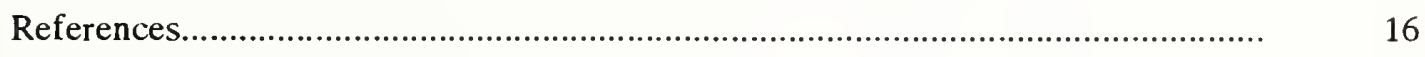

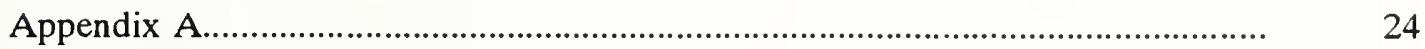



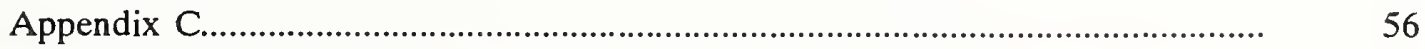


Table 1.

Table 2.

Table 3.

Table 4.

Table 5.

Table A-1.

Table A-2.

Table A-3.

Table A-4. Table A-5.

Table A-7.

Table C-1.
Characteristics of Fabric and Cushioning Material.

4

Ignition and Sustained Burning Propensity

6

Number of Predicted Deaths from HAZARD I...................................... 11

Number of Predicted Deaths from HAZARD I (fire in living room)........ 13

Number of Predicted Deaths from HAZARD I

13

(fire in living room, 1/2 original room size)

Average Heat Flux for Match Equivalent Burner.

Average Direct Contact Heat Fluxes for Various Types of Bulbs............. 26

Flux Gage Location and Average Flux Measurements for

55 W Halogen Bulb

Heat Flux Measurements of Quartz Heater.

Heat Flux Measurements of Quartz Heater........................................... 29

Heat Flux Measurements of Quartz Heater............................................. $\quad 30$

Status of Fire at Time of Occupant Alert and at Time Occupant Fate..... is Decided; Based on HAZARD I Simulations 


\section{LIST OF FIGURES}



Figure 2. $\quad$ Peak heat release rate versus time for chair type A................................. 19

Figure 3. Peak heat release rate versus time for chair type B............................. 20

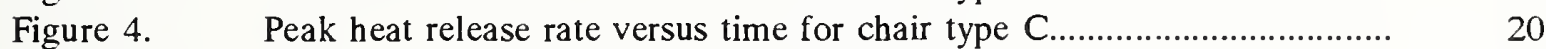

Figure 5. Peak heat release rate versus time for chair type D............................... 21

Figure 6. Peak heat release rate versus time for chair type E................................. 21

Figure 7. Floor plan of house specified in HAZARD I simulations.......................... 22

Figure 8. Total heat released versus heat release rate at time of alert...................... 23

Figure A-1. Position of heat flux gages relative to match-like flaming...................... 31

Figure A-2. Isoflux lines on vertical plane immediately behind the........................... 31

Figure A-3. Flux gage positions relative to quartz/halogen spot lamp....................... 32

Figure A-4. Approximate isoflux lines for $55 \mathrm{~W}$ quartz/halogen lamp........................ 33

Figure A-5. Schematic of quartz tube radiant heater.............................................

Figure A-6. Flux gage locations in vertical plane in front of quartz.......................... 35

Figure A-7. Isoflux lines in vertical plane......................................................... 36

Figure A-8. Flux gage locations in seat, back, and side arm of chair mock-up........... 37

Figure A-9. Isoflux line on interior of left chair arm surface due to quartz heater...... 38

Figure A-10. Isoflux lines on chair seat cushion plane due to quartz heater.................. 39

Figure A-11. Isoflux lines on chair seat back plane due to quartz heater...................... 39

Figure B-1. Furniture Calorimeter results for CTB 133 equivalent gas burner............ 41

Figure B-2. Furniture Calorimeter results for CTB 133 equivalent gas burner............ 42

Figure B-3. Furniture Calorimeter results for CTB 133 equivalent gas burner............ 43

Figure B-4. Furniture Calorimeter results for CTB 133 equivalent gas burner............ 44

Figure B-5. Furniture Calorimeter results for CTB 133 equivalent gas burner............ 45

Figure B-6. Furniture Calorimeter results for radiant heater ignition of...................... 46

Figure B-7. Furniture Calorimeter results for radiant heater ignition of...................... 47

Figure B-8. Furniture Calorimeter results for radiant heater ignition of..................... 48

Figure B-9. Furniture Calorimeter results for radiant heater ignition of........................ 49

Figure B-10. Furniture Calorimeter results for radiant heater ignition of....................... 50

Figure B-11. Furniture Calorimeter results for match-like flame ignition of................ 51

chair type B

Figure B-12. Furniture Calorimeter results for match-like flame ignition of................ 52 chair type C 
Figure B-13. Furniture Calorimeter results for match-like flame ignition of

chair type D

Figure B-14. Furniture Calorimeter results for lamp ignition of

chair type D

Figure B-15. Furniture Calorimeter results for cigarette ignition of

chair type A

Figure C-1. Heat release rate and total heat released at $t_{\text {alert }}$ and $t_{\text {fina }}$ from HAZARD I simulations for living room fire and ignitions caused by the CTB 133 equivalent gas burner

Figure C-2. Heat release rate and total heat released at $t_{\text {alert }}$ and $t_{\text {final }}$. from HAZARD I simulations for living room fire and ignitions caused by the radiant heater

Figure C-3. Heat release rate and total heat released at $t_{\text {alert }}$ and $t_{\text {final }}$ from HAZARD I simulations for living room fire and ignitions caused by the match-like flame, lamp, and cigarette


from HAZARD I simulations for bedroom fire and ignitions caused by the CTB 133 equivalent gas burner

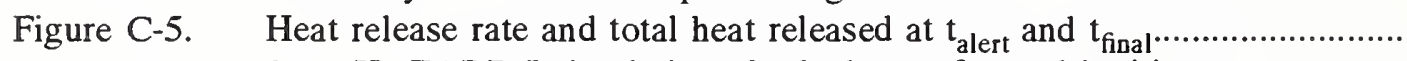
from HAZARD I simulations for bedroom fire and ignitions caused by the radiant heater

Figure C-6. Heat release rate and total heat released at $t_{\text {alert }}$ and $t_{\text {fina }}$ from HAZARD I simulations for bedroom fire and ignitions caused by the match-like flame, lamp, and cigarette 


\title{
The Influence of Ignition Source on the Flaming Fire Hazard of Upholstered Furniture
}

\author{
Thomas G. Cleary, Thomas J. Ohlemiller and Kay Villa
}

\begin{abstract}
A set of upholstered chairs constructed from five different fabric/foam combinations was subjected to a variety of ignition sources suggested by fire statistics. The sources included a cigarette, a small matchlike flame, an incandescent lamp, a space heater, and a large flame source (CTB 133 equivalent gas burner). The tests were performed in a furniture calorimeter where heat release rate and species production rates were obtained. For any chair type, the time to the peak heat release rate depended on the ignition sequence, but the magnitude of the peak did not, within the scatter of the data for any given chair. HAZARD I, the fire hazard assessment method developed at NIST, was used to quantify the hazard posed by the different ignition scenarios. No deaths were predicted when a working smoke detector was present. When a detector was not present, the results from the limited number of scenarios considered confirm the importance of a low peak heat release rate and a slow rate of rise to lessen the hazard of upholstered furniture fires. No one of the ignition scenarios examined consistently yielded the greatest potential hazard for all chair types tested when ignition and sustained burning was achieved. It is recommended that the hazards of upholstered furniture for residential use be assessed on the basis of resistance to small flame and cigarette ignition combined with peak heat release rate and time to peak subsequent to ignition by a strong source such as the CTB 133 equivalent gas burner.
\end{abstract}

KEYWORDS: chairs; fabrics; fire statistics; fire hazard; furniture calorimeters; hazard analysis; home fires; ignition sources; upholstered furniture

\section{$\underline{\text { Introduction }}$}

In the United States, upholstered furniture fires are the single leading cause of residential fire deaths, accounting for $23 \%$ of such deaths in the period 1983-87 [1]. Smoking materials, principally cigarettes, are implicated in the majority of these fires, about 53\%. Cigarette ignition resistance of upholstery materials is the focus of a voluntary industry standard, promulgated by the Upholstered Furniture Action Council in the late 1970's. The role of this standard in explaining a downward trend in upholstered furniture fire deaths in the early 1980's has been judged to be unclear, at best [2]. In any event, the current study is focused primarily on heat sources which cause direct flaming ignition of upholstered furniture, rather than on cigarettes which initiate smoldering combustion.

The flaming ignition sources involved in upholstered furniture fires cover a considerable spectrum but their characteristics are not always well-defined. For example, "incendiary or suspicious" ignition sources comprised nearly 15\% of residential upholstered furniture fires in 1983-87 [1]. This suggests strong, arson-like sources but these sources are not further specified in this reference. Children playing with matches, cigarette lighters or candles resulted in $10 \%$ of such fires in this time period. Such sources are relatively well-defined and, to some extent, characterized with respect to duration and heat flux [3] but this category is the exception. The nature of the remaining ignition sources is suggested by studies done by the Consumer Product Safety Commission on fire statistics from the 1970's [4]. These comprise a mix 
of sources such as space heaters, electric blankets/pads, extension cords, electric lamps, etc. Each of these types of sources obviously can vary substantially depending on particular circumstances. Further lacking with essentially all of these potential ignition sources is information on where they typically come into contact with a furniture item.

In the present, study the goal is to obtain some assessment of the extent to which the fire hazard of an upholstered furniture item depends on how it is ignited. (Whether or not ignition occurs is a very relevant part of the hazard assessment since it may not happen with some of the weaker sources.) Given the variability of ignition sources, it is quite conceivable that the time for a fire to develop to its peak level in an item of furniture might depend on where and how it is ignited. The measure of the fire "level" referred to here is the time-dependent heat release rate from the furniture fire; it is this characteristic of a fire which is believed to best characterize the potential hazard the fire would usually present in the context of a residential structure [5,6]. If the heat release rate versus time is appreciably sensitive to the details of the ignition process, this would complicate the assessment of the hazard implicit in a given design of upholstered furniture. This assessment is already made quite complex by the known sensitivity to exact material combinations used in chair construction, especially the fabric and cushioning materials [6].

In order to pursue the above goal with finite resources, it has been necessary to make somewhat arbitrary choices regarding ignition sources and upholstery materials. Five ignition sources, suggested by the above discussion, were chosen and applied, in duplicate tests, to five material combinations. The chair geometry and underlying structural materials were fixed. The chosen ignition sources were:

1) The propane gas burner now accepted as an alternative igniter in California Technical Bulletin 133 (CTB 133) [7]. This is a strong, arson-like ignition source of about $15 \mathrm{~kW}$.

2) A space heater based on a pair of quartz tubes whose principal output is radiative.

3) A match-like source now incorporated in British Standard 5852, Part 1.

4) An incandescent lamp that might mimic a reading lamp.

5) A cigarette included principally to ascertain whether the transition from smoldering to flaming constitutes a flaming ignition mode more severe than those above. (For chairs which smolder, the smoldering process may extensively preheat a large portion of the chair, thus enhancing the subsequent flaming process.)

Each source was applied at only one locale on the chair. Each location was chosen to be plausible, given the nature of the source. A related study of the effect of varied ignition location for a single ignition source is reported in Reference 15.

It was only possible to investigate five material combinations; an effort was made to choose from across the spectrum of typical residential materials but no statistical justification for the particular materials is possible.

The above combinations were tested in the NIST Furniture Calorimeter to obtain their heat release rate behavior. It is not possible to make quantitative judgements about relative or absolute hazard from these results alone. A given fire in a residential structure poses a varying hazard depending on its location, the time of day, the age and health of the occupants, presence of smoke detectors, etc. Fortunately there is a quantitative framework which allows one to estimate the net effect of all these complications; it is the 
HAZARD I methodology developed at NIST over the past several years [8]. In applying this methodology to this problem there remain numerous choices to be made to define specific scenarios. The quite limited number of scenarios which could be examined here were chosen with the aid of an extensive effort to reproduce US furniture fire statistics, employing HAZARD I $[9,10,11]$.

\section{Experimental Details}

Upholstered Chairs. As noted, the chairs all had the same geometric configuration; Figure 1 shows this shape and the dimensions. This is the same chair geometry used in our previous studies of CTB 133 [7,12]. The chairs were custom manufactured for this study by Shelby-Williams Inc.; the basic chair model is their lounge chair, Style No. $495 .^{1}$

The chair frame was composed of a mixture of hard wood structural elements and plywood panels with the latter utilized in such places as the tops of the chair arms and the front panel below the seat cushion. The seat was supported by a platform spring of steel wire.

The fabrics are described in Table 1 which also gives the letters by which all of the chairs are referred to in the report. The polyurethane, present in all of the chairs, was a conventional non-retarded material with a nominal density of $24 \mathrm{~kg} / \mathrm{m}^{3}\left(1.5 \mathrm{lb} / \mathrm{ft}^{3}\right)$. Note that only chair type $B$ incorporated a wrap of polyester batting around the foam cushions; this was avoided in the others, despite its current market popularity, in order to simplify the number of interacting materials. Chair type A did have a comparable wrap of cotton batting around the foam cushions and along the inner surface of the chair arms. This wrap, in combination with the rather light weight cotton fabric, rendered this chair type uniquely ignitable by a smoldering cigarette. (The cotton batting was nominally non-fire retarded but there were some indications during the experiments of a slight boric acid presence.)

Reference [10] gives some rough estimates of the range of upholstered furniture fabric and padding materials currently in use in the US. The results indicate that $57 \%$ of the currently used furniture has the kind of materials that would make it potentially susceptible to smoldering ignition by cigarettes; this includes furniture having a cellulosic cover fabric over cotton, latex or polyurethane materials. The remaining $43 \%$ has a thermoplastic fabric over a polyester batting and polyurethane foam. It is this latter type of furniture which is being promoted by the Upholstered Furniture Action Council because of its inherent cigarette ignition resistance. Inspection of Table 1 indicates that we have included only one type of chair representative of the biggest fraction of current usage (chair type A); the others are intended to cover the spectrum of the current market, at least in some crude sense, since a more detailed breakdown of that market is not available.

Ignition Sources. As noted, the five ignition sources used in this study were chosen to approximate the spectrum of sources indicated by U. S. fire statistics. Of course, these statistics do not provide specific information on materials and circumstances of usage which are most likely to result in furniture ignition. Lacking such information, we have tended toward choices which should accentuate the severity of the effects of the particular source.

For the future reference of those who may wish to pursue such ignition sources further, we have characterized the spatial heat flux patterns of those used here. The results are summarized in Appendix A.

\footnotetext{
${ }^{1}$ Specific brand names are mentioned for clarity only and do not imply any endorsement by the National Institute of Standards and Technology.
} 
Table 1. Characteristics of Fabrics and Cushioning Materials

\begin{tabular}{|c|l|}
\hline Chair Designation & \multicolumn{1}{|c|}{ Description } \\
\hline A & $\begin{array}{l}340-410 \mathrm{~g} / \mathrm{m}^{2}\left(10-12 \mathrm{oz} / \mathrm{yd} \mathrm{d}^{2}\right) \text { cotton fabric (no backcoating); non-retarded } \\
\text { cotton batting overwrap on polyurethane cushions }{ }^{2} \text { and on interior of side } \\
\text { arms }\end{array}$ \\
\hline B & $\begin{array}{l}63 \% \text { nylon/ 26\% olefin/ 11\% acrylic fabric with latex backcoating; non- } \\
\text { retarded polyester batting overwrap on polyurethane cushions }\end{array}$ \\
\hline C & $\begin{array}{l}100 \% \text { olefin fabric with latex backcoating; no overwrap on polyurethane } \\
\text { cushions }\end{array}$ \\
\hline D & $\begin{array}{l}\text { acrylic facing on rayon/cotton backing fabric; no overwrap on polyurethane } \\
\text { cushions }\end{array}$ \\
\hline E & expanded vinyl fabric; no overwrap on polyurethane cushions \\
\hline
\end{tabular}

For an arson-like source, the CTB 133 propane gas burner, developed and characterized at NIST, was used [7]. The burner simulates the impact of burning five crumpled sheets of newspaper piled up on the chair seat. Its use here followed CTB 133 procedure which calls for an 80 second exposure with direct flame impingement on the chair seat and seat back. This source leads to rapid involvement of the whole chair.

The feature of radiant heat sources (room heaters, light bulbs) which can potentially increase the severity of a fire is their tendency to preheat a significant portion of the upholstered furniture item. Such preheating will tend to accelerate flame spread over the surface where it has occurred. The two sources of this nature used here were thus given an opportunity to provide such preheating.

The radiant heater, described more fully in Appendix A, contains two $38 \mathrm{~cm}$ long vertical quartz tubes backed with a metallic reffector; the heater is rated at 1500 watts. To increase the severity of the preheating, the heater was placed $10 \mathrm{~cm}$ (distance from front guard grill to front edge of seat cushion) in front of the chair, centered on the left/right plane of symmetry of the chair. The preheating was thus most intense on the front edge of the seat cushion and the front panel of the chair but it extended to all surfaces visible in Figure 1. This exposure caused only a weak, localized pyrolysis of the chair materials in a 30 minute preheat time. At the end of this interval, the heater was tipped forward so that the front guard touched the front top edge of the seat cushion; pyrolysis of the fabric/foam materials was greatly accelerated so that an ignitable mixture of fuel gases was available typically in about one minute after tip over. Here, as elsewhere, the ignitability of the gases was tested at 10 second intervals with an electric spark. $^{3}$ Sustained flaming typically followed immediately and the heater was removed to prevent its destruction in the subsequent fire.

${ }^{2}$ All of the polyurethane foam was conventional unretarded material with a density of $24 \mathrm{~kg} / \mathrm{m}^{3}(1.5 \mathrm{lb} /$ $\left.\mathrm{ft}^{3}\right)$.

${ }^{3}$ The use of an electric spark is an artifice that assures ignition if, indeed, ignition is possible. It is probable that in the real world many exposures of the type used here do not progress to flaming ignition even though a flammable mixture of gases may be produced. Here it was necessary to guarantee ignition of these gases on a reproducible basis. 
The electric light source was utilized in an analogous manner, though in a location more suited to its role as a reading lamp. It should be noted that the light bulb used here was rather unique in that it was a focused quartz-halogen lamp with a more intense local heat flux than would be expected from most reading lights; in this sense it provides a worst case situation. The light (enclosed in a typical hooded desk lamp fixture) was placed near a rear comer of the chair and was allowed to preheat an area centered around the rear top of one chair arm and the side of the back seat cushion. The preheating lasted for 30 minutes, as above, but the incident heat fluxes were much lower than with the radiant heater, because the closest distance from lamp to chair was about $35 \mathrm{~cm}$. At the end of the preheat interval, the lamp was tipped onto the top of the chair arm. As a result the front of the bulb ended up about $5 \mathrm{~cm}$ from the top of the chair arm at a point about $33 \mathrm{~cm}$ from the rear end of the arm. The focused radiation from the lamp then quickly acted to cause a localized area of pyrolysis and an ignitable mixture of gases was present after about 1 to 2 minutes with certain chairs, as determined by application of the electric spark igniter in the same manner as above. The chair types which produced flaming ignition in this manner were $A$ and $D$ though the flames died in less than one minute on chair type A. The other chairs did not yield flaming ignition as a consequence of this sequence. ${ }^{4}$

The match-like flaming ignition source was adapted from British Standard 5852, Part 1. For convenience, propane was used instead of butane; this should have little impact on the heat fluxes imposed [3]. The

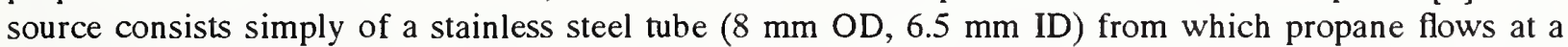
metered rate of $45 \mathrm{~cm}^{3} / \mathrm{sec}$; this produces a flame shown to be representative of a variety of matches found in Great Britain. After a two minute free burn to warm the tube, the source is placed in the top of the crevice formed by the seat cushion and the inner side arm; the flame location is approximately midway front/back along the crevice. The flame impinges on both the edge of the seat cushion and the side arm. After 20 seconds it is removed carefully so as not to extinguish what are typically quite fragile flames on the upholstery surfaces.

The cigarette used was a non-filter Pall Mall. It was lit and given 2 minutes to approach a steady state before being placed similarly to the match source above. It was not removed unless it had burned its full length with no ignition of the chair.

Test Apparatus. The tests were all performed in the NIST Furniture Calorimeter [12]. This consists of a large overhead hood which captures the plume from the burning chair. The oxygen level and flow rate of the exhaust gases are monitored continuously during a burn. From this information one can infer the amount of oxygen being used in the burning process per unit time. The amount of heat evolved per mass of oxygen consumed is nearly constant for most organic materials so that one can thus infer the rate of heat release. The chair rests on a load cell so that its mass can be recorded during a burn. The exhaust gases are also monitored for $\mathrm{CO}$ and $\mathrm{CO}_{2}$; the yields of these gases can thus be obtained.

The calorimeter was calibrated using a $0.91 \mathrm{~m}$ diameter burner which consumed natural gas. Calibration fires up to $750 \mathrm{Kw}$ were used to infer a correction factor for the raw rate of heat release data.

\footnotetext{
${ }^{4}$ Note that the preceding procedure does not directly simulate what would happen if the light-bulb broke on the chair arm. In that case the local ignition source could be expected to be briefer but more intense possibly igniting other material combinations. The subsequent rate of heat release curve would not be expected to be appreciably influenced by this change in ignition detail, however.
} 


\section{Experimental Results}

General Observations. Out of the total combination of 25 chair type/ignition source combinations, 15 combinations ignited and burned. Each test was repeated once for a total of 30 ignitions with sustained burning out of 50 tests. The CTB 133 equivalent gas burner and the radiant space heater caused ignition and sustained burning for all chair types. The match-like source caused ignition and sustained burning for three of the five chair types. The lamp and the cigarette ignited one chair type. Table 2 shows the ignition and sustained burning propensity for each chair type/ignition source combination. Here and throughout the rest of this report, we use a short-hand notation for the ignition sources as follows:

$$
\begin{aligned}
& \text { B - CTB } 133 \text { equivalent gas burner } \\
& \text { H - radiant space heater } \\
& \text { M - match-like source } \\
& \text { L - lamp } \\
& \text { C - cigarette }
\end{aligned}
$$

For the following comparisons we focus on the heat release rate results since this represents the most significant hazard for typical furniture items $[5,6]$. The results for each chair that ignited and burned are given in Appendix B. Repeated tests are shown on the same plot and indicate the level of repeatability achieved. Heat release rate, mass loss rate, $\mathrm{CO}, \mathrm{CO}_{2}$ yield, and "smoke" yield (specific extinction area from light extinction measurements) are shown there. These data are the required time-varying values used as inputs into HAZARD I (though the actual input data are in a different form).

Table 2. Ignition and Sustained Burning Propensity

\begin{tabular}{||c|c|c|c|c|c||}
\hline \multirow{2}{*}{ Chair } & \multicolumn{5}{|c||}{ Ignition Source } \\
\hline & $\checkmark$ & H & M & L & C \\
\hline A & $\checkmark$ & $\checkmark$ & & \\
\hline B & $\checkmark$ & $\checkmark$ & $\checkmark$ & & \\
\hline C & $\checkmark$ & $\checkmark$ & $\checkmark$ & & \\
\hline D & $\checkmark$ & $\checkmark$ & $\checkmark$ & $\checkmark$ & \\
\hline E & $\checkmark$ & $\checkmark$ & & & \\
\hline
\end{tabular}

Observations of Ignition and Early Development. The CTB 133 equivalent gas burner is by far the most severe in terms of heat flux exposure and area directly ignited of all of the ignition sources. This source promotes symmetrical burning of a chair due to its location, with a plane of symmetry given by cutting the chair in half from front to back. The $80 \mathrm{~s}$ duration of this source is sufficient to ignite the side arms, seat cushion and seat back cushion of the chair. The heat release rate from the ignition source is approximately $15 \mathrm{Kw}$ for the $80 \mathrm{~s}$ duration and it is included in the heat release rate curve reported here. 
The radiant space heater is positioned such that the (vertical) front portion of the seat cushion is preheated and then ignited. Surface temperatures at various positions were recorded for each chair after approximately 20 minutes of preheating; temperatures after the full 30 minutes of preheat are expected to be slightly higher. Surface temperatures for three positions, the front (vertical) center of the seat cushion (position 1, the closest distance to the source), the center of the front of the chair below the seat cushion (position 2), and the center of the seat back cushion (position 3) were recorded at the $20 \mathrm{~min}$. point as:

$\begin{array}{crrr}\text { Chair Type } & \text { Position } 1 & \text { Position } 2 & \text { Position } 3 \\ \text { A } & 157^{\circ} \mathrm{C} & 81^{\circ} \mathrm{C} & 44^{\circ} \mathrm{C} \\ \text { B } & 171^{\circ} \mathrm{C} & 80^{\circ} \mathrm{C} & 34^{\circ} \mathrm{C} \\ \mathrm{C} & 164^{\circ} \mathrm{C} & 93^{\circ} \mathrm{C} & 37^{\circ} \mathrm{C} \\ \text { D } & 204^{\circ} \mathrm{C} & 80^{\circ} \mathrm{C} & 47^{\circ} \mathrm{C} \\ \text { E } & 147^{\circ} \mathrm{C} & 91^{\circ} \mathrm{C} & 51^{\circ} \mathrm{C}\end{array}$

The temperature differences among chair types result from differing fabric weights and differing radiation absorptivities. The rate of flame spread on thick materials is expected to vary inversely as the square of the difference between the ignition temperature of the material and its initial temperature assuming heat feedback rate does not vary [14]. Given this and an estimate of $375^{\circ} \mathrm{C}$ as an ignition temperature, one infers that Position 1 temperatures imply a considerable increase in flame spread rates (2-3X) and Position 2 temperatures imply an increase of only about $30 \%$. Thus, the above temperature information, supplemented by the heat flux distribution information in Appendix A, implies that the acceleratory effect of the preheating is largely localized to the front of the chair, closest to the heater.

After ignition, the flames travel upward on the front lip of the seat cushion and then across its horizontal surface slowly at first. When the flames reach the chair arms, more upward spread is possible which accelerates the heat release rate of the chair. For the repeat test of chair $A$, the initial flames went out. This chair was allowed to smolder for an additional $3600 \mathrm{~s}$ then was ignited by electrical spark. This smoldering period did not appreciably affect the magnitude of the peak heat release rate, but it did affect the shape of the heat release rate curve in that a faster rise in heat release rate was observed. Chair types $B$ and $C$ both exhibit double peaks in the heat release rate curve. It is not obvious what causes the pronounced double peaks for these chairs.

The match-like source was placed approximately midway along the length of the inner arm of the chair at the top opening of the crevice between the seat cushion and arm. This source ignited and yielded sustained flaming for three of the five chair types. Chair type $C$ was subjected to this ignition source a total of seven times, and only yielded sustained flaming in two of those attempts. Sustained flaming with this source and chair type $C$ appeared to be a random event which depended on how the fabric opened up initially as it melted and whether the flames could anchor to the exposed foam before the flaming fabric extinguished. Here we only distinguish between chairs that ignited and those that did not ignite, and do not include an ignition probability factor in any of the analysis which follows.

The lamp ignited and yielded sustained burning of only one of the chair types (D). The maximum surface temperature after approximately 20 minutes of preheating of chair type $\mathrm{D}$ by the lamp was $37^{\circ} \mathrm{C}$. The horizontal top portion of the chair arm was ignited approximately $8 \mathrm{~cm}$ from the seat back cushion. The initial burning area grew from a few centimeters in diameter outward in a circular pattern until it reached the sides of the arm and the seat back cushion. This initial spread was a relatively slow process and was 
reflected in the very slow initial rise in the rate of heat release curve. After the flames spread to the seat back cushion, the heat release rate picked up substantially.

The cigarette source was the only source that yielded smoldering ignition initially. The lit cigarettes were laid down at the top of the crevice between the chair seat cushion and side arm, approximately midway along the length of that crevice. Only chair type A smoldered as a result of this exposure. A spontaneous transition from smoldering to flaming occurred after approximately 3 hours. Prior to the transition to flaming, approximately $100 \%$ of the seat cushion was smoldering, as indicated by light to dark brown color of the fabric. The smoldering had elevated the temperature of a large portion of the chair. This preheating effect is reflected in the shape of the heat release rate curve where the time of the peak is less and the magnitude of the peak is higher than the results from the other sources, in spite of there having been some fuel loss due to the smoldering process.

Peak Heat Release Rate. If we consider the time from the first appearance of flaming to the time to reach the peak heat release rate for all sources, that time generally is minimized with the CTB 133 equivalent gas burner. Chair type $\mathrm{A}$ is an exception; the cigarette source consistently yielded an earlier flaming peak than did the other sources, presumably because of the extensive preheating in the smoldering phase, (the second space heater test with chair D is also an exception.)

At the peak heat release rate, the exposed surfaces of the seat cushion and seat back cushion are usually fully involved in the burning for all chair types and ignition sources. At the peak, the chair arms are also involved and have either burned through to the exterior, or are close to doing so. Thus it is not surprising that the CTB 133 equivalent gas burner, which ignites a substantial fraction of all these surfaces, tends to yield the earliest peak.

The main differences in heat release behavior among the sources are in the time from initial flaming (ignition) ${ }^{5}$ to the peak heat release rate and in the magnitude of the peak. Figures 2-6 capture these features of the heat release rate curves by showing only the magnitude of the peak heat release rate (after the data was smoothed with a running three-point average) and the time from initial flaming to the peak for each chair, for each source that yielded sustained burning of that chair. The next fastest peak after the CTB 133 equivalent gas burner is achieved with the radiant space heater for most cases (the radiant space heater is third with chair type A and D), followed by the match-like source, then the lamp. Inspection of Figures 2-6 shows that, for each chair type, the magnitude of the peak heat release rates are similar regardless of ignition source, and, given the noise level in the peak heights, no definite trend in the peak heat release rate is observed for any particular ignition source, across the spectrum of chair types, with the exception being cigarette ignition of chair type A. In this last case, it does appear that the preheating during the very extended smoldering phase does facilitate more rapid flame spread over the chair surfaces yielding a higher mass loss rate and rate of heat release. The effect is not very strong, however.

It should be noted that the data in Appendix B also show appreciable (factor of two) variations in $\mathrm{CO}$ yield curves for a given chair type as the ignition source varies. This is also potentially relevant to hazard development.

${ }^{5}$ For all sources, including those involving either preheating or smoldering, time zero is taken to be the first appearance of flames. 
We can summarize the main points that emerge from examination of the experimental data as follows:

1. Some of the weak ignition sources do not have sufficient energy input to yield sustained spreading flames for all of the chair types.

2. There can be substantial differences in the time to the peak heat release rate for different ignition sources.

3. The magnitudes of the peak heat release rates for the different ignition sources, given the same chair type, are close and appear to be within the scatter of the data (cigarette ignition of chair type A appears to be an exception).

In other words, when ignition and sustained burning did occur as the result of an ignition source, the effects of extent-of-preheat, and the size of initially ignited area did not appear to significantly impact the peak heat release rate, but they did impact the time to reach the peak for these chair types.

In the related study of the effect of ignition location on heat release behavior [15], the same ignition source, a $10 \mathrm{~kW}$ gas burner (not used in the present study), was applied to four locations on chairs having the same geometry (but different materials) as those used here. The locations were: 1) the center of the seat cushion, 2) lower center of the chair back, 3) lower center of the chair front, and 4) the lower center of one side of the chair. It was found that the peak rate of heat release was independent of ignition location. However, the time at which the peak occurred could vary widely with location of the ignition source. Generally, ignition of the seat cushion gave the quickest peak. This result implies that most of the differences in heat release curves with differing ignition sources seen in the present study are a consequence of the differing locations, as well.

In order to quantify the impact of the differences between ignition sources on hazard development within a residential context, we use the HAZARD I fire hazard assessment methodology. Below we describe our approach and some results from HAZARD I.

\section{HAZARD I Simulations}

HAZARD I is a prototype fire hazard assessment methodology that can predict, to a reasonable extent, the outcome of a building fire scenario in terms of the survivability of occupants [8]. Computer models in HAZARD I include a fire and smoke transport model, a human response-to-fire model, and a model that predicts deaths of occupants based on their exposure to the environmental hazards of the fire. The PC-based software is limited to a total of six individual rooms including the fire room. The user specifies the room sizes and layout. The fire, in the form of a heat release rate curve, is a prescribed input to the model. The fire and smoke transport model is a so-called zone model where each room is split into upper and lower layers. Transport of the smoke and hot gases into and out of individual rooms is calculated. The temperatures, chemical species concentrations, and heat release rates of both the upper and lower layer are some of the variables calculated. The occupancy set is specified by the user. Each person must be specified according to their sex, age, position (i.e., room), whether they are awake or asleep, whether they are intoxicated, and whether they require assistance in order to flee the fire. For a given fire scenario, HAZARD I predicts whether or not the occupants will escape the building or die. The time to escape and the exit route or, alternatively, the time, location, and cause of death are provided for each occupant. 
The National Fire Protection Research Foundation sponsored an effort to develop a fire risk assessment method for new products that utilized HAZARD I as the fire outcome predictor [9-11]. That program attempted to reproduce the U.S. national fire statistics for various specific fire scenarios. One case studied extensively was upholstered furniture fires in residences. That study was employed here to focus and guide the procedure for quantifying the differences between ignition sources with respect to fire hazard.

Analysis Procedure. A six room, one story ranch house was selected for the computations here since U.S. census data, as quoted in Reference [9], indicate that approximately $70 \%$ of single family homes are onestory (this is the same building configuration used in the NFPRF upholstered furniture study [10]). A floor plan for the ranch house is shown in figure 7. For the occupant set it was not possible to select a most prevalent set since, from census data as quoted in reference [10], the frequency of any one set is small (the distribution is broad). The occupant set selected consisted of a father, mother, infant, and grandmother. The infant and grandmother require assistance to move and thus each must be rescued by either the father or mother. The scenario is based on a night-time fire, therefore, all occupants were placed in bedrooms and assumed to be asleep. A daytime fire scenario would result in few or no casualties due to rapid detection of the fire and subsequently rapid escape.

HAZARD I simulations were run with and without a working smoke detector (with a working smoke detector, HAZARD I determines the time of detector response). Based on fire statistics quoted in reference [9], the probability that a working smoke detector is present in a house where a fire occurs is approximately 19\%. In HAZARD I, it is assumed that smoke has an odor to it and can wake up sleeping occupants; the thicker the smoke, the stronger the stimulus to awake and alert occupants. Thus, that is the main mechanism by which the occupants are alerted to the fire if no properly functioning smoke detector is present. HAZARD I was run two separate times specifying the fire as being in the living room/dining room or as being in the master bedroom since most upholstered furniture fires occur in these spaces [10].

The measured data from each chair burn were input into HAZARD I to describe the fire ${ }^{6}$. A total of 30 chairs was burned, and two separate fire locations were specified (living room/dining room and master bedroom), therefore 60 simulations of the smoke and heat transport were run. In addition, the escape and tenability program had to be run twice (with a working smoke detector and without a working smoke detector) for each of the fire simulations. It was assumed that once occupants reached a window they could escape after a $20 \mathrm{~s}$ delay. This was the delay time specified and used in the NFPRF project [10].

Results. Table 3 shows the results for all of the simulations in terms of total deaths for each chair type/ignition source combination. Note that the maximum possible number of deaths in any box in the Table is 32.

\footnotetext{
${ }^{6}$ Time resolved data that is input into HAZARD I is limited to a maximum of 21 points at user specified times. Thus the heat release rate curve was approximated by selecting a limited number of values representative of the curve.
} 
Table 3. Number of Predicted Deaths from HAZARD I

\begin{tabular}{|c|c|c|c|c|c|c|}
\hline \multirow{2}{*}{$\begin{array}{c}\text { Chair } \\
\text { Type }\end{array}$} & \multicolumn{7}{|c|}{ Ignition Source } \\
\cline { 2 - 7 } & $\mathrm{E}$ & $\mathrm{H}$ & $\mathrm{M}$ & $\mathrm{L}$ & $\mathrm{C}$ & $\sum$ \\
\hline A & 12 & $\boldsymbol{2}$ & NI & NI & 0 & 16 \\
\hline B & 12 & 8 & 8 & NI & NI & 28 \\
\hline C & 8 & 4 & 2 & NI & NI & 14 \\
\hline D & 8 & 8 & 6 & 10 & NI & 32 \\
\hline E & 0 & 0 & NI & NI & NI & 0 \\
\hline$\sum$ & 40 & 24 & 10 & 16 & 0 & 90 \\
\hline
\end{tabular}

None of the chair fires was large enough by itself to cause flashover in the room of origin (assuming a flashover criterion of a $600^{\circ} \mathrm{C}$ upper layer temperature), and since we only consider the chair rate of heat release and not any secondarily ignited items, the concomitant increase in CO due to ventilation limitations as a fire approaches flashover $[5,13]$ was not included here. This approach differs from that of the NFPRF project committee in that they supplemented their generic upholstered furniture heat release rate curve by adding a " $\mathrm{t}^{2}$ fire" ${ }^{7}$ to the heat release rate curve when the peak heat release rate for the chair was reached. This served to model secondarily ignited items in the room and essentially forced the fire to flashover if a sufficient oxygen supply rate was available $[9,10]$. In every case run here, the occupants either escaped the house or were incapacitated by temperature (convected heat) prior to the observed peak heat release rate, therefore the provision of secondarily ignited items behaving in accord with the NFPRF study is inconsequential for these simulations. This lack of dependence of the outcome on secondary item ignition simplifies the present analysis but it cannot be said to be a general result.

It should be reiterated that the input fire is the chair heat release rate, mass loss rate, and species production rates from an open-configuration furniture calorimeter where the chairs are tested in essentially a free-burning condition. No heat feedback from hot walls or hot accumulated gases is taken into account in these simulations. In general, an item will burn more vigorously in an enclosure due to the heat feedback from the surroundings as those surroundings become heated by the fire. This type of heat feedback becomes more pronounced at high upper layer gas temperatures, and since the upper layer gas temperature in an enclosure is a strong function of the heat release rate, one would not expect a big effect at low heat release rates. Indeed, Parker observed that for upholstered chairs similar to the ones tested here, the heat release rate results from the furniture calorimeter and room fire tests in the proposed ASTM room were nearly identical up to an output of approximately $600 \mathrm{~kW} \mathrm{[12].} \mathrm{In} \mathrm{the} \mathrm{HAZARD} \mathrm{I} \mathrm{simulations}$ run here, the outcome (prediction of escape or of death) was usually decided prior to the maximum heat release rate (usually below $600 \mathrm{~kW}$ but occasionally up to $800 \mathrm{~kW}$ ). This suggests that increased burning rates due to room effects would not appreciably change the results here.

${ }^{7} \mathrm{~A}$ " $\mathrm{t}^{2}$ fire" is a specified fire that grows in terms of heat release rate as the square of time. A constant multiplier determines the absolute value, dictated by the fire load posed by other objects. 
In a majority of these cases the reason the occupants could not escape the building was due to incapacitation from heat exposure (a temperature criterion specified in HAZARD I), and in $86 \%$ of the cases the cause of death was due to heat exposure. Lethal conditions from smoke inhalation usually followed death due to convected heat exposure by a long time interval. The $14 \%$ of the deaths not attributed to heat exposure were caused by smoke inhalation. The living room/dining room fire scenario accounted for all smoke inhalation deaths. The lethal conditions were given by the concentration-time criterion [9]. The concentration-time criterion specifies a constant smoke toxic potency. Here a value of $900 \mathrm{mg}-\mathrm{min} / \mathrm{l}$ was assumed; this is the same value specified in the NFPRF study [10]. Evidently the differences in $\mathrm{CO}$ yield curves noted above are not relevant to the fire scenarios examined here. A factor of three increase in the smoke toxic potency to $300 \mathrm{mg}-\mathrm{min} / \mathrm{l} \mathrm{did} \mathrm{not} \mathrm{yield} \mathrm{an} \mathrm{increase} \mathrm{in} \mathrm{the} \mathrm{number} \mathrm{of}$ deaths attributed to the smoke, but it did hasten time of death for the original $14 \%$ of deaths caused by smoke inhalation. In the NFPRF study it was found that toxic potency had to be increased by an order of magnitude in order for smoke inhalation to account for the majority of furniture fire deaths [11].

No deaths were observed in any case where a working smoke detector was prescribed. The alarm from the detector woke the occupants and they were able to escape before they were exposed to fatal fire conditions. This result emphasizes the significant safety impact smoke detectors can have. It is also noteworthy that it applies regardless of the severity of the ignition source examined here.

On the other hand, Table 3, which applies to cases where a working smoke detector was not present, does point to some relative differences between the hazards from the various ignition sources. In all cases except one, the number of deaths from the CTB 133 equivalent gas burner is the highest, compared to the other sources, for any given chair type, with the exceptions being ignition of chair type $D$ with the lamp and a tie between ignition with the CTB 133 equivalent gas burner and the radiant space heater of chair type D. Also, the number of deaths from fires initiated with the radiant space heater is at least as great as the number for all other sources except the CTB 133 equivalent gas burner (again lamp ignition of chair type $\mathrm{D}$ is the exception).

Therefore, based on Table 3, one might conclude that the fire hazard of an upholstered chair is significantly dependent on the nature of the ignition source and the scenario chosen irrespective of the chair make-up. Intuitively, this conclusion seems plausible, but analysis of a subset of the data provides a counter argument to that conclusion. Table 4 shows the simulation results for the fire originating in the living room/dining room only. Here it is observed that the CTB 133 equivalent gas burner is the worst case fire for only one of the chair types (chair type C). In addition, for chair type $\mathrm{D}$, the radiant space heater, the match-like source and the lamp are equally the worst case ignition scenarios. Evidently, remoteness from the room of fire origin makes the rapid early spread found with the largest ignition sources less relevant in the overall hazard development. Thus one cannot make the generalization that the larger sources are always more hazardous.

Furthermore, as a check on sensitivity to fire room size and total house volume, the living room/dining room fire simulations were re-run after specifying a fire room floor area of $1 / 2$ the original size (therefore the local room volume was decreased by $1 / 2$ and the total house volume was decreased by $20 \%$ ). The simulation results are shown in Table 5. Contrary to expectations, the total number of deaths actually decreased slightly from the original simulations. Also, there is some shift in scenario/death numbers. The CTB 133 equivalent gas burner dominates the death predictions for 3 chair types. In the cases where both the match-like source and radiant space heater ignited and yielded sustained burning of the chairs (types $B, C, D)$, the total number of deaths is the same (i.e., 12). The lamp ignition scenario of chair type D yields the maximum number of deaths for that chair. Again, the larger source is not necessarily the most hazardous. 
Table 4. Number of Predicted Deaths from HAZARD I

(fire in living room/dining room)

\begin{tabular}{|c|c|c|c|c|c|c||}
\hline \multirow{2}{*}{$\begin{array}{c}\text { Chair } \\
\text { Type }\end{array}$} & \multicolumn{7}{|c|}{ Ignition Source } \\
\cline { 2 - 7 } & B & H & M & L & C & $\sum$ \\
\hline A & 4 & 4 & NI & NI & 0 & 8 \\
\hline B & 8 & 6 & 6 & NI & NI & 22 \\
\hline C & 8 & 4 & 2 & NI & NI & 10 \\
\hline A & 4 & 6 & 6 & 8 & NI & 22 \\
\hline E & 0 & 0 & NI & NI & NI & 0 \\
\hline$\sum$ & 24 & 22 & 14 & 6 & 0 & 66 \\
\hline
\end{tabular}

Table 5. Number of Predicted Deaths from HAZARD I

(fire in living room/dining room, $1 / 2$ original room size)

\begin{tabular}{||c|c|c|c|c|c|c||}
\hline \multirow{2}{*}{$\begin{array}{c}\text { Chair } \\
\text { Type }\end{array}$} & \multicolumn{7}{|c||}{ Ignition Source } \\
\cline { 2 - 7 } & B & H & M & L & C & $\sum$ \\
\hline A & 0 & 4 & NI & NI & 0 & 4 \\
\hline B & 8 & 6 & 4 & NI & NI & 18 \\
\hline C & 6 & 0 & 4 & NI & NI & 10 \\
\hline D & 4 & 6 & 4 & 8 & NI & 22 \\
\hline D & 2 & 5 & NI & NI & NI & 2 \\
\hline$\sum$ & 20 & 16 & 12 & 8 & 0 & 56 \\
\hline
\end{tabular}

The results above demonstrate that the potential hazard for a given chair type depends on both the ignition source and the scenario. Therefore, no specific ignition source out of those chosen for this study clearly presents the greatest potential hazard for all chair types in the limited set of fire scenarios considered.

Considering only the simulations where the original house size was specified, and with no smoke detector present, a total of 60 simulations was run. Of these 60 simulations, 28 resulted in fatalities, with 21 living room/dining room and 7 bedroom scenarios proving fatal. These 60 simulations consist of 30 pairs of identical test and simulation conditions with the different, repeated, furniture calorimeter results input into 
HAZARD I. Eight of these 30 pairs of repeat burns gave different results in terms of the outcome of the simulations (they split between predicting deaths versus not predicting deaths). Exploration of this sensitivity to the variations in repeated chair burns indicates that it is due, in most part, to differences in smoke production of the chairs and not to slight differences between the heat release rate curves of the repeated tests. In one of these eight cases the occupants chose to exit through the fire room because of low smoke which proved to be fatal, whereas in the repeated chair burn higher smoke levels persuaded the occupants to chose an alternate, though less direct route through windows. In four of the eight cases, dense smoke trapped the occupants whereas, in the repeat chair burns, smoke opacities were lower, making escape possible. In three of the eight cases, alert times were delayed because of lower smoke output, which allowed the occupants less time to make rescues or escape thus proving fatal, whereas higher smoke output for the repeat chair burns decreased the alert time, allowing escape.

Appendix $\mathrm{C}$ shows, in both tabular and graphical form, the status of the fire (heat release rate and total heat released) at two critical times. The first time is that at which an occupant is alerted to the fire; the second is that at which it is clear that at least one occupant will die (due to incapacitation or entrapment leading to death) or all occupants will escape. The difference between these two times is also indicated. It is sobering to note that this time difference is almost always less than 30 seconds.

Figure 8 shows the total heat released versus the heat release rate of each chair at the time of alert. The dark symbols indicate predicted deaths for the specific scenario while open symbols indicate no deaths. All of the predicted deaths occurred when the total heat released was $10 \mathrm{MJ}$ or greater at the time of alert, and of these all are greater than $15 \mathrm{MJ}$ except for one simulation. In that simulation, excessive smoke trapped the occupants in the early stages of the fire. In addition, all simulations where the size of the fire at the time of alert was greater than $450 \mathrm{~kW}$ proved fatal. These observations hint at, but do not firmly establish, the kinds of limitations on heat release behavior that could substantially cut down on furniture fire fatalities.

From these simulations one can draw the following conclusions:

1. The presence of a working smoke detector has a dramatic impact on the survivability of occupants exposed to the furniture fire scenarios considered here.

2. No single one of the ignition sources utilized here always presents the greatest potential hazard for all chair types. When chair ignition occurs and burning is sustained, ignition source rankings (in terms of the number of predicted deaths) are not always maintained for the fire scenarios considered here.

3. Rate of heat release is an important parameter. Slow fire growth rates and relatively low peak heat release rates are desirable to reduce the predicted deaths for the scenarios considered here.

4. Since residential fire statistics indicate that the majority of fires derive from cigarettes and small flames and, since this and other studies indicate small flame ignition resistance is possible, such resistance must be considered as another key element in reducing upholstered furniture fire deaths.

We must point out some of the limitations and caveats of the preceding hazard analysis. First, the numerical results are not known to be representative in any way of statistical fire data. The chair types were not picked to represent a known cross-section of chairs in use in residences today, but were picked only to be representative of a wide range of fabric combinations. Second, U.S. fire statistics implicate 
cigarette ignition in a large fraction of upholstered furniture ignitions where the furnishing was the first item ignited, and fires initiated by cigarettes are a major cause of fire deaths. In the analysis above, the one chair type that did smolder and burst into flames did not kill anyone in these simulations, but that fact is tempered by the realization that only two fire/occupant-set scenarios were considered out of the many identified in the NFPRF report, and the fact that no probability weighting factors for these specific scenarios were attached to the results. Third, toxic potency was not fully addressed since only $\mathrm{CO}, \mathrm{CO}_{2}$, $\mathrm{O}_{2}$ species concentrations were predicted. The toxicological impact of other species produced ( $\mathrm{HCN}$ or $\mathrm{HCl}$ for example) in addition to those measured is not known.

\section{$\underline{\text { Recommendations }}$}

Certain recommendations pertaining to the measurement of upholstered furniture flammability and performance criteria guidelines can be made based on the work performed in this study and on previous published results. First, it makes sense to enhance resistance to ignition from cigarettes and small flame sources since, from the fire statistics, these types of ignition sources are the most frequent causes of upholstered furniture ignition. It is clear that such resistance can be achieved. Second, limitations on the peak heat release rate and rate of fire growth (following ignition by, for example, the CTB 133 equivalent gas burner) would reduce the number of deaths due to furniture items that did ignite irrespective of the ignition source. Limitations on the rate of heat release would also affect, in a positive (hazard reducing) manner, the propensity of the furniture fire to ignite secondary items through radiant heat transfer [5]. Third, toxic potency of upholstered furniture combustion products must be addressed more fully to quantify the fire hazard in a definitive manner. 


\section{$\underline{\text { References }}$}

1. Miller, A., What's Burning in Home Fires, NFPA Journal, Sept./Oct., 1991.

2. Miller, A., Where There's Smoking There's Fire, NFPA Journal, Jan./Feb., 1991.

3. Paul, K.T., and Christian, S.D., Standard Flaming Ignition Sources for Upholstered Composites, Furniture and Bed Assembly Tests, J. Fire Sciences, 5, 1987, p.178-211

4. Harwood, B., and Kale, D., Fires in Upholstered Furniture, U.S. Consumer Product Safety Commission, May, 1980.

5. Quintiere, J.G., Furniture Flammability: An Investigation of the California Technical Bulletin 133 Test. Part I: Measuring the Hazards of Furniture Fires, NISTIR 4360, Natl. Inst. Stand. Tech. (1990).

6. Babrauskus, V., and Krasny, J.F., Fire Behavior of Upholstered Furniture, NBS Monograph 173, Natl. Bur. Stand., 1985.

7. Ohlemiller, T.J., Villa K., Furniture Flammability: An Investigation of the California Bulletin 133 Test. Part II: Characterization of the Ignition Source and Comparable Gas Burner, NISTIR 4348, U.S. Natl. Inst. Stand. Tech., (1990)

8. Bukowski, R.W., Peacock, R.D., Jones, W.W., and Forney, C.L., Technical Reference Guide for the HAZARD I Fire Hazard Assessment Method, NIST Handbook 146, Volume II, Natl. Inst. Stand. Tech., Gaithersburg, MD. (1989).

9. Bukowski, R.W., Stiefel, S.W., Hall Jr,. J.R., and Clarke, F.B., Fire Risk Assessment Method: Description of Methodology, available from the National Fire Protection Research Foundation, Quincy, MA 02269, 1990.

10. Bukowski, R.W., Clarke, F.B., Hall Jr, J.R., and Stiefel, S.W., Fire Risk Assessment Method: Case Study 1 Upholstered Furniture in Residences, available from the National Fire Protection Research Foundation, Quincy, MA 02269, 1990.

11. Clarke, F.B., Bukowski, R.W., Stiefel, S.W., Hall Jr, J.R., and Steele, S.A., The National Fire Risk Assessment Research Project Final Report, available from the National Fire Protection Research Foundation, Quincy, MA 02269, 1990.

12. Parker, W.J., Tu, K., Nurbakhsh, S., and Damant, G.H., Furniture Flammability: An Investigation of the California Technical Bulletin 133 Test. Part III: Full Scale Chair Burns., NISTIR 4375, Natl. Inst. Stand. Tech., Gaithersburg MD, (1990).

13. Beyler, C.L., Major Species Production by Solid Fuels in a Two Layer Compartment Fire Environment, Proceedings of the Fire Safety Science 1st. Int. Symp., Hemisphere Pub. Corp. , NY, pp. 431-440, (1986).

14. Quintiere, J.G., Surface Flame Spread, The SFPE Handbook of Fire Protection Engineering, SFPE/NFPA, 1-360, Sept. 1988. 
15. Mitler, H., and Tu, K., Furniture Flammability Report to be published, 1992 


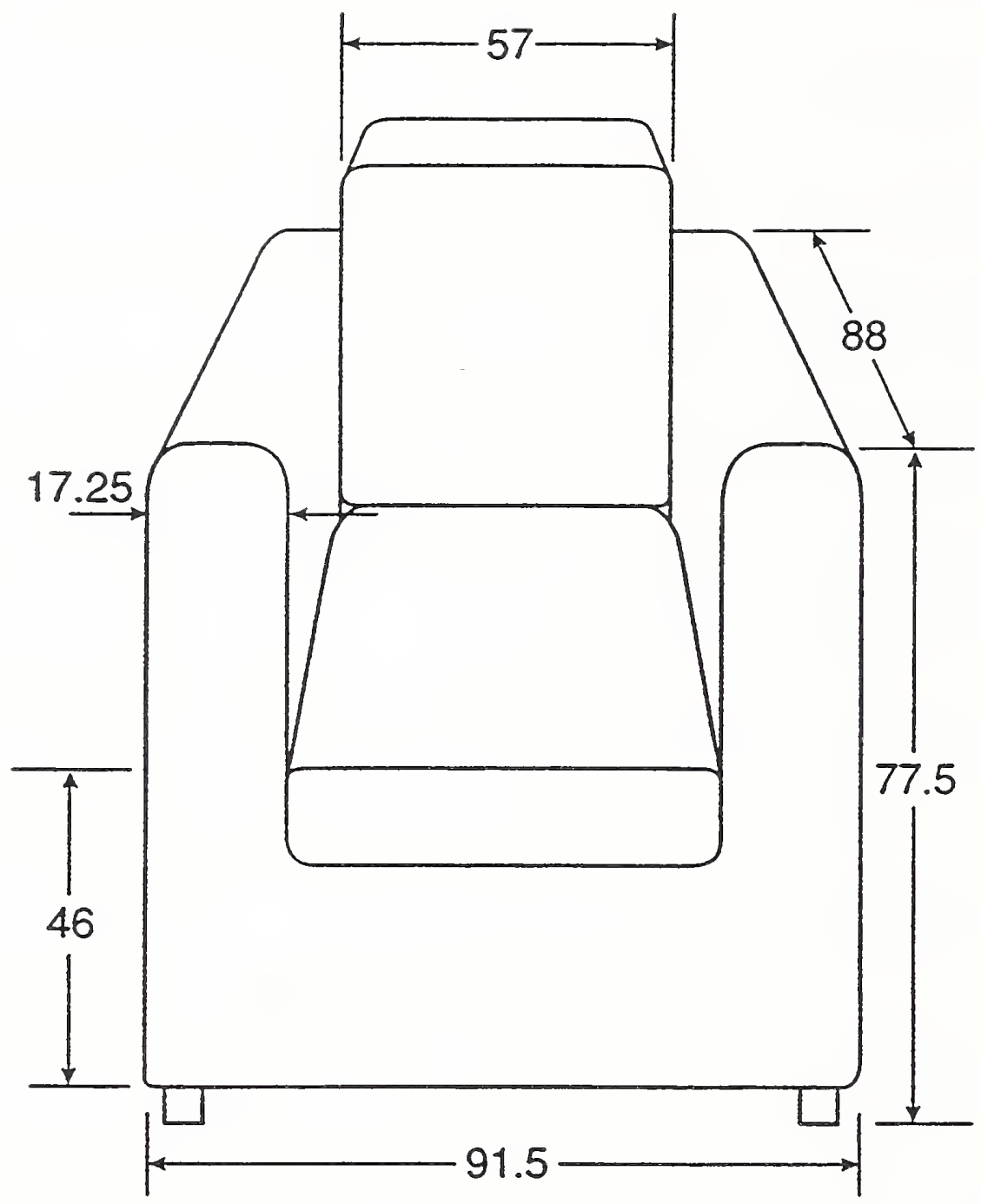

All dimensions in centimeters

Figure 1. Style of chair tested 




Figure 2. Peak heat release rate versus time for various ignition scenarios applied to chair type $A$. Time $=0$ at sustained flaming.



Figure 3. Peak heat release rate versus time for various ignition scenarios applied to chair type B. Time $=0$ at sustained flaming. 


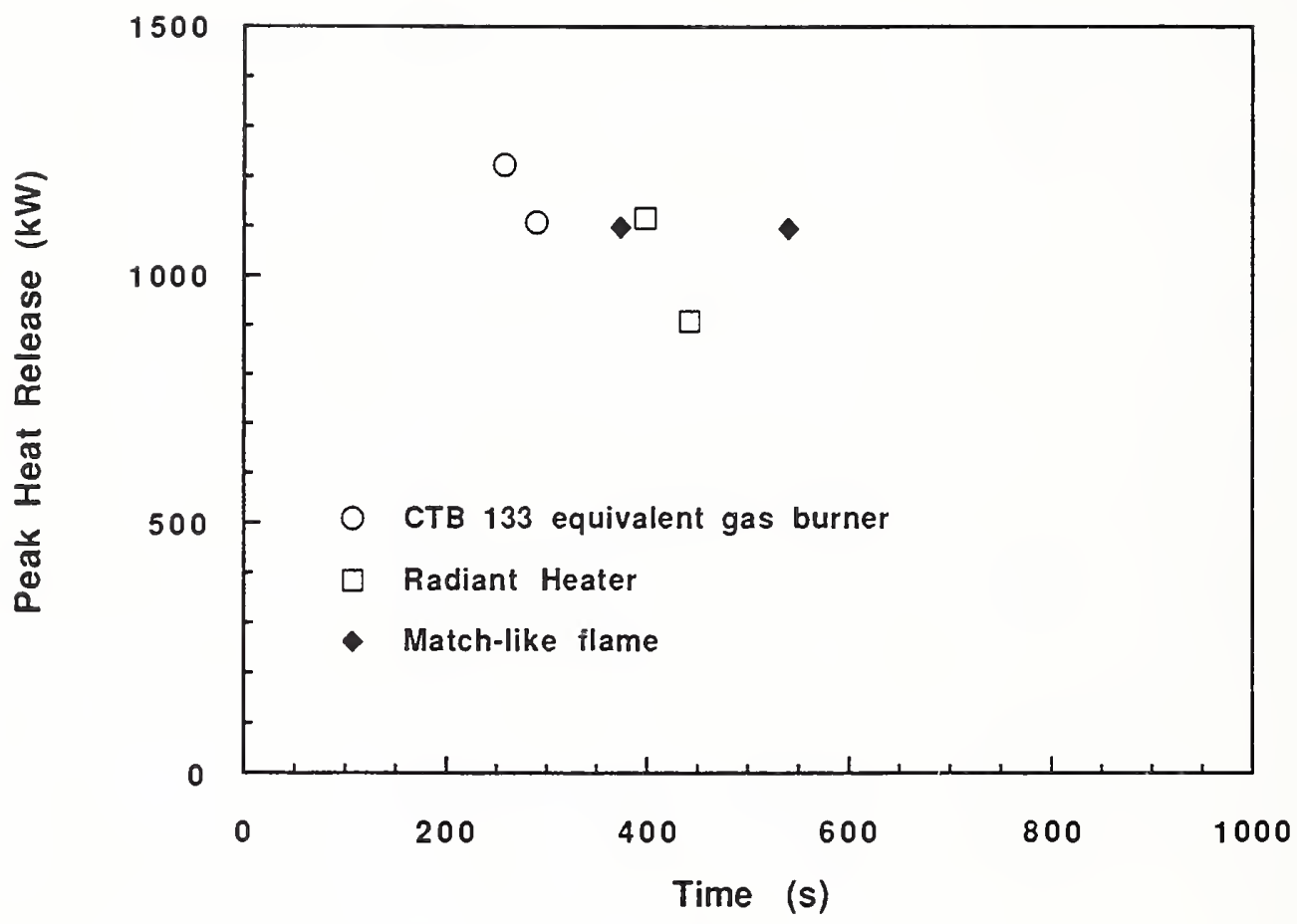

Figure 4. Peak heat release rate versus time for various ignition scenarios applied to chair type $\mathrm{C}$. Time $=0$ at sustained flaming.

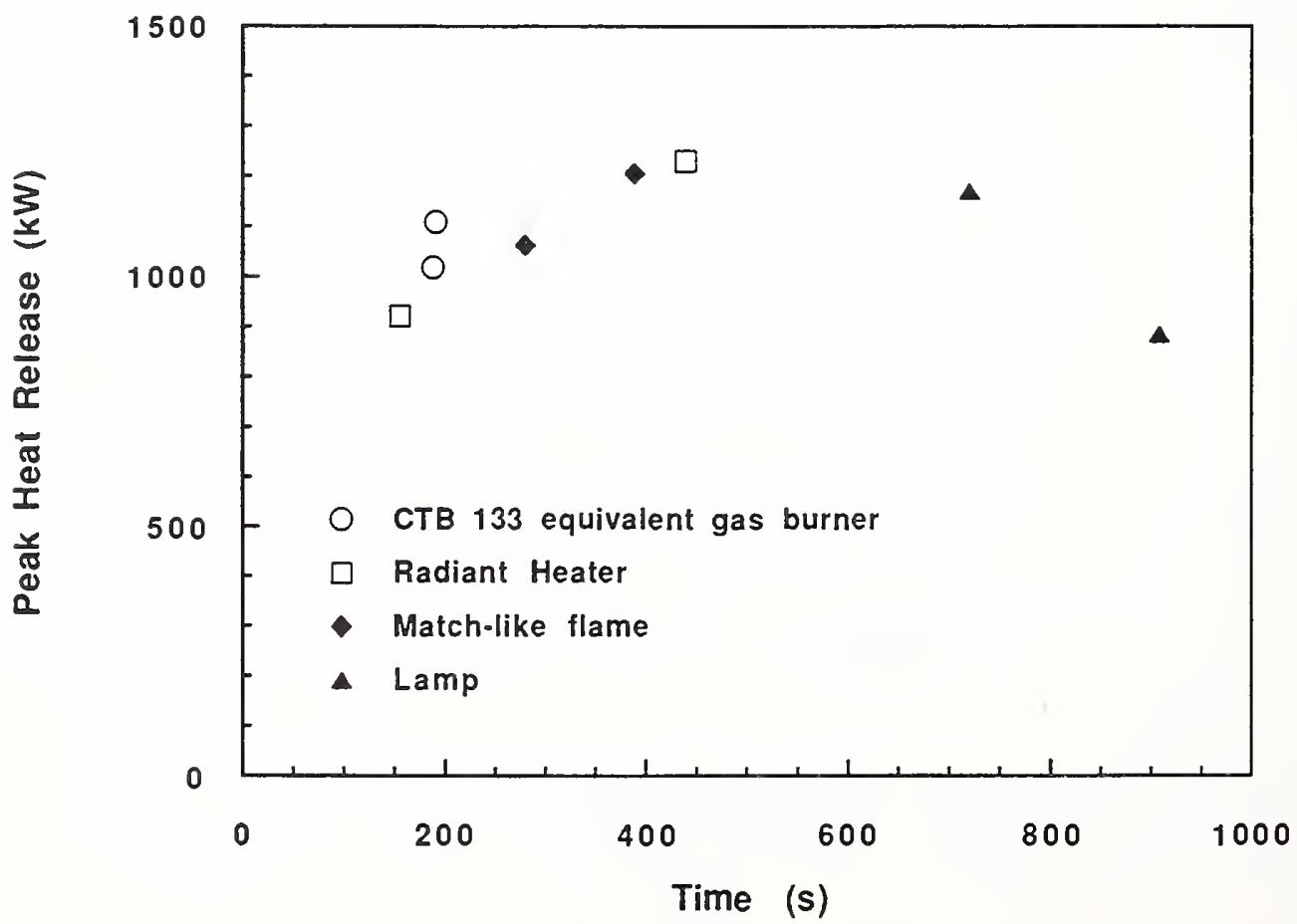

Figure 5. Peak heat release rate versus time for various ignition scenarios applied to chair type D. Time $=0$ at sustained flaming. 




Figure 6. Peak heat release rate versus time for various ignition scenarios applied to chair type $\mathrm{E}$. Time $=0$ at sustained flaming. 




Figure 7. Floor plan of house specified in HAZARD I simulations. 


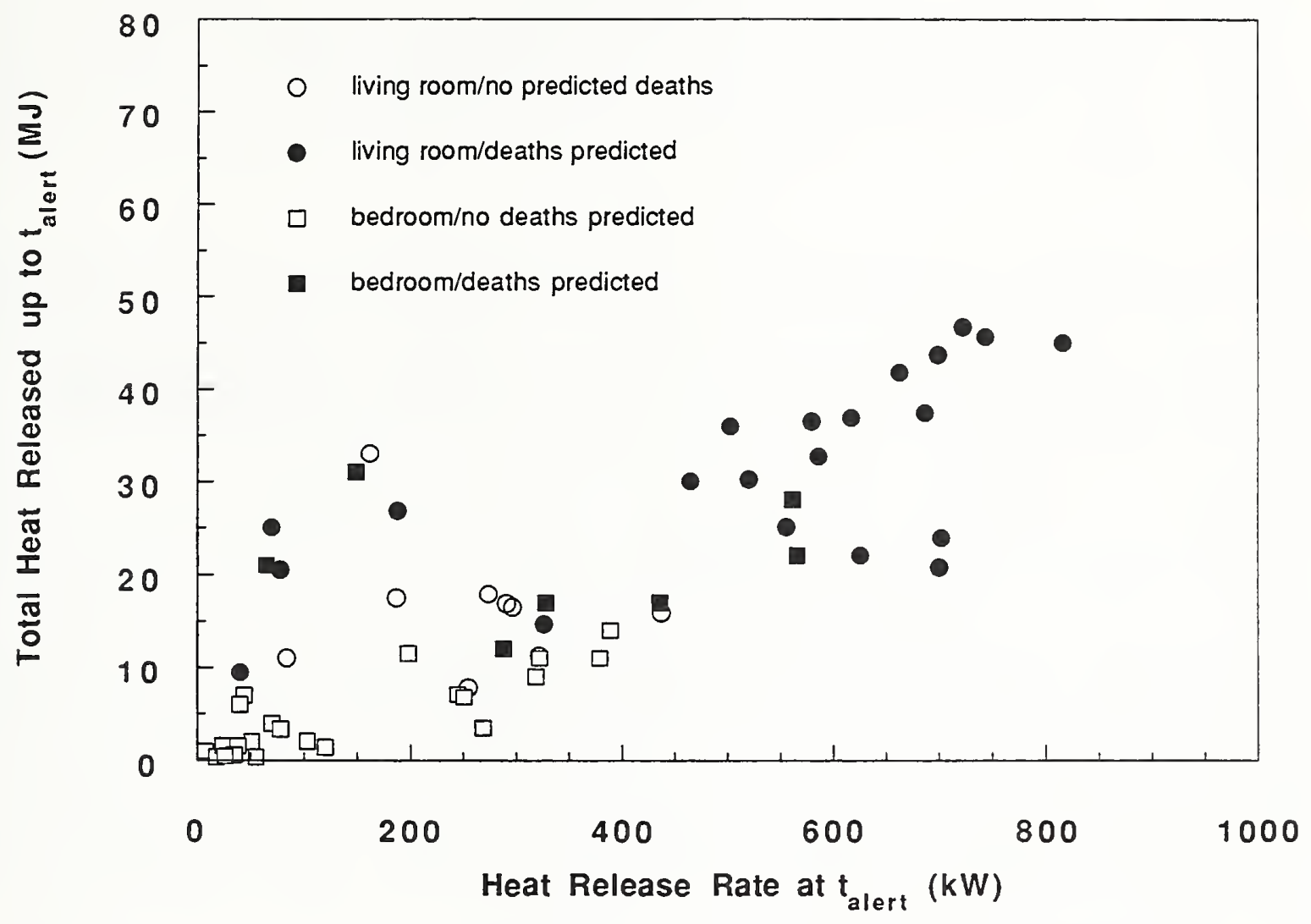

Figure 8. Total heat released versus heat release rate at the time to alert of the occupant alerted first. 


\section{APPENDIX A}

\section{CHARACTERIZATION OF THE IGNITION SOURCES}

\section{A. Match Source}

The British Standard Butane Flame Ignition Source (British Standard 5852, Part 1) satisfied our requirements for this type of small flaming ignition source. However, the experiments described in the report utilized $\mathrm{CP}$ propane as the fuel, not butane. The flame developed from this source was approximately $35 \mathrm{~mm}$ high. It emerged from the end of an $8 \mathrm{~mm}$ OD stainless steel tube. The tube was typically oriented parallel to a crevice, touching both planes which form the crevice.

The heat flux patterns here and elsewhere were measured with Medtherm Schmidt-Boelter flux gages; 3 $\mathrm{mm}(1 / 8 \mathrm{in}$.) and $6 \mathrm{~mm}(1 / 4 \mathrm{in}$.) diameter gages were utilized throughout. These gages were water cooled and their sensing surface remains low in temperature. Thus they effectively read a cold wall heat flux.

For the present measurements, a 90 degree crevice was formed from an inert material ( $3 \mathrm{~mm}$ thick ceramic felt insulation). An array of four flux gages was placed such that the sensor surface of each was flush with the vertical plane of the crevice in the arrangement shown in Figure A-1. The average heat flux measurements thus obtained are located in Table A-1. The approximate isoflux profile obtained by linear interpolation from these results is shown in Figure A-2. Gage one exhibits the highest average flux, 4.7 $\mathrm{W} / \mathrm{cm}^{2}$, due to its close proximity to the flame. Gages two and three, located above gage one, exhibit proportionally lower fluxes due to the longer distances from the flame. Gage four exhibits a flux one tenth that of gage one due to non-contact with the flame.

\section{B. Light Bulb Sources}

Five light bulbs were evaluated as potential ignition sources in this study. The bulbs evaluated were: a 30 watt, R-20, reflective-tungsten-spot; a 50 watt, R-20, reflective-tungsten-spot; a 75 watt, R-30, reflective-tungsten-spot; a 75 watt, R-30, reflective-tungsten-flood; and a 55 watt, reflectivetungsten/halogen-spot. The bulbs were contained in a typical gooseneck desk lamp, standard government issue, rated for a maximum of 60 watts, at $60 \mathrm{hertz}$ and 120 volts. The lamp had a circular base, a moveable neck, and a white reflective shield to protect the bulb and to reflect light (though all of the bulbs tested had their own internal reflectors). The reflective shield had a diameter of $14.6 \mathrm{~cm}$, a depth of 16.5 $\mathrm{cm}$, and the shield was vented near the top in order to allow heat to escape from the base of the bulb.

Each bulb was tested for the heat flux it yielded upon direct contact with the center of the exposed face after the lamp had been on for fifteen minutes. Average heat fluxes for these tests are listed in Table A-2. The tests showed that there were little differences in the average heat fluxes for the normal tungsten bulbs, and that the halogen bulb produced a total heat flux seven times larger than the other types. It was concluded that because of the higher heat output of the halogen bulb, it would represent the most hazardous ignition source of the five bulbs evaluated.

The spatial heat flux pattern was determined for the tungsten/halogen bulb. This was accomplished by placing flux gages at various locations relative to the bulb. The faces of the gages were placed either parallel or perpendicular to the face of bulb through the central, horizontal plane of the projected light cone. Figure A-3 shows the locations of the flux gages relative to the halogen bulb; Table A-3 lists the values measured at these locations (average value over a 7 minute period). In general, the most significant 
heat output from the bulb is located in the central region of the extended cone of light, or within twenty degrees of either side from the center axis of the cone. The heat output from the bulb appears to be symmetrical, however regions of the right side of the cone of light exhibit slightly lower flux readings than the left side, which could be attributed to asymmetry of the lamp, bulb, or filament within the bulb. Figure A-4 shows the approximate isoflux lines obtained by linear interpolation of the data in Table A-3.

\section{Quartz Space Heater}

The quartz space heater was evaluated for its radiant heat output pattern. Figure A-5 is a schematic of the assembled heater; the two quartz filament bulbs, $38 \mathrm{~cm}$ in length, are located $16.5 \mathrm{~cm}$ behind the front guard grill at the focus of a roughly parabolic reflector. The heater was operated at its maximum input power of 1500 watts at 120 volts.

The initial heat flux pattern characterization utilized flux gages placed at two distances, $10.2 \mathrm{~cm}$ and 15.2 $\mathrm{cm}$, from the heater, while the height of these gages also varied from $5.1 \mathrm{~cm}$ to $78.7 \mathrm{~cm}$ from the floor. The gages were mounted in an adjustable frame system so that they could be moved to designated positions. The faces of the gages were oriented parallel to the face of the quartz heater. Mounted directly below and above the gages, in a vertical orientation, were sheets of ceramic felt insulation which simulated a vertical chair surface; see Figure A-6. The heating of these surfaces had a small but measurable effect on the output of the quartz heater since it was run as a constant power input device. The test results are shown in Table A-4 and A-5. The results showed a $15-20 \%$ higher heat flux for the tests at the 10.2 $\mathrm{cm}$ than those in which the heater was placed $15.2 \mathrm{~cm}$ from the chair. The maximum heat flux was 0.667 $\mathrm{W} / \mathrm{cm}^{2}$ which was located directly centered in front of the heater at a height of $42 \mathrm{~cm}$ from the floor. An approximate isoflux diagram for the $10.2 \mathrm{~cm}$ distance, is shown in Figure A-7; bilateral symmetry is assumed.

A second set of measurements utilized heat flux gages embedded at specific locations in the surface of a simulated chair. Ceramic felt was placed across the surface of a metal chair frame to simulate the chair surfaces. See Figure A-8. In all cases the gages were mounted with their sensor faces flush with and parallel to the surface in which they were embedded.

The quartz heater was placed $10.2 \mathrm{~cm}$ in front of the "chair", along its centerline; this was the same placement as was used in the ignition tests. The fluxes measured at the locations shown in Figure A-8 are listed in Table A-6. Figures A-9, A-10 and A-11 show the approximate isoflux lines on the "chair" surfaces, as inferred from the measurements in Table A-6; bilateral symmetry is again assumed. No gages were embedded in the vertical plane below the front "seat cushion" plane since Figure A-7 describes this area. The peak heat flux at the foot of the chair is approximately ten times higher than the peak heat exposure on the back cushion of the chair. The back cushion of the chair, however, exhibits higher flux levels than the seat or side arm cushions because of the surface orientation. 
Table A-1. Average Heat Flux for Match Equivalent Burner

\begin{tabular}{|c|c|c||}
\hline Flux Gage & $\begin{array}{c}\text { Length of } \\
\text { Exposure }(\mathrm{s})\end{array}$ & $\begin{array}{c}\text { Heat Flux } \pm \mathrm{sd} \\
(\mathrm{W} / \mathrm{cm} 2)\end{array}$ \\
\hline 1 & 60 & $4.68 \pm 0.23$ \\
\hline 2 & 60 & $3.61 \pm 0.42$ \\
\hline 3 & 60 & $1.93 \pm 0.45$ \\
\hline 4 & 60 & $0.57 \pm 0.44$ \\
\hline
\end{tabular}

Table A-2. Average Direct Contact Heat Fluxes for Various Types of Bulbs

\begin{tabular}{|c|c|c|}
\hline Light Bulb & $\begin{array}{c}\text { Average Flux } \\
\left(\mathrm{W} / \mathrm{cm}^{2}\right)\end{array}$ & $\begin{array}{c}\text { Length of Exposure } \\
(\mathrm{s})\end{array}$ \\
\hline $30 \mathrm{~W}$ Reflective Tungsten Spot & $1.51 \pm 0.16$ & 900 \\
\hline 50 W Reflective Tungsten Spot & $1.75 \pm 0.20$ & 900 \\
\hline 75 W Reflective Tungsten Spot & $1.61 \pm 0.11$ & 900 \\
\hline 75 W Reflective Tungsten Flood & $1.50 \pm 0.12$ & 900 \\
\hline 55 W Halogen Spot & $9.18 \pm 0.59$ & 420 \\
\hline
\end{tabular}


Table A-3. Flux Gage Location and Average Flux Measurements for $55 \mathrm{~W}$ Halogen Bulb.

// - Gage oriented parallel to bulb face.

$\perp$ - Gage oriented ninety degees from the bulb face.

\begin{tabular}{|c|c|c|c|c|c|}
\hline \multirow{2}{*}{$\begin{array}{c}\text { Gage } \\
\text { Location }\end{array}$} & \multirow{2}{*}{$\begin{array}{c}\text { Side } \\
\text { of Bulb }\end{array}$} & \multirow{2}{*}{ Orientation } & \multicolumn{2}{|c|}{ Coordinates from Center of Bulb Face } & \multirow{2}{*}{$\begin{array}{c}\text { Flux } \pm s d \\
\left(W / \mathrm{cm}^{2}\right)\end{array}$} \\
\hline & & & width $(\mathrm{cm})$ & depth $(\mathrm{cm})$ & \\
\hline 1 & Left & $/ /$ & 1.1 & 0 & $.01 \pm 0.00$ \\
\hline 2 & Center & $/ /$ & 0 & 0 & $9.37 \pm 1.08$ \\
\hline 3 & Right & $\|$ & 1.1 & 0 & $3.03 \pm 0.00$ \\
\hline 1 & Left & $/ 1$ & 4.1 & 5.1 & $0.10 \pm 0.00$ \\
\hline 5 & Left & $\perp$ & 4.1 & 5.1 & $0.06 \pm 0.00$ \\
\hline 6 & Center & $/ 1$ & 0 & 5.1 & $3.23 \pm 0.00$ \\
\hline 7 & Right & 11 & 4.1 & 5.1 & $0.08 \pm 0.00$ \\
\hline 6 & Right & 1 & 4.1 & 5.1 & $0.04 \pm 0.00$ \\
\hline 3 & Left & $1 /$ & 10.6 & 12.7 & $0.02 \pm 0.00$ \\
\hline 10 & Left & $\perp$ & 10.6 & 12.7 & $0.01 \pm 0.00$ \\
\hline 18 & Center & /I & 0 & 12.7 & $0.55 \pm 0.00$ \\
\hline 12 & Right & $/ /$ & 10.6 & 12.7 & $0.02 \pm 0.00$ \\
\hline 13 & Right & $\perp$ & 10.6 & 12.7 & $0.01 \pm 0.00$ \\
\hline 13 & Left & $/ /$ & 21.3 & 25.4 & $0.01 \pm 0.00$ \\
\hline 15 & Left & $\perp$ & 21.3 & 25.4 & $0.01 \pm 0.00$ \\
\hline 16 & Left & 11 & 10.6 & 25.4 & $0.04=0.00$ \\
\hline 17 & Center & $/ /$ & 0 & 25.4 & $0.28 \pm 0.00$ \\
\hline 18 & Right & $/ /$ & 10.6 & 25.4 & $0.01 \pm 0.00$ \\
\hline 18 & Right & $\|$ & 21.3 & 25.4 & $0.02 \pm 0.00$ \\
\hline 20 & Right & $\perp$ & 21.3 & 25.4 & $0.01 \pm 0.00$ \\
\hline 21 & Left & 11 & 40.6 & 38.1 & $0.01 \pm 0.00$ \\
\hline 22 & Left & $\perp$ & 40.6 & 38.1 & $0.01 \pm 0.00$ \\
\hline 23 & Left & /I & 20.3 & 38.1 & $0.02 \pm 0.00$ \\
\hline 24 & Center & 11 & 0 & 38.1 & $0.10 \pm 0.00$ \\
\hline 25 & Right & $/ 1$ & 20.3 & 38.1 & $0.01 \pm 0.00$ \\
\hline 26 & Right & /I & 40.6 & 38.1 & $0.1-0.00$ \\
\hline 27 & Right & $\perp$ & 40.6 & 38.1 & $0.01 \pm 0.00$ \\
\hline
\end{tabular}


Table A-4. Heat Flux Measurements of Quartz Heater - $15.2 \mathrm{~cm}$ from Heater to Ceramic Felt

\begin{tabular}{|c|c|c|c|c|}
\hline \multirow{2}{*}{$\begin{array}{c}\text { Gage } \\
\text { Location }\end{array}$} & \multirow{2}{*}{$\begin{array}{l}\text { Side } \\
\text { from Center }\end{array}$} & \multicolumn{2}{|c|}{ Coordinates } & \multirow{2}{*}{$\begin{array}{c}\text { Flux \& sd } \\
\left(\mathrm{W} / \mathrm{cm}^{2}\right)\end{array}$} \\
\hline & & $\begin{array}{l}\text { width from } \\
\text { center (cm) }\end{array}$ & $\begin{array}{l}\text { height from } \\
\text { floor (cm) }\end{array}$ & \\
\hline $\mathbf{R}$ & Center & 0 & 5.1 & $0.19 \pm 0.00$ \\
\hline$T$ & Center & 0 & 23.5 & $0.31 \pm 0.00$ \\
\hline $\mathrm{C}$ & Center & 0 & 41.9 & $0.59 \pm 0.01$ \\
\hline $\mathrm{Fi}$ & Center & 0 & 60.3 & $0.03 \pm 0.00$ \\
\hline L & Center & 0 & 78.7 & $0.14 \pm 0.00$ \\
\hline$L$ & Left & 15.5 & 5.1 & $0.07 \pm 0.01$ \\
\hline G & Left & 15.5 & 23.5 & $0.05 \pm 0.01$ \\
\hline $\mathrm{H}$ & Left & 15.5 & 41.9 & $0.30 \pm 0.03$ \\
\hline $\mathrm{T}$ & Left & 15.5 & 60.3 & $0.19 \pm 0.00$ \\
\hline $\mathbf{J}$ & Left & 15.5 & 78.7 & $0.09 \pm 0.01$ \\
\hline e & Left & 31.0 & 5.1 & $0.05 \pm 0.01$ \\
\hline L & Left & 31.0 & 23.5 & $0.07 \pm 0.01$ \\
\hline J & Left & 31.0 & 31.0 & $0.08 \pm 0.00$ \\
\hline $\mathrm{N}$ & Let & 41.9 & 60.3 & $0.08 \pm 0.00$ \\
\hline $\mathrm{Q}$ & Left & 31.0 & 78.7 & $0.05 \pm 0.00$ \\
\hline $\mathrm{P}$ & Left & 46.4 & 5.1 & $0.03 \pm 0.00$ \\
\hline $\mathrm{Q}$ & Left & 46.4 & 23.5 & $0.02 \pm 0.00$ \\
\hline $\mathbf{R}$ & Left & 46.4 & 31.9 & $0.08 \pm 0.00$ \\
\hline e & Left & 46.4 & 60.3 & $0.03=0.00$ \\
\hline $\mathrm{T}$ & Left & 46.4 & 78.7 & $0.03 \pm 0.00$ \\
\hline $\mathrm{U}$ & Right & 15.5 & 31.0 & $0.24 \pm 0.01$ \\
\hline v & Right & 31.0 & 41.9 & $0.06 \pm 0.00$ \\
\hline W & Right & 46.4 & 41.9 & $0.02 \pm 0.01$ \\
\hline
\end{tabular}


Table A-5. Heat Flux Measurements of Quartz Heater $-10.2 \mathrm{~cm}$ from Heater to Ceramic Felt

\begin{tabular}{|c|c|c|c|c|}
\hline \multirow{2}{*}{$\begin{array}{l}\text { Gage } \\
\text { Location }\end{array}$} & \multirow{2}{*}{$\begin{array}{c}\text { Side } \\
\text { from Center }\end{array}$} & \multicolumn{2}{|c|}{ Coordinates } & \multirow{2}{*}{$\begin{array}{l}\text { Flux \& sd } \\
\left(W / \mathrm{cm}^{2}\right)\end{array}$} \\
\hline & & $\begin{array}{l}\text { width from } \\
\text { center }(\mathrm{cm})\end{array}$ & $\begin{array}{l}\text { height from } \\
\text { floor }(\mathrm{cm})\end{array}$ & \\
\hline A & Center & 0 & 5.1 & $0.07 \pm 0.00$ \\
\hline B & Center & 0 & 23.5 & $0.38 \pm 0.00$ \\
\hline C & Center & 0 & 41.9 & $0.07 \pm 0.00$ \\
\hline e & Center & 0 & 60.3 & $0.44 \pm 0.00$ \\
\hline$E$ & Center & 0 & 78.7 & $0.17 \pm 0.02$ \\
\hline 1 & Left & 15.5 & 5.1 & $0.07 \pm 0.00$ \\
\hline G & Left & 15.5 & 23.5 & $0.19 \pm 0.00$ \\
\hline $\mathrm{H}$ & Left & 15.5 & 41.9 & $0.30=0.02$ \\
\hline 1 & Left & 15.5 & 60.3 & $0.22 \pm 0.01$ \\
\hline $\mathrm{N}$ & Left & 15.5 & 78.7 & $0.09 \pm 0.00$ \\
\hline B & Left & 31.0 & 5.1 & $0.24 \pm 0.00$ \\
\hline $\mathrm{C}$ & Left & 31.0 & 23.5 & $0.04 \pm 0.00$ \\
\hline M & Left & 31.0 & 41.9 & $0.06 \pm 0.01$ \\
\hline $\mathrm{N}$ & Left & 31.0 & 60.3 & $0.05 \pm 0.01$ \\
\hline o & Left & 31.0 & 78.7 & $0.04 \pm 0.01$ \\
\hline$P$ & Left & 46.4 & 5.1 & $0.03 \pm 0.00$ \\
\hline o & Left & 46.4 & 23.5 & $0.3 \pm \pm 0.00$ \\
\hline B & Left & 46.4 & 41.9 & $0.03 \pm 0.00$ \\
\hline - & Left & 46.4 & 60.3 & $0.03 \pm 0.00$ \\
\hline - & Left & 46.4 & 78.7 & $0.01 \pm 0.00$ \\
\hline U & Right & 15.5 & 41.9 & $0.30 \pm 0.00$ \\
\hline $\mathrm{v}$ & Right & 31.0 & 41.9 & $0.04 \pm 0.00$ \\
\hline w & Right & 46.4 & 41.9 & $0.02 \pm 0.00$ \\
\hline
\end{tabular}


Table A-6. Heat Flux Measurements of Quartz Heater $-10.2 \mathrm{~cm}$ from Heater to Simulated Chair

\begin{tabular}{|c|c|c|c|c|c|c|}
\hline \multirow{2}{*}{$\begin{array}{c}\text { Gage } \\
\text { Location }\end{array}$} & \multirow{2}{*}{$\begin{array}{l}\text { Location on } \\
\text { Simulated Chair }\end{array}$} & \multirow{2}{*}{$\begin{array}{l}\text { Side } \\
\text { from } \\
\text { Center }\end{array}$} & \multicolumn{3}{|c|}{ Coordinates } & \multirow{2}{*}{$\begin{array}{c}\text { Flux \& sd } \\
\left(W / \mathrm{cm}^{2}\right)\end{array}$} \\
\hline & & & $\begin{array}{l}\text { depth from fropt } \\
\text { edge of chair }(\mathrm{cm})\end{array}$ & $\begin{array}{l}\text { width from } \\
\text { center }(\mathrm{cm})\end{array}$ & $\begin{array}{l}\text { height from } \\
\text { floor }(\mathrm{cm})\end{array}$ & \\
\hline A & Seat Cushion & Left & 12.7 & 22.2 & 49.3 & $0.05 \pm 0.01$ \\
\hline B & Seat Cushion & Left & 12.7 & 6.4 & 49.3 & $0.06 \pm 0.03$ \\
\hline C & Seat Cushion & Right & 12.7 & 14.6 & 49.3 & $0.05 \pm 0.02$ \\
\hline$A$ & Seat Cushion & Left & 38.1 & 22.2 & 49.3 & $0.03 \pm 0.01$ \\
\hline $\mathrm{L}$ & Seat Cushion & Left & 38.1 & 6.4 & 49.3 & $0.04 \pm 0.03$ \\
\hline $\mathrm{F}$ & Seat Cushion & Right & 38.1 & 14.6 & 49.3 & $0.04 \pm 0.01$ \\
\hline C & Back Cushion & Left & 52.1 & 22.2 & 54.6 & $0.06 \pm 0.01$ \\
\hline $\mathrm{H}$ & Back Cushion & Left & 52.1 & 6.4 & 54.6 & $0.07 \pm 0.01$ \\
\hline $\mathbf{J}$ & Back Cushion & Right & 52.1 & 14.6 & 54.6 & $0.07 \pm 0.00$ \\
\hline $\mathrm{J}$ & Back Cushion & Left & 52.1 & 22.2 & 62.2 & $0.07 \pm 0.01$ \\
\hline $\mathrm{K}$ & Back Cushion & Left & 52.1 & 6.4 & 62.2 & $0.06 \pm 0.01$ \\
\hline $\mathrm{L}$ & Back Cushion & Right & 52.1 & 14.6 & 62.2 & $0.07 \pm 0.00$ \\
\hline $\mathrm{M}$ & Back Cushion & Left & 52.1 & 22.2 & 69.9 & $0.08 \pm 0.01$ \\
\hline $\mathrm{N}$ & Back Cushion & Left & 52.1 & 6.4 & 69.9 & $0.08 \pm 0.01$ \\
\hline$A$ & Back Cushion & Right & 52.1 & 14.6 & 69.9 & $0.07 \pm 0.01$ \\
\hline $\mathrm{P}$ & Back Cushion & Left & 52.1 & 22.2 & 77.5 & $0.07 \pm 0.01$ \\
\hline 2 & Back Cushion & Left & 52.1 & 6.4 & 77.5 & $0.08 \pm 0.01$ \\
\hline$P$ & Back Cushion & Right & 52.1 & 14.6 & 77.5 & $0.07 \pm 0.01$ \\
\hline $\mathrm{s}$ & Back Cushion & Left & 52.1 & 22.2 & 85.1 & $0.06 \pm 0.01$ \\
\hline $\mathbf{J}$ & Back Cushion & Left & 52.1 & 6.4 & 85.1 & $0.06 \pm 0.01$ \\
\hline $\mathrm{U}$ & Back Cushion & Right & 52.1 & 14.6 & 85.1 & $0.07 \pm 0.01$ \\
\hline $\mathbf{B}$ & Interior Side Arm & Right & 8.9 & 29.9 & 69.9 & $0.08 \pm 0.02$ \\
\hline $\mathbf{P}$ & Interior Side Armo & Right & 26.0 & 29.9 & 54.6 & $0.06 \pm 0.03$ \\
\hline$x$ & Interior Side Arm & Right & 43.2 & 29.9 & 54.6 & $0.05 \pm 0.02$ \\
\hline A & Interior Side Arm & Right & 8.9 & 29.9 & 67.3 & $0.08 \pm 0.01$ \\
\hline $\mathrm{Z}$ & Interior Side Arm & Right & 26.0 & 29.9 & 67.3 & $0.08 \pm 0.03$ \\
\hline $\mathrm{ZA}$ & Interior Side Arm & Right & 43.2 & 29.9 & 67.3 & $0.06 \pm 0.02$ \\
\hline $\mathrm{ZB}$ & Interior Side Arm & Right & 8.9 & 29.9 & 83.8 & $0.05 \pm 0.01$ \\
\hline $\mathrm{ZC}$ & Interior Side Arm & Right & 26.0 & 29.9 & 83.8 & $0.04 \pm 0.02$ \\
\hline $\mathrm{ZD}$ & Interior Side Arm & Right & 43.2 & 29.9 & 83.8 & $0.04 \pm 0.02$ \\
\hline
\end{tabular}




\section{$X$ DENOTES \\ FLUX GAGE \\ LOCATION}

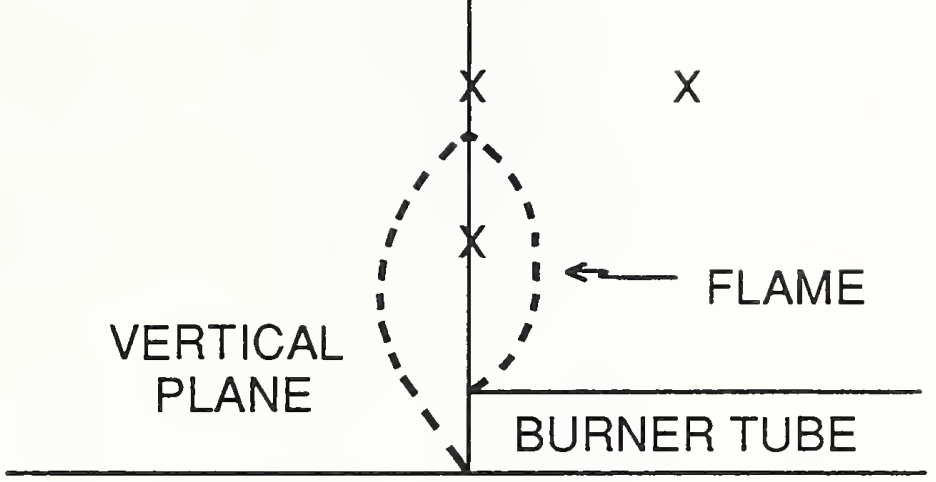

HORIZONTAL

PLANE

Fig. A-1. Position of heat flux gages relative to match-like flaming ignition source.

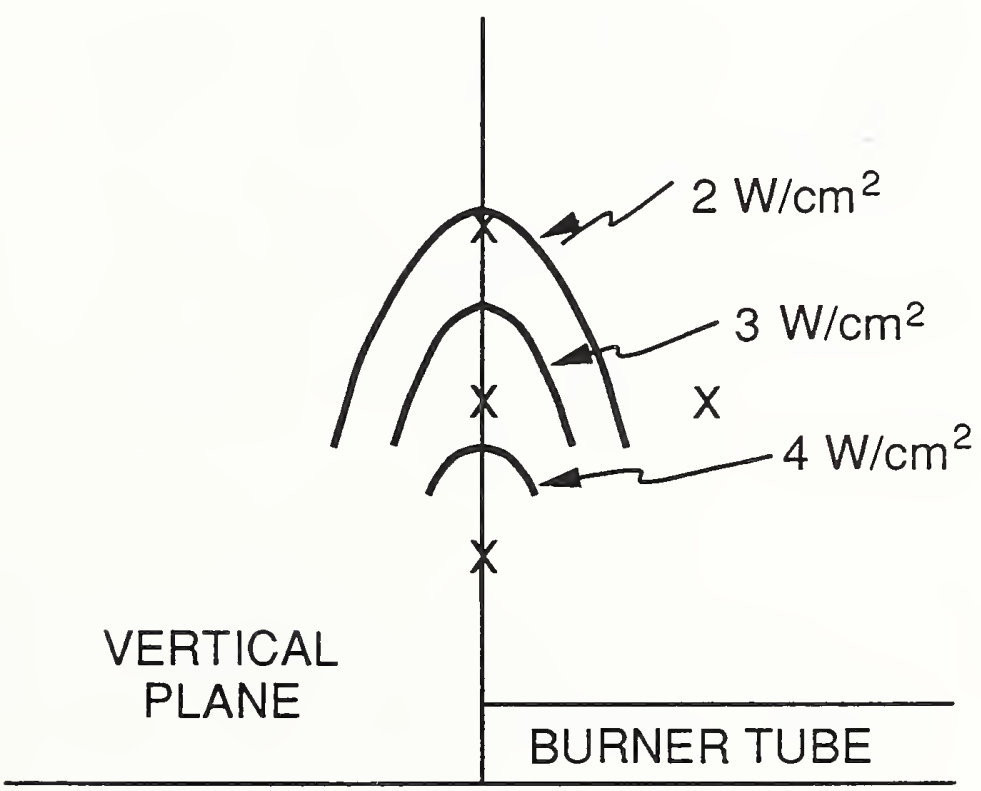

Flg. A-2. Isoflux lines on vertical plane immediately behind the match-like source. 

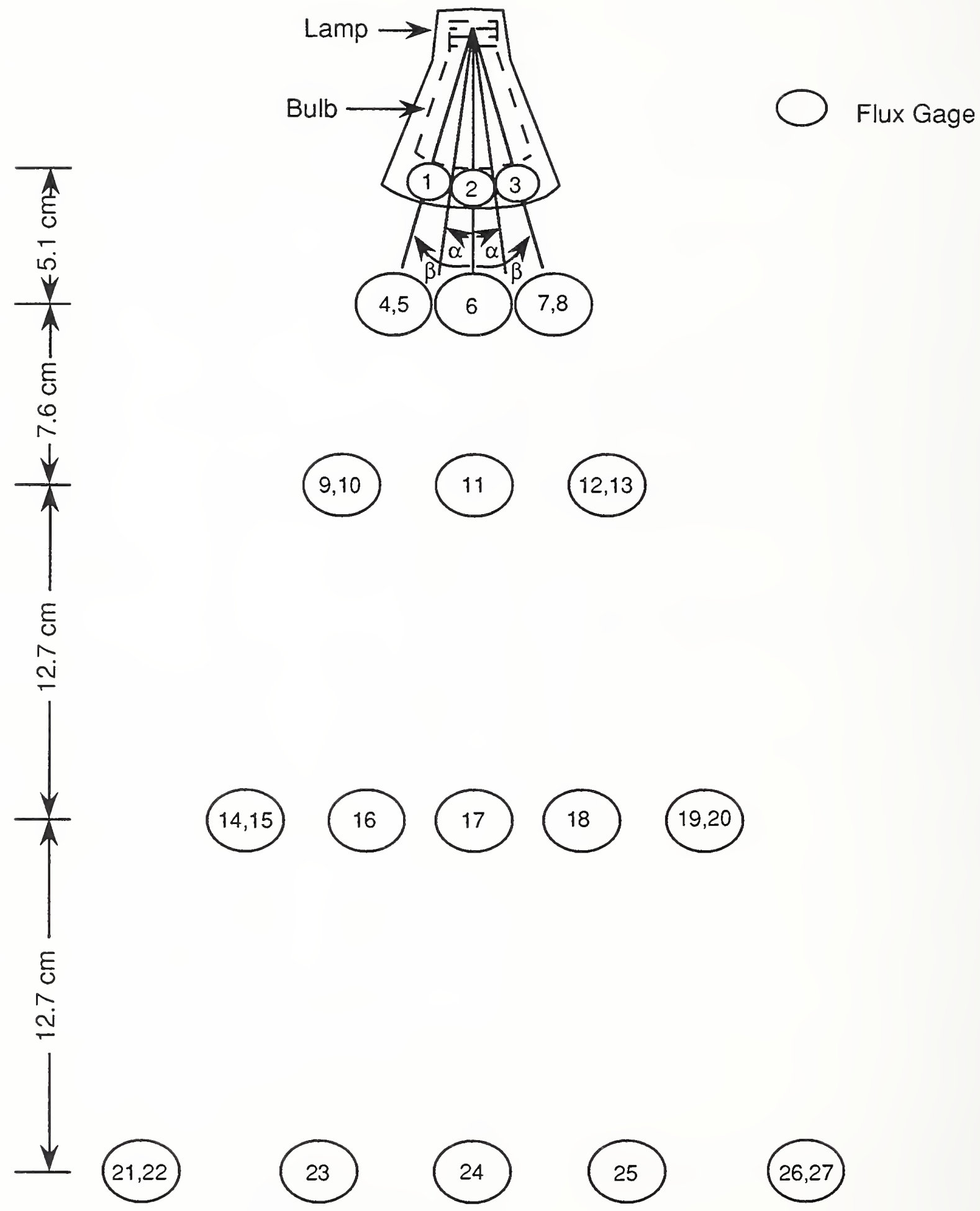

Fig. A-3. Flux gage positions relative to quartz/halogen spot lamp; lateral dimension is compressed here. 


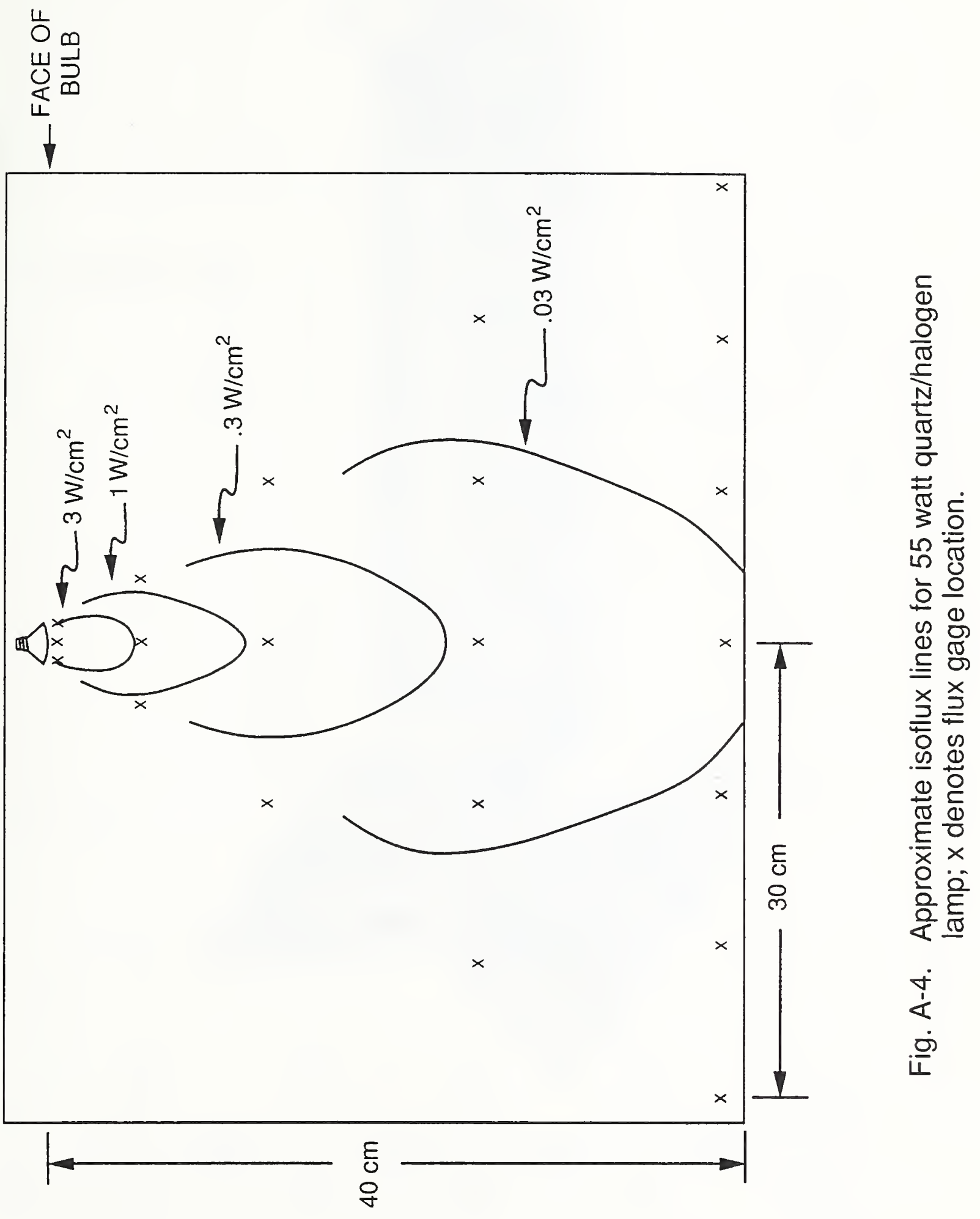




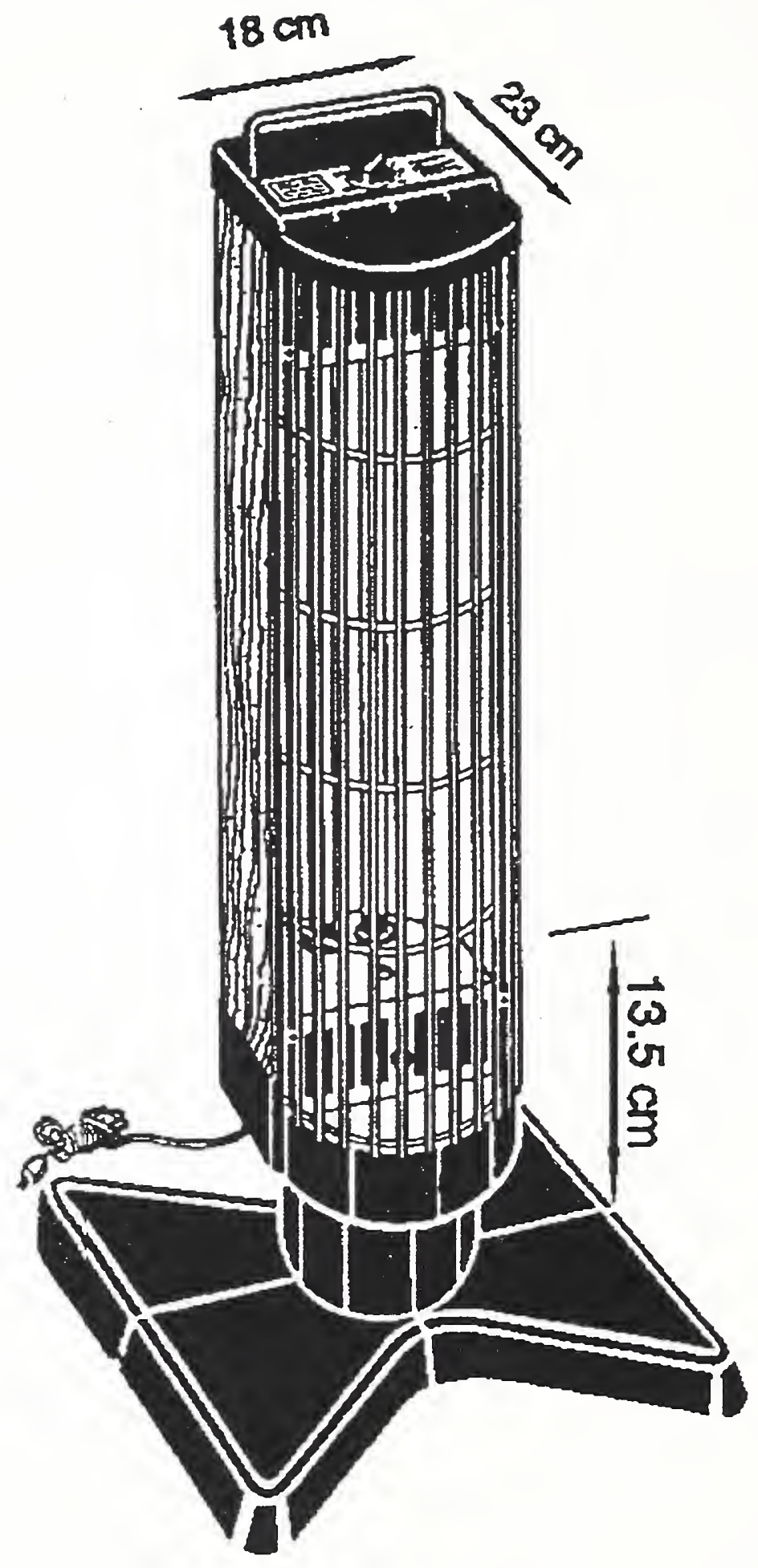

Fig. A-5. Schematic of quartz tube radiant heater; the tubes can be discerned behind the protective cage. The overall height of the unit is $71 \mathrm{~cm}$. 


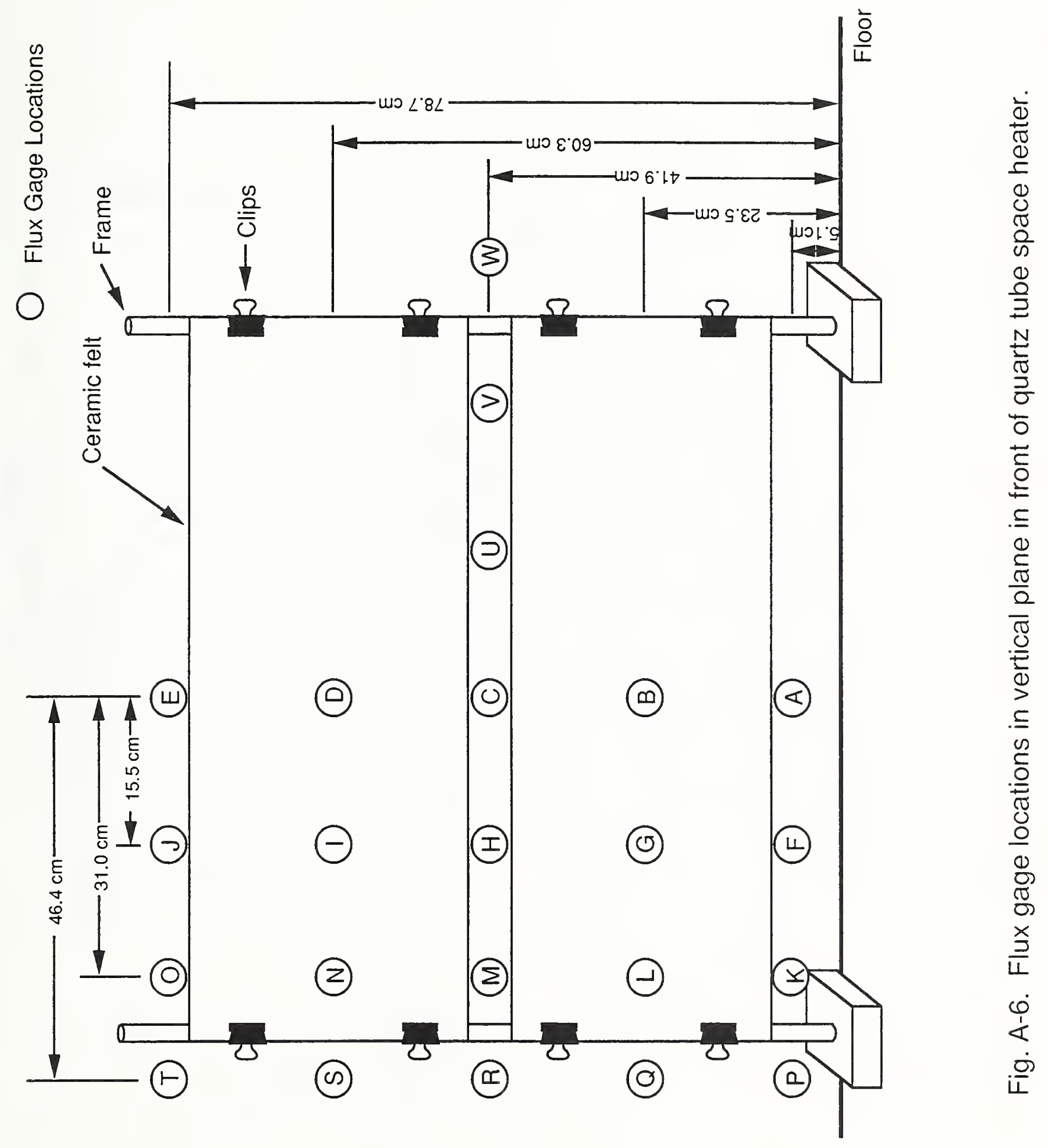


응

$E$
은
응

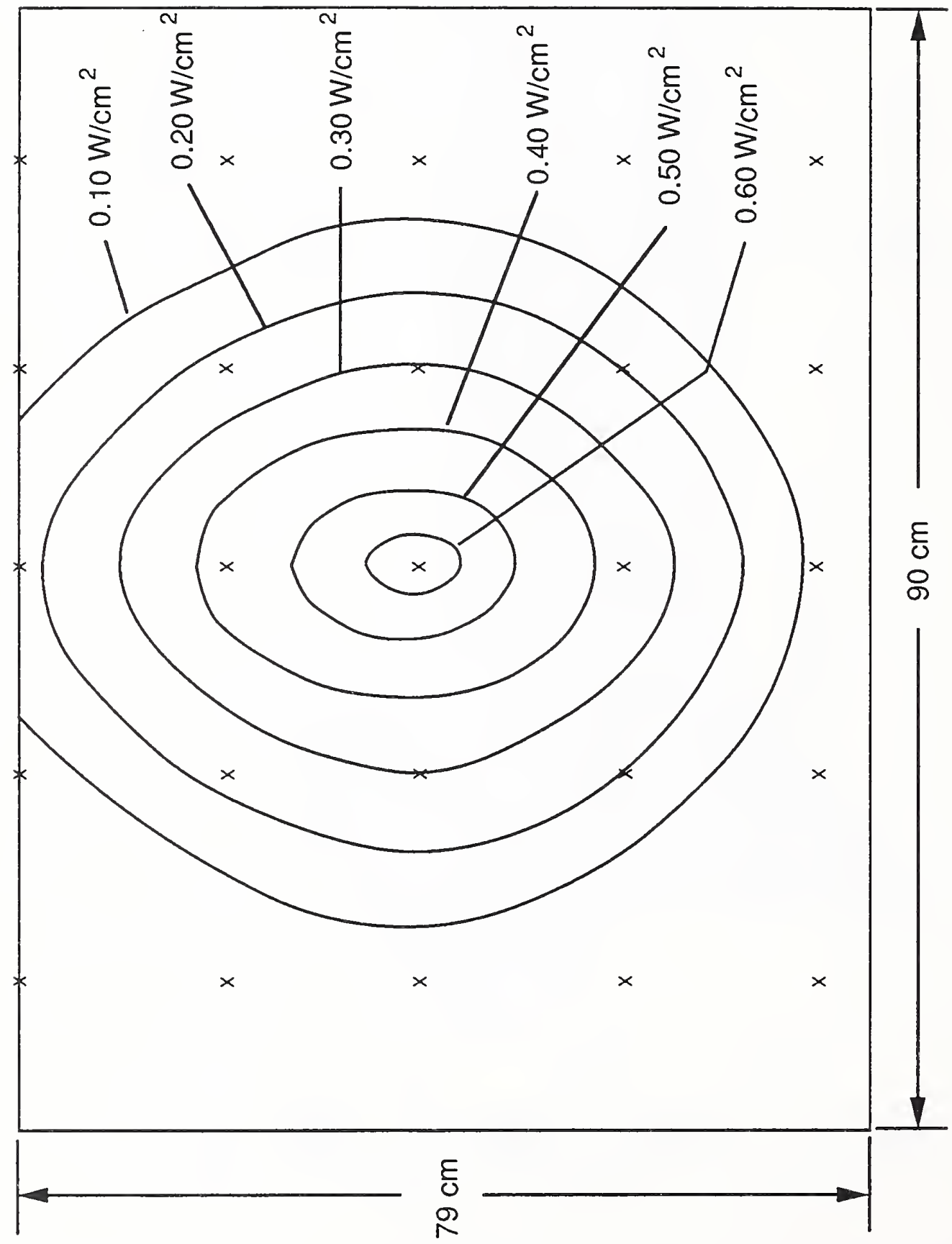

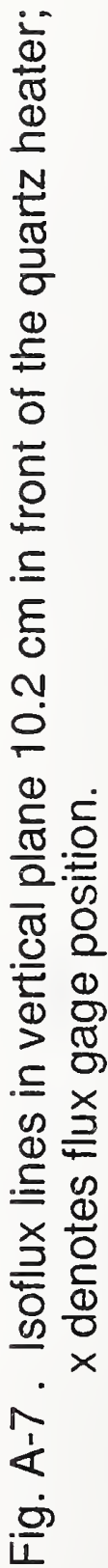




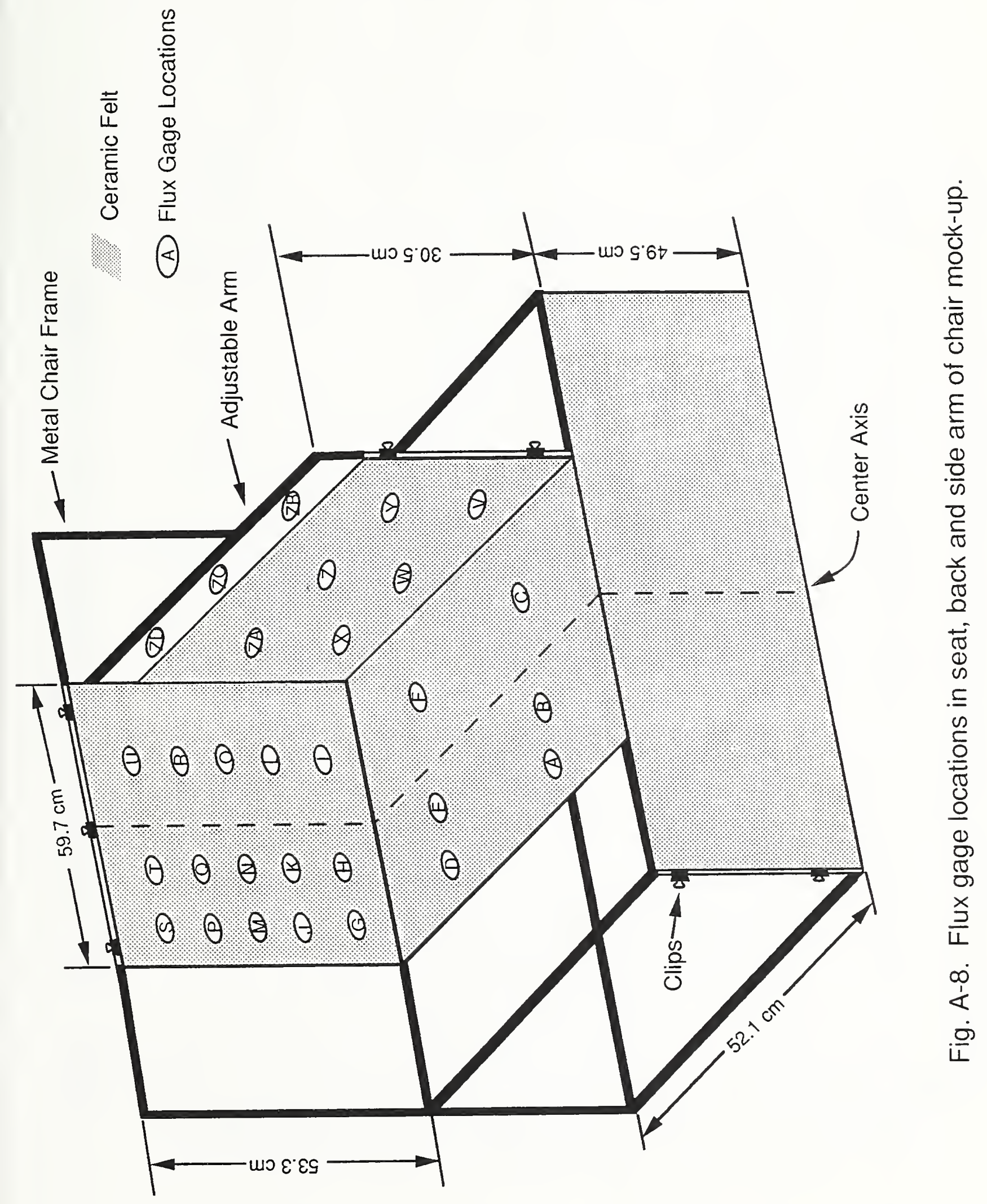




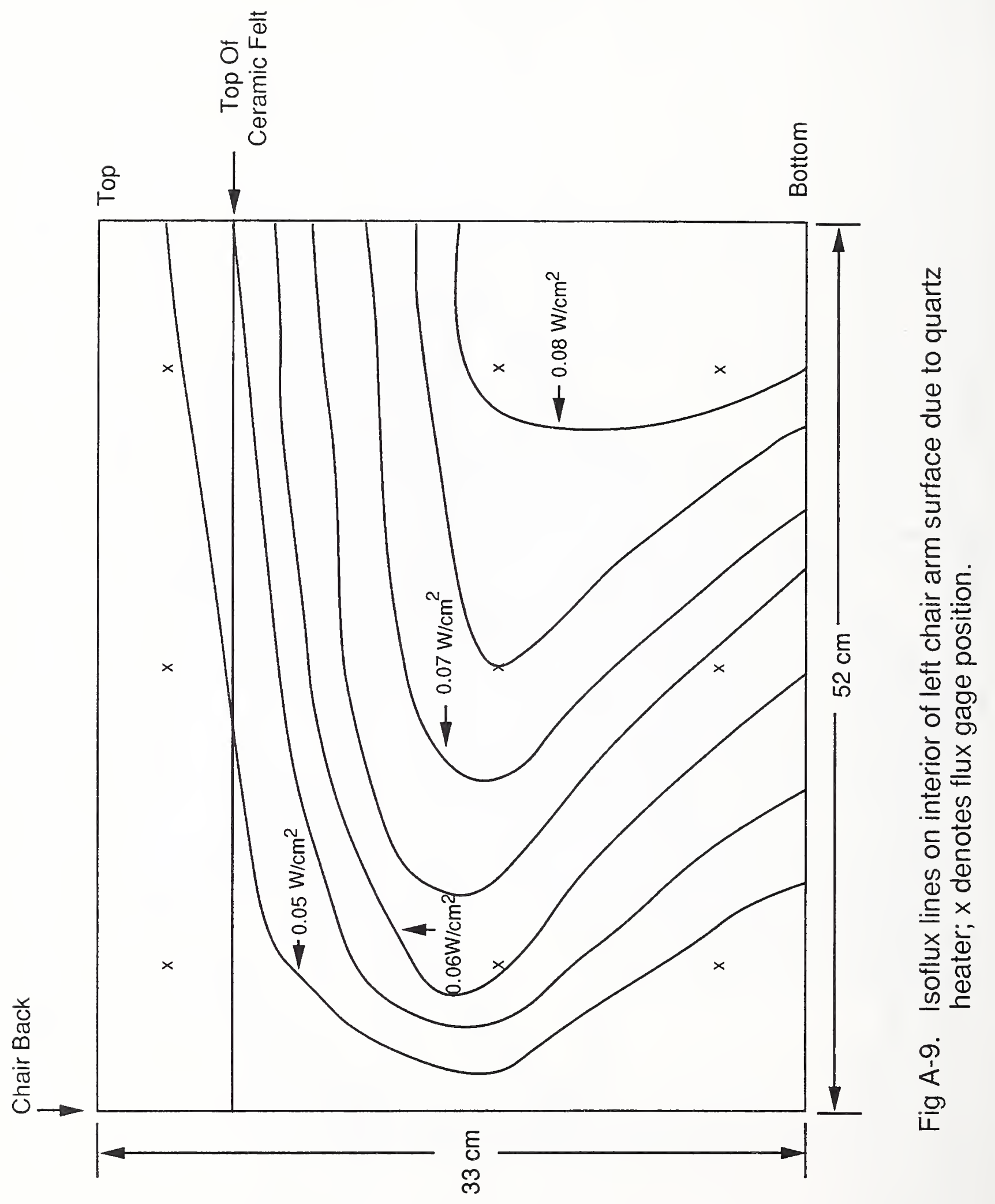




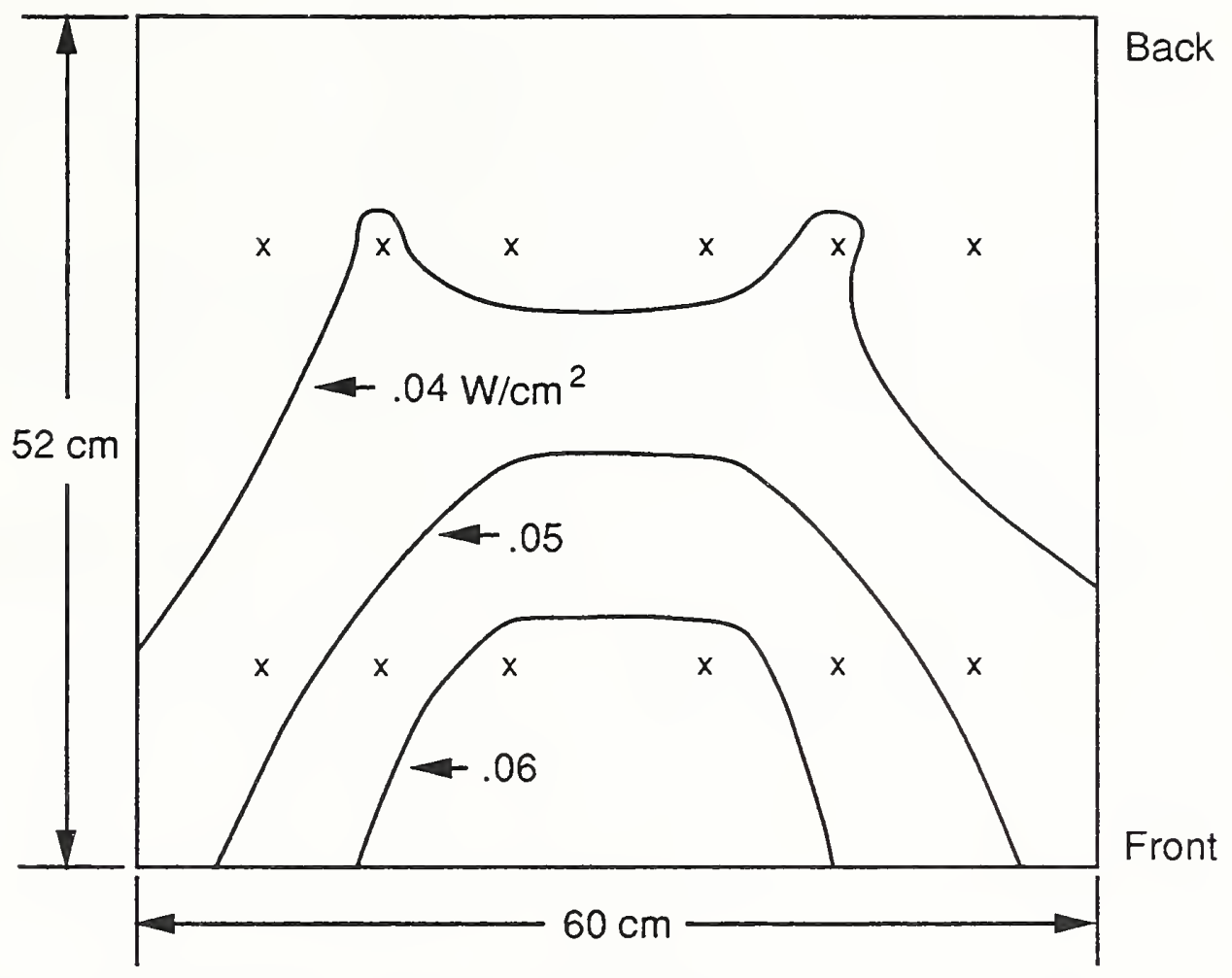

Fig. A-10. Isoflux lines on chair seat cushion plane due to quartz heater; $x$ denotes flux gage position.

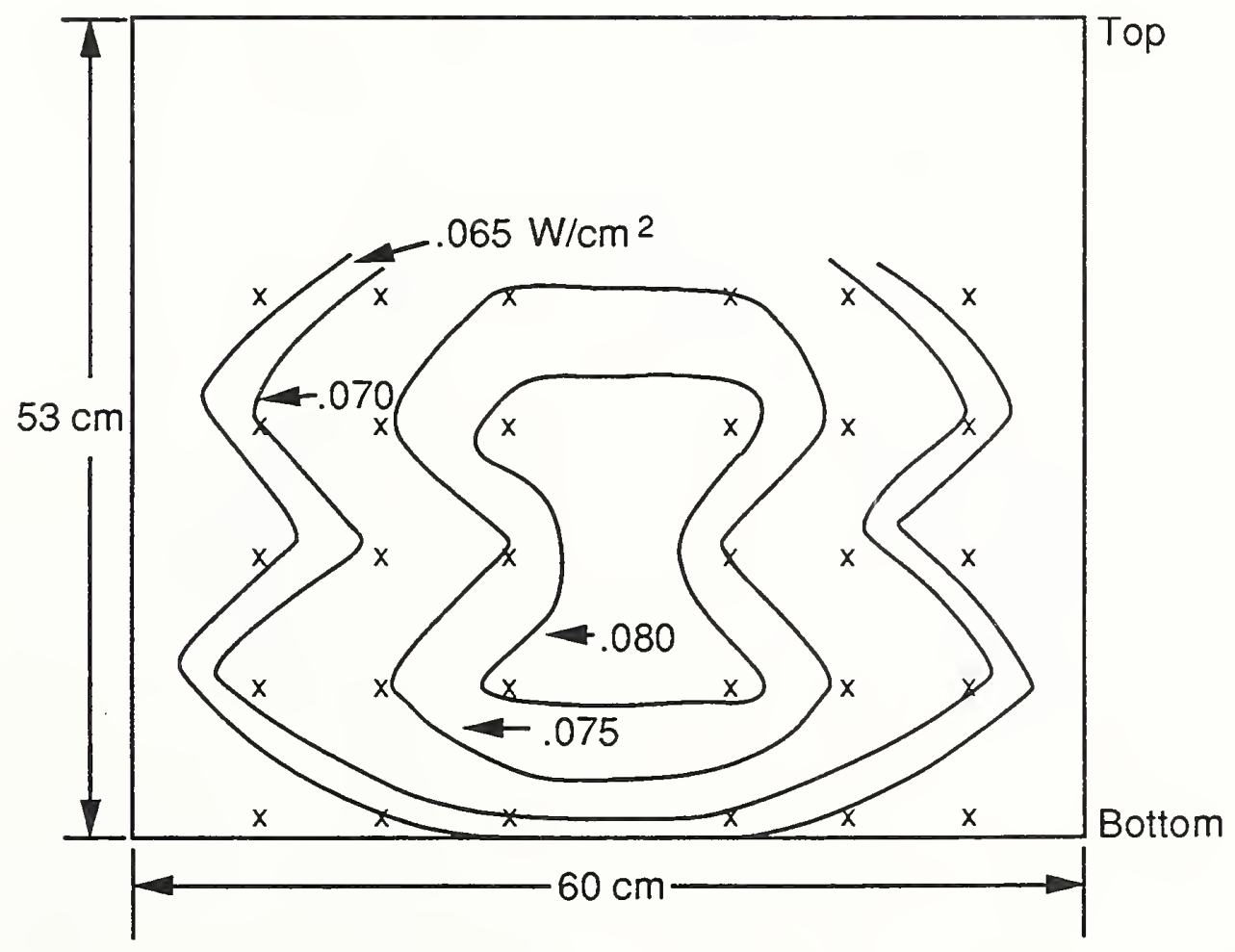

Fig. A-11. Isoflux lines on chair seat back plane due to quartz heater. 


\section{APPENDIX B \\ RESULTS FROM FURNITURE CALORIMETER TESTS}

The results from the furniture calorimeter are presented in the following graphs. Heat release rate, mass loss rate, $\mathrm{CO}$ and $\mathrm{CO}_{2}$ production, and specific extinction area for each chair burn is shown. The starting time $(t=0)$ is fixed at the time to sustained flaming. The legend indicates the source (first letter, see page 6), the chair type (second letter, see page 4) and the test number. 

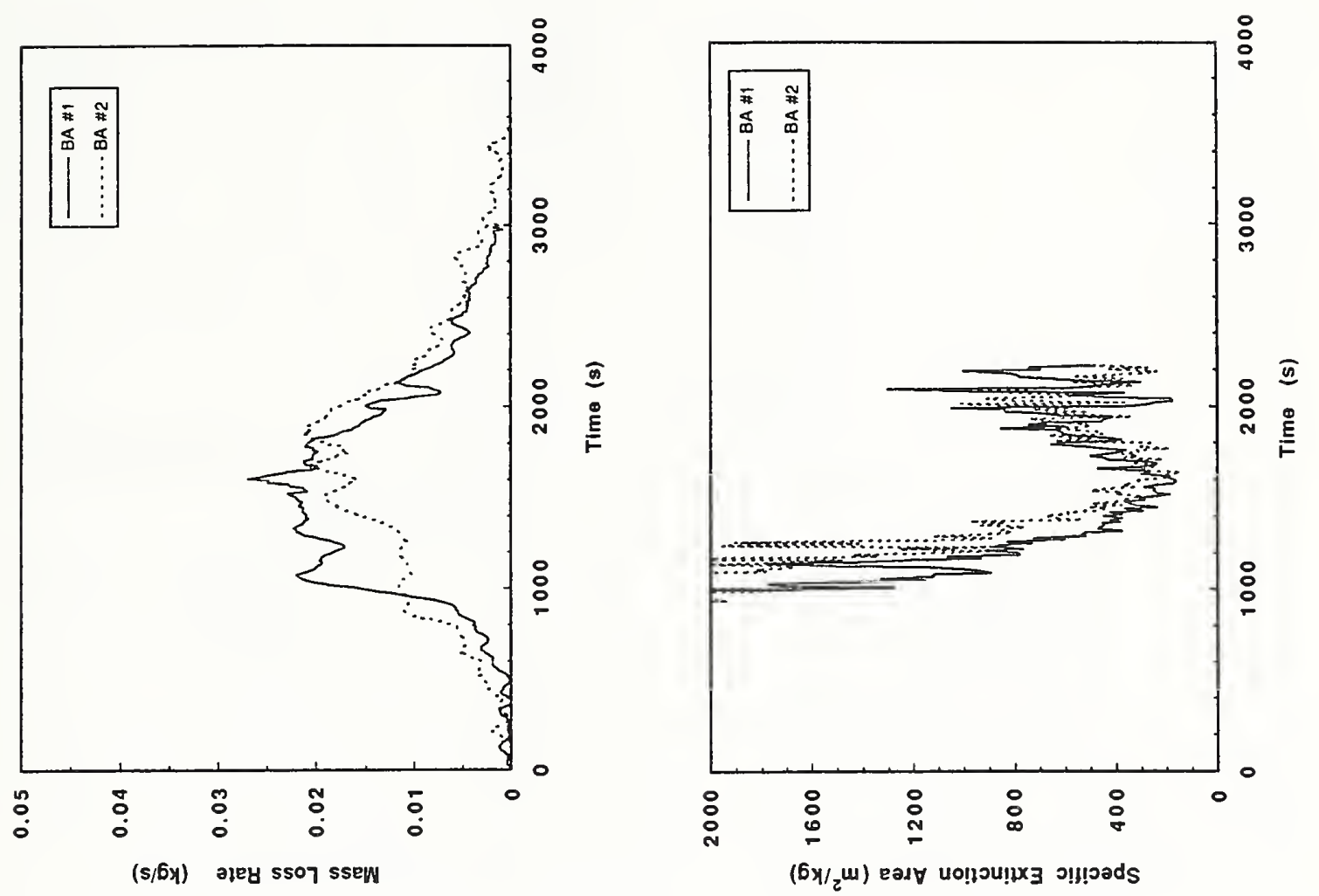

व


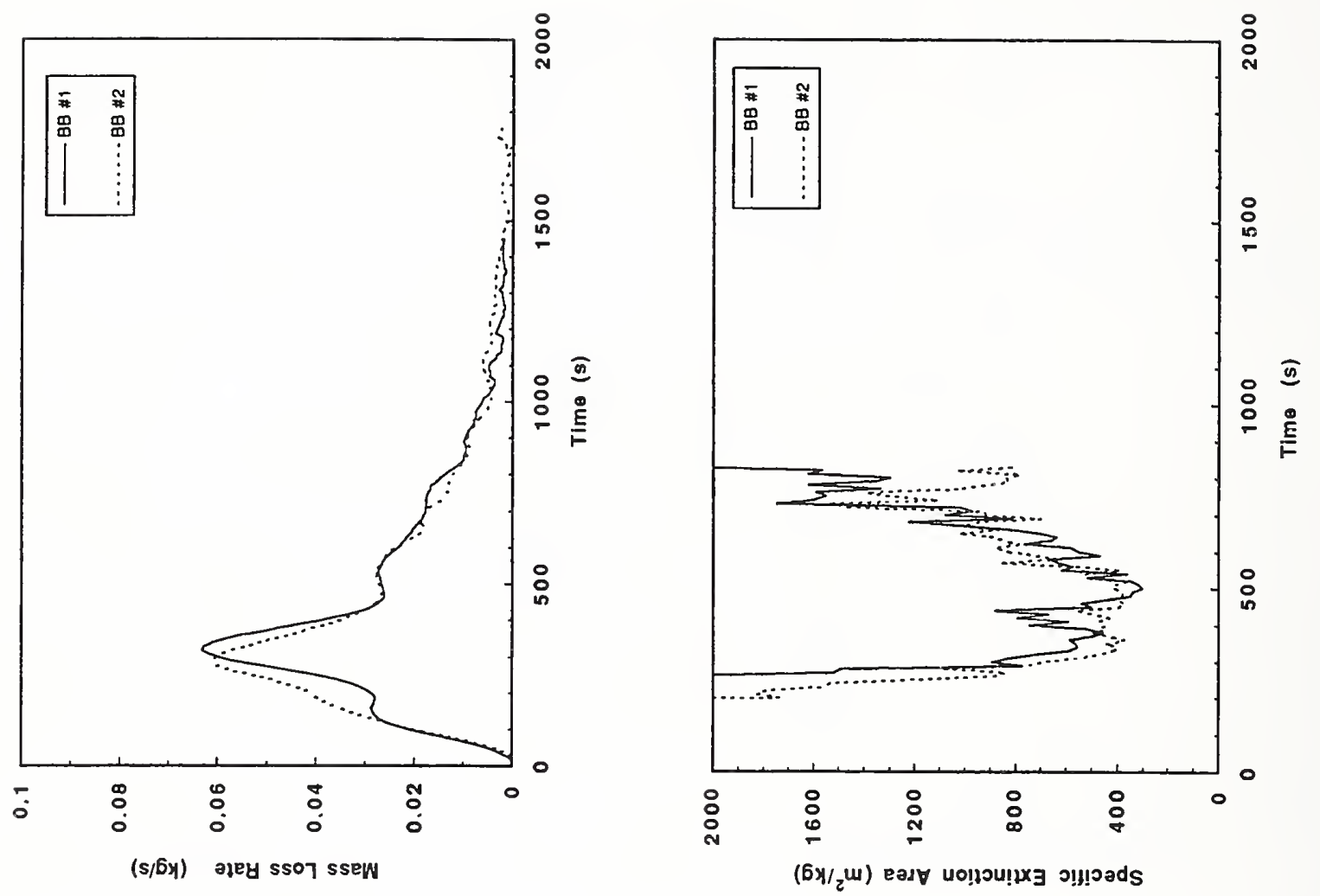

0

(s/6y) plə!र ${ }^{2} \circ 0$
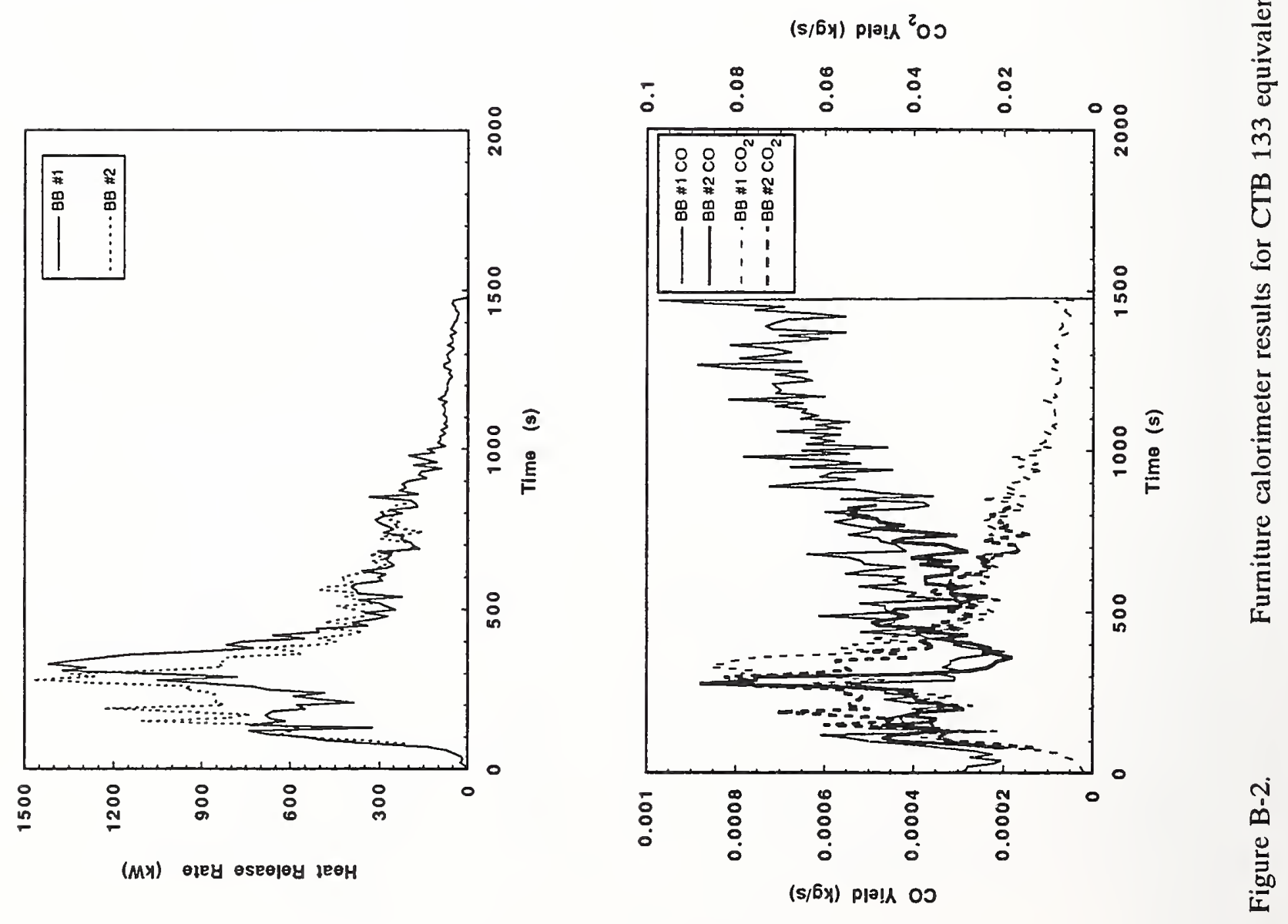

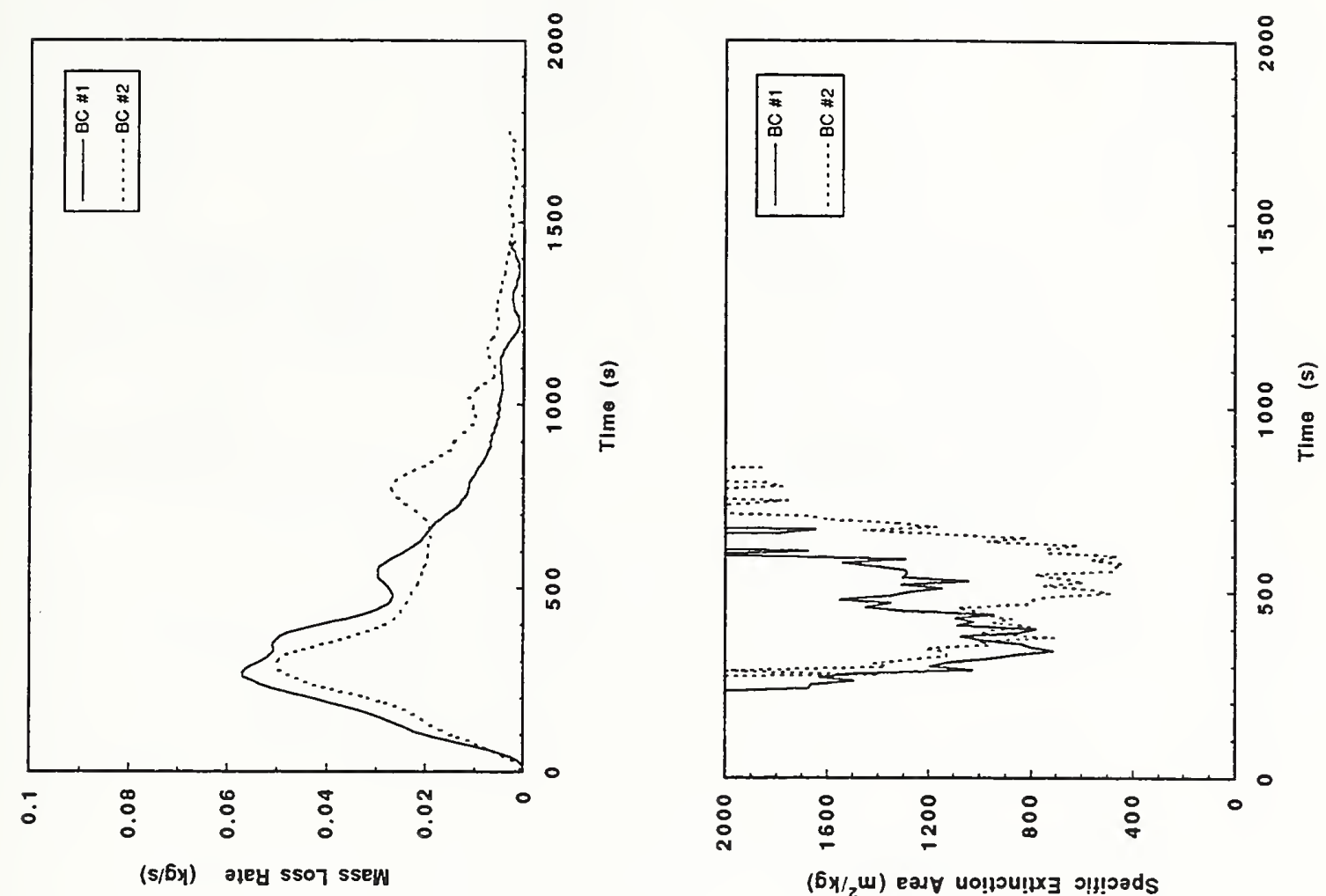

(6x/zw) eas uo!!ou!1X ग!!!oads

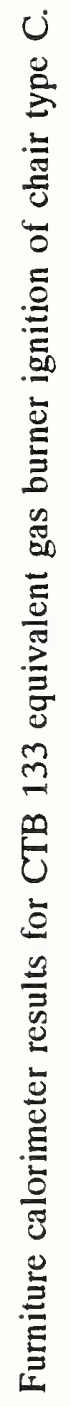


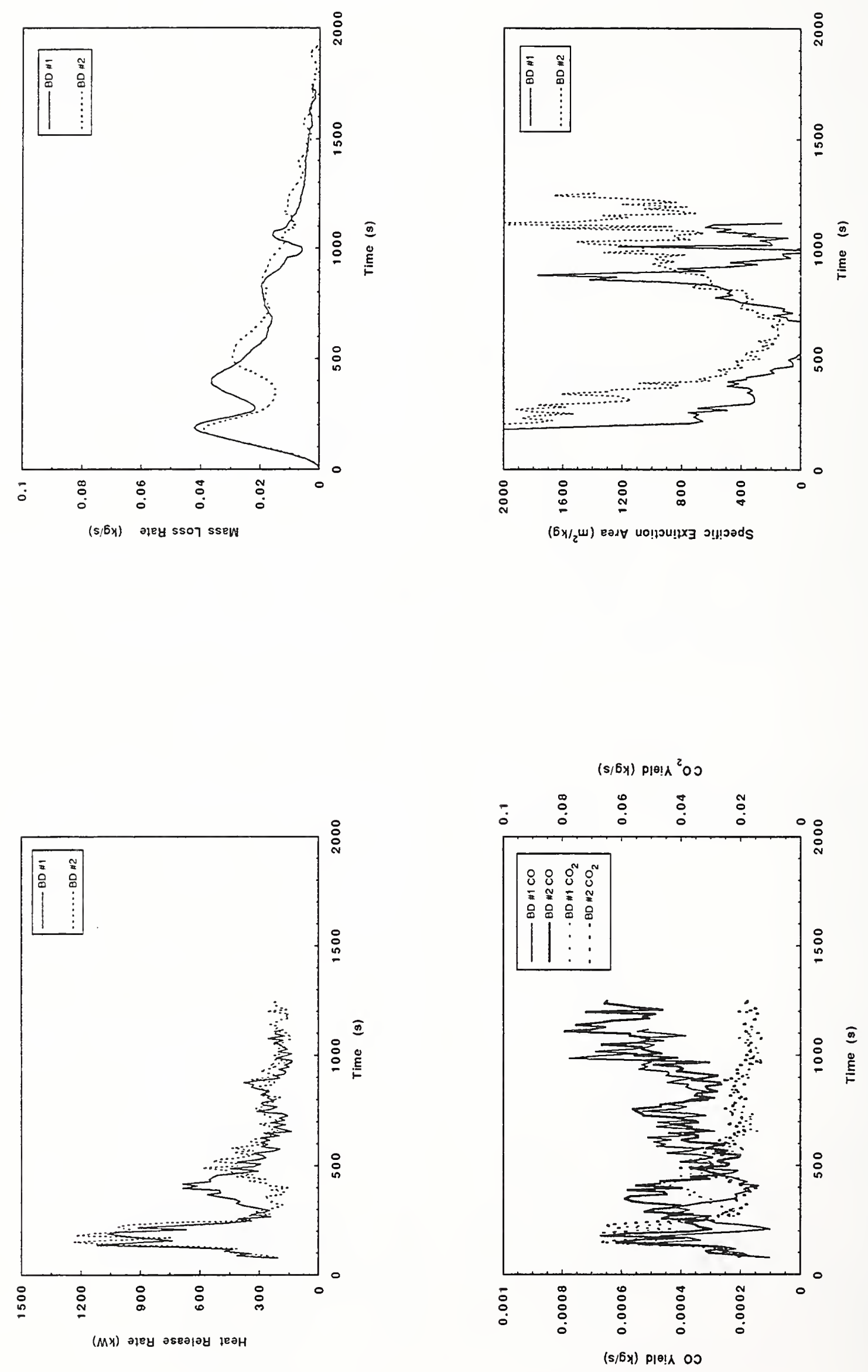





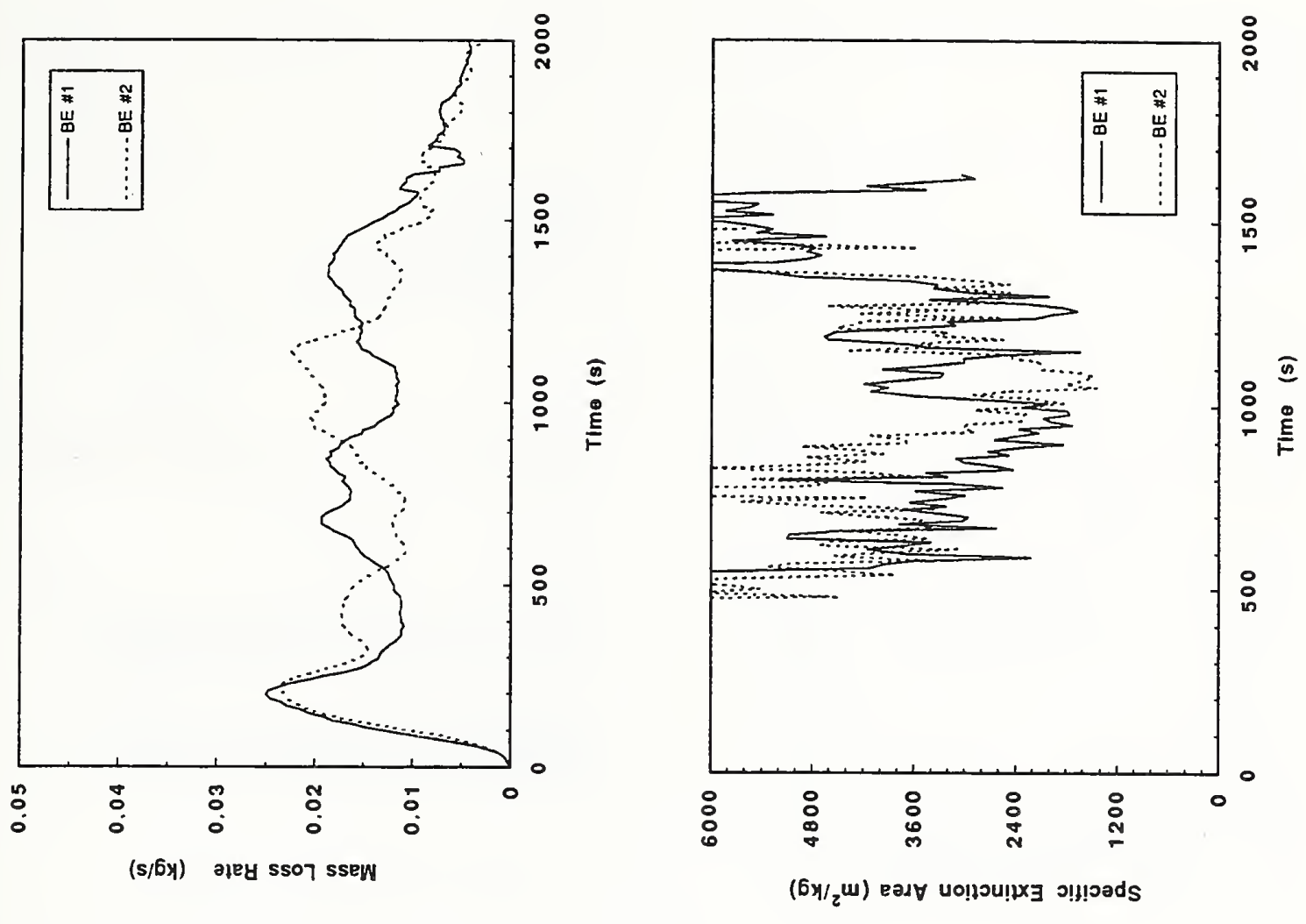

व)



(Mx) efey eseojer jeor

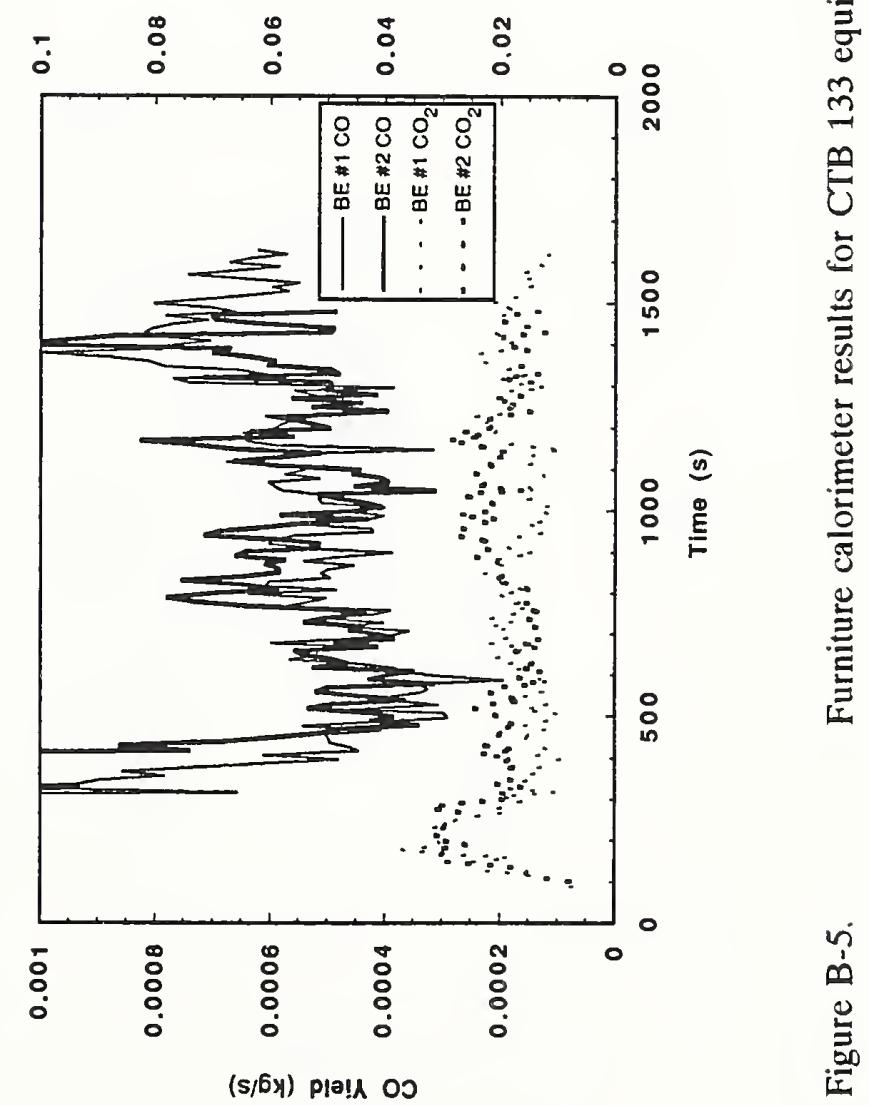



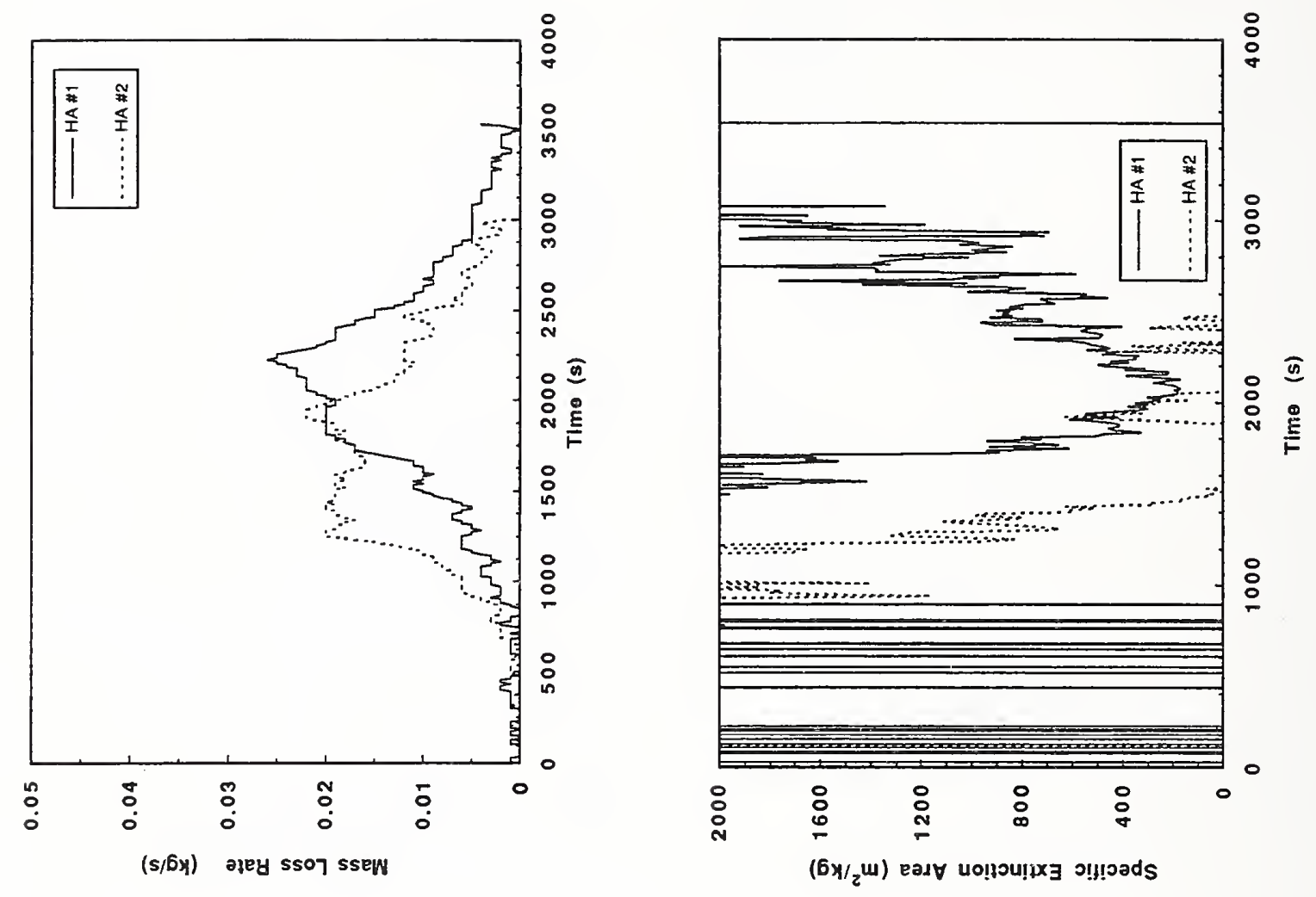



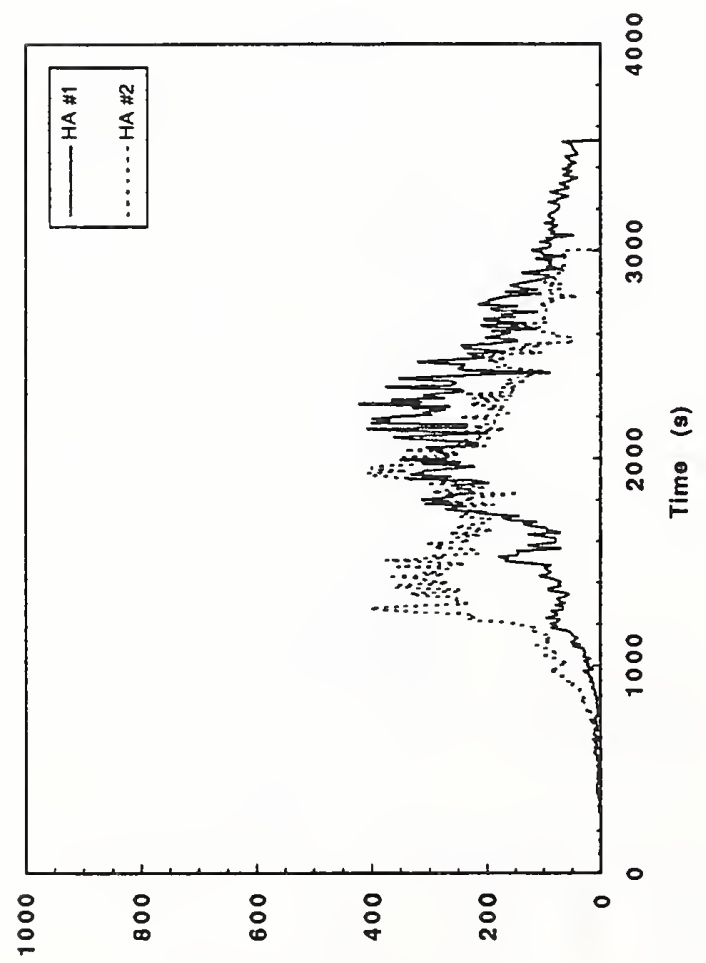

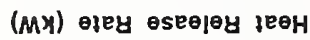

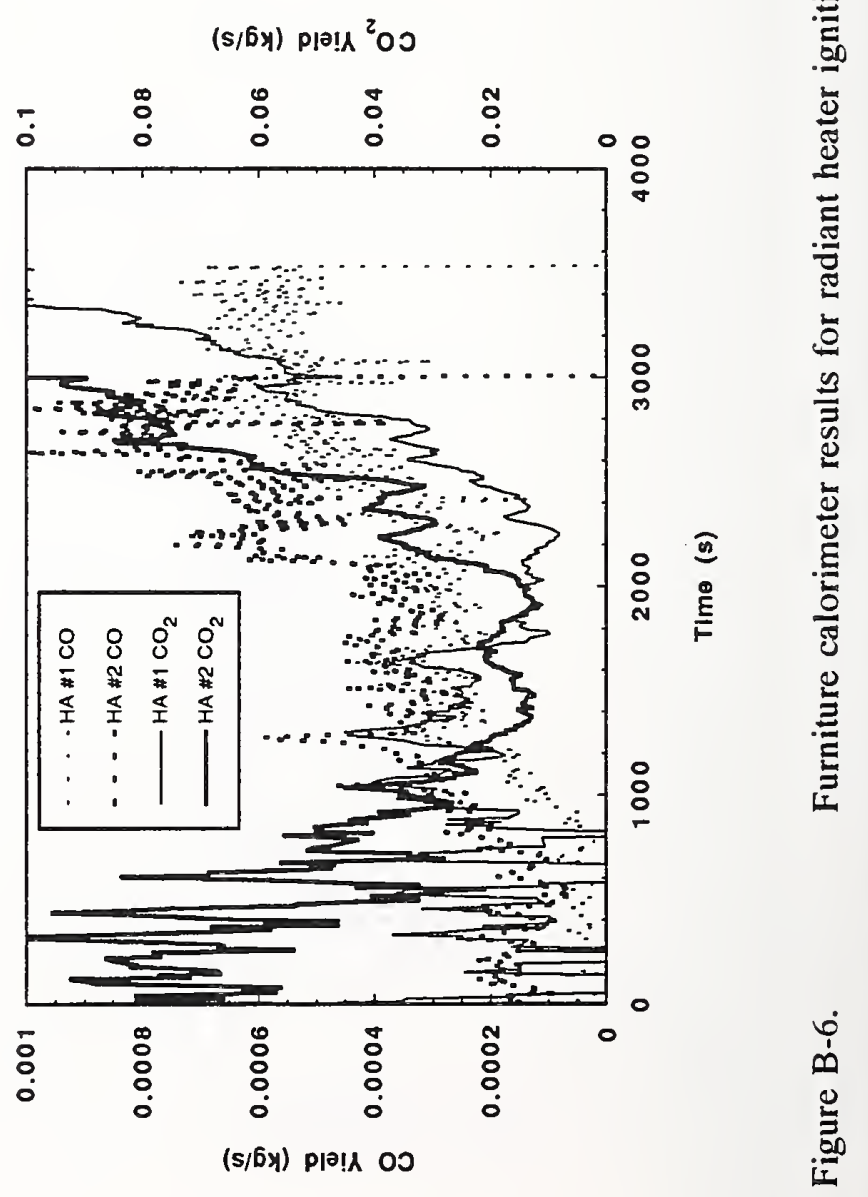



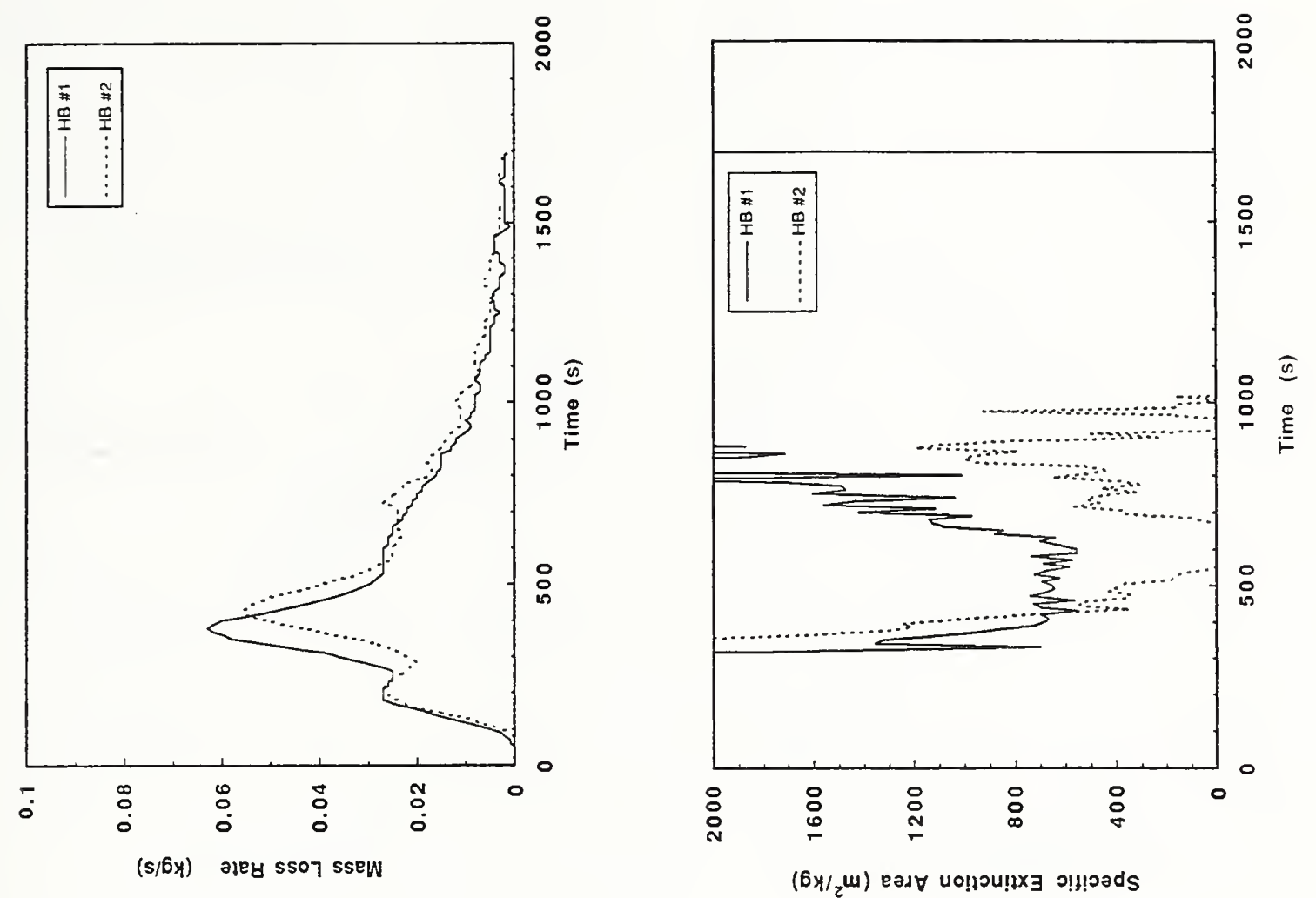

电
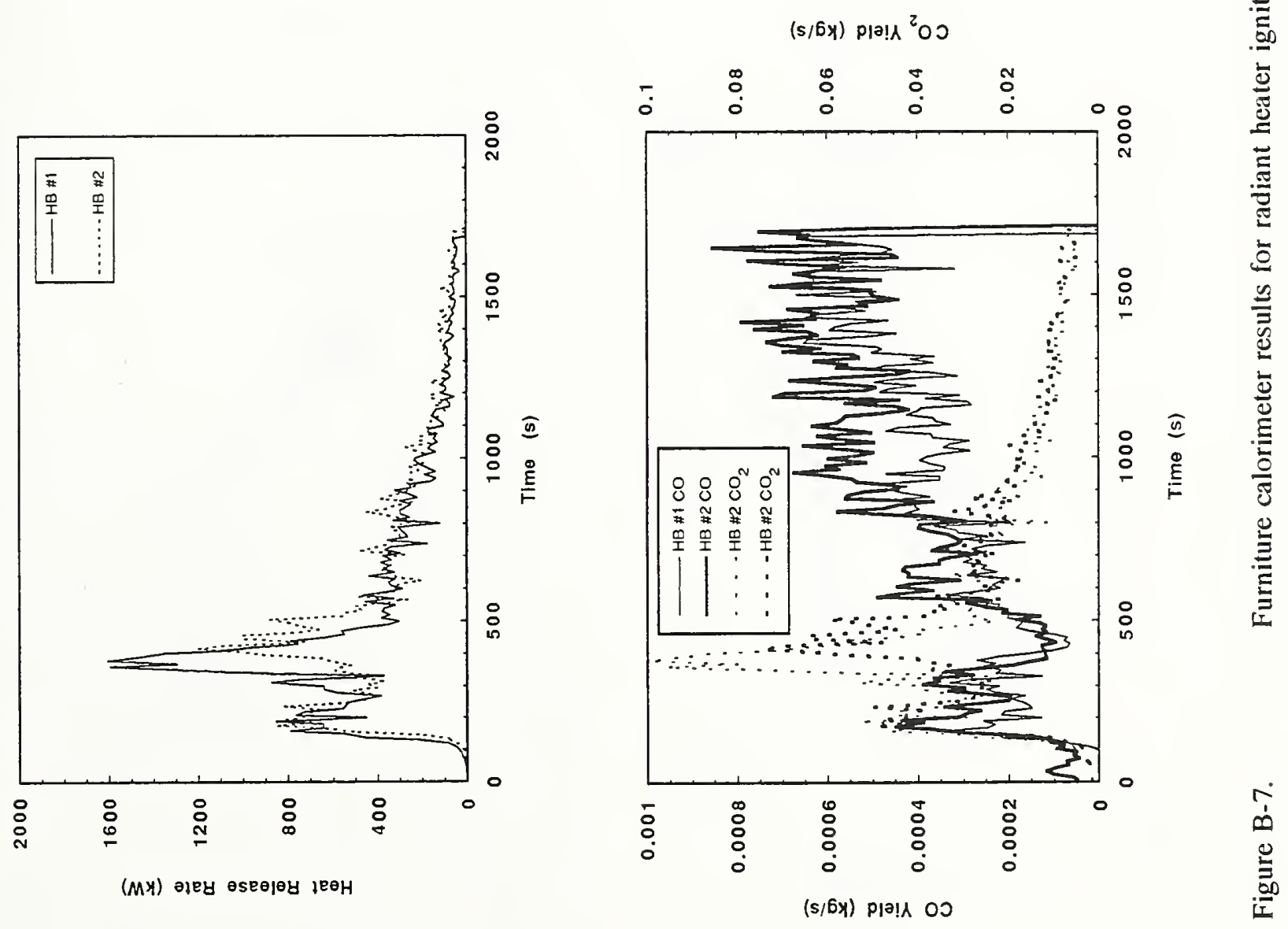



$\left(6 x / z^{m)}\right.$ ead
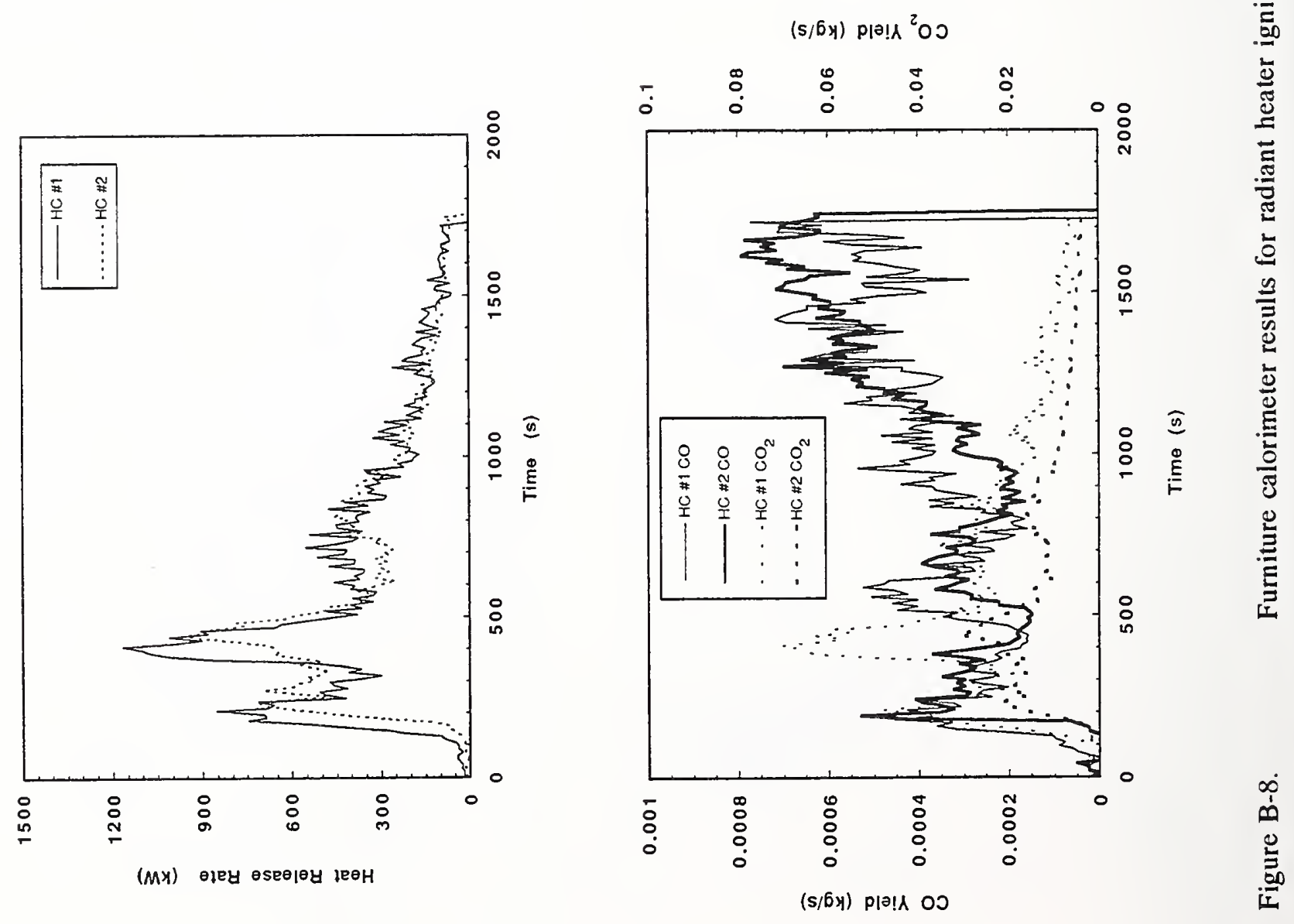

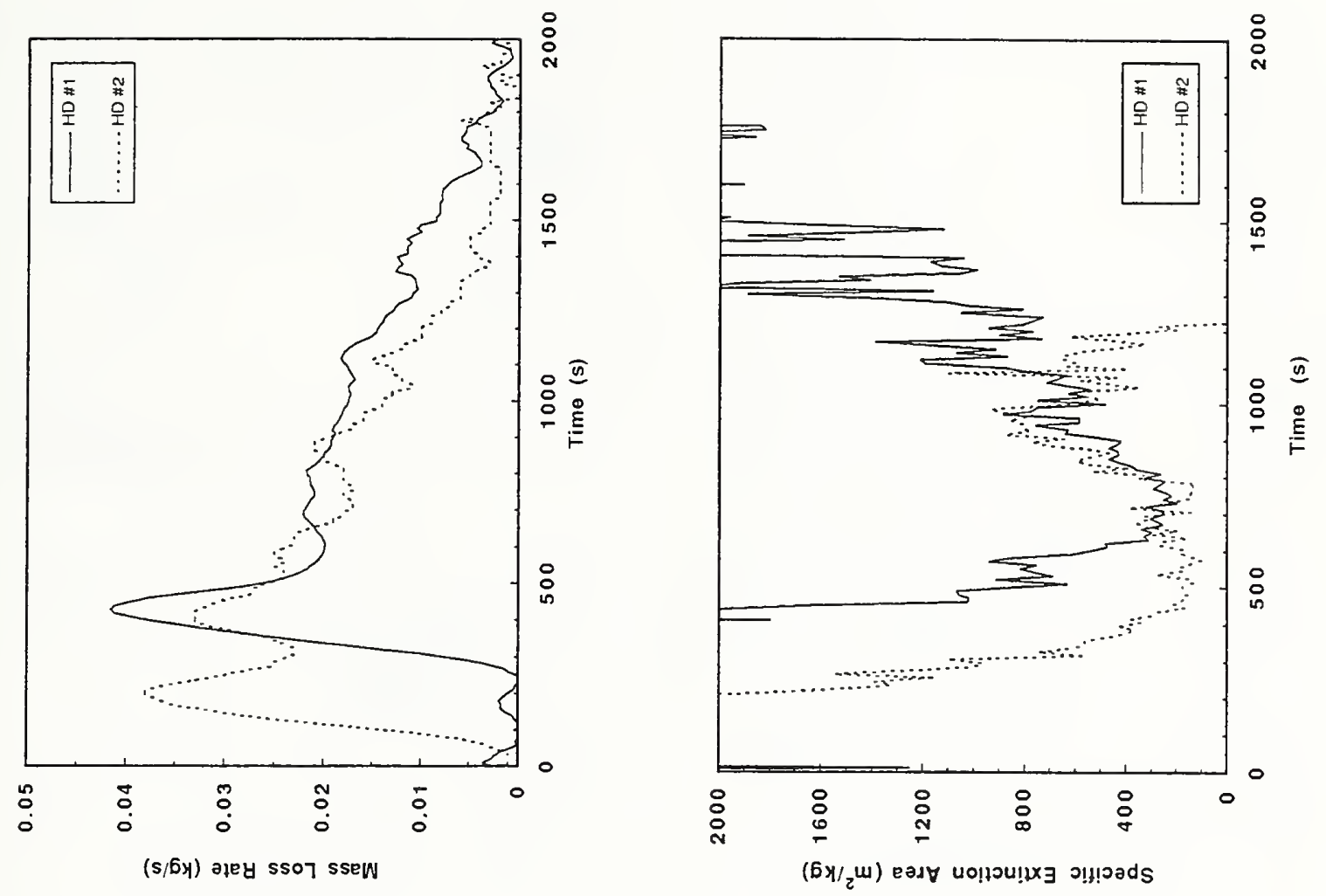

Oे
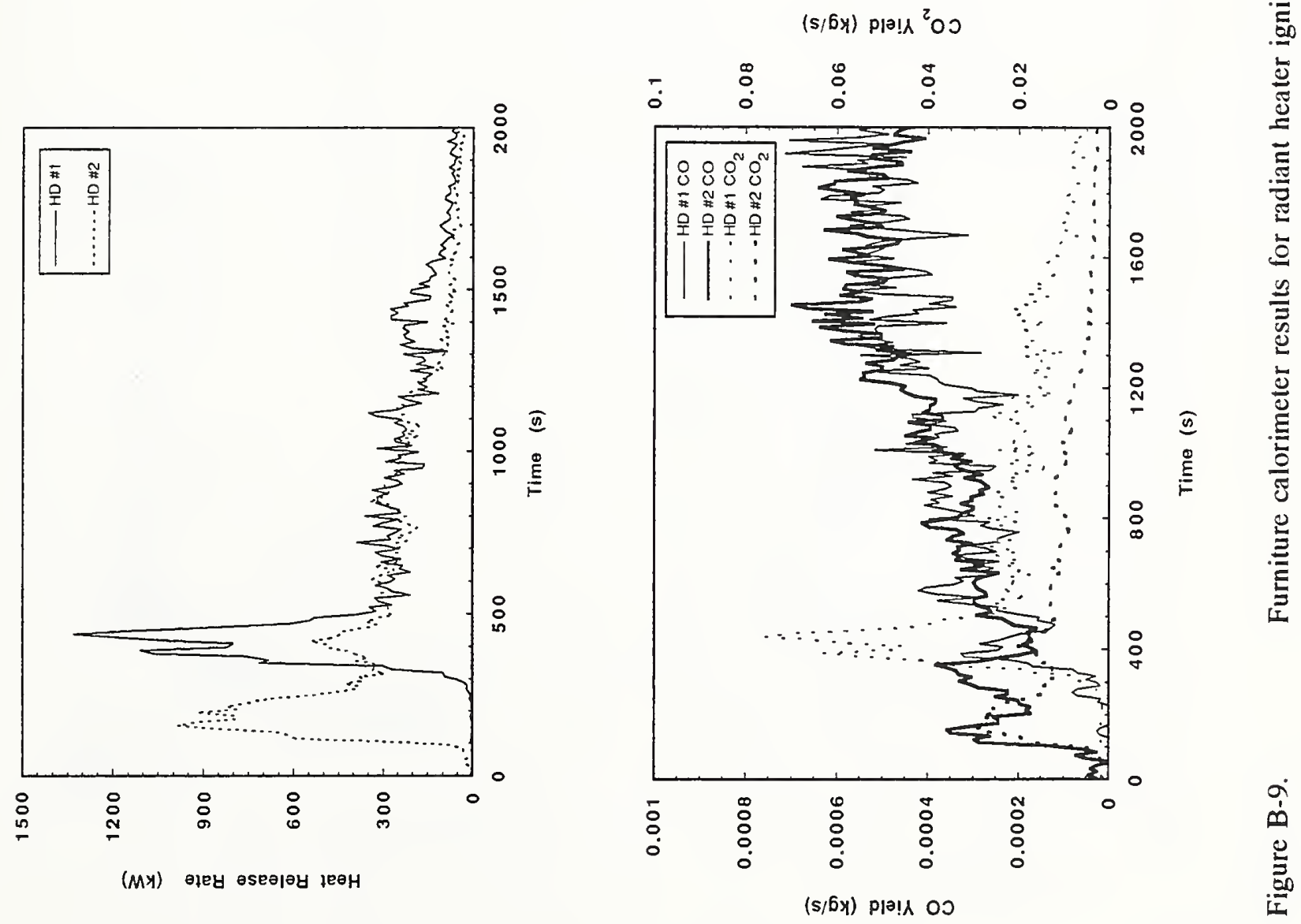

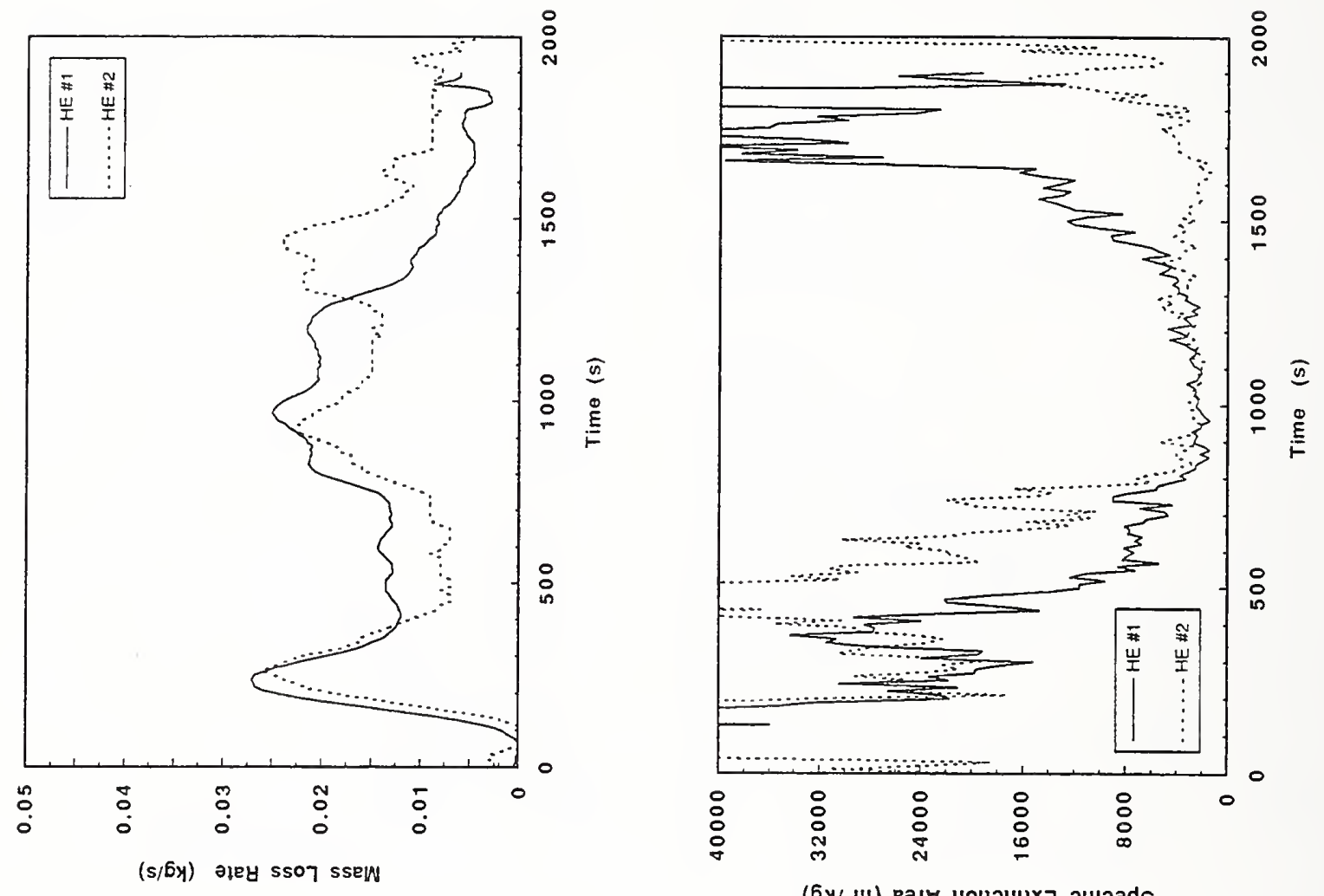



몰

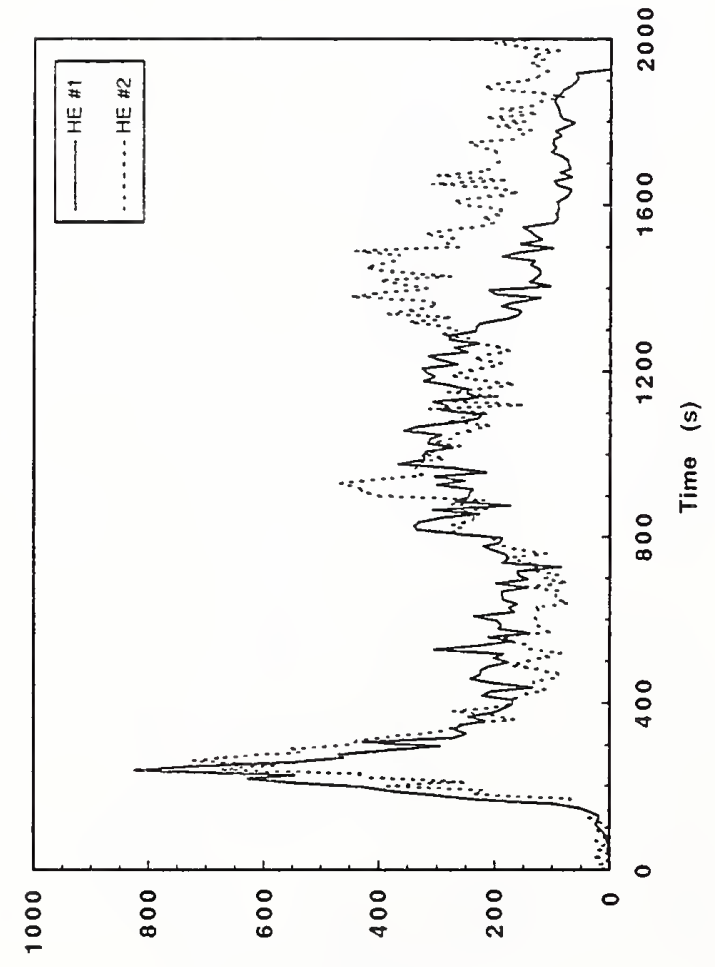

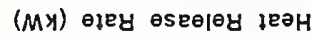

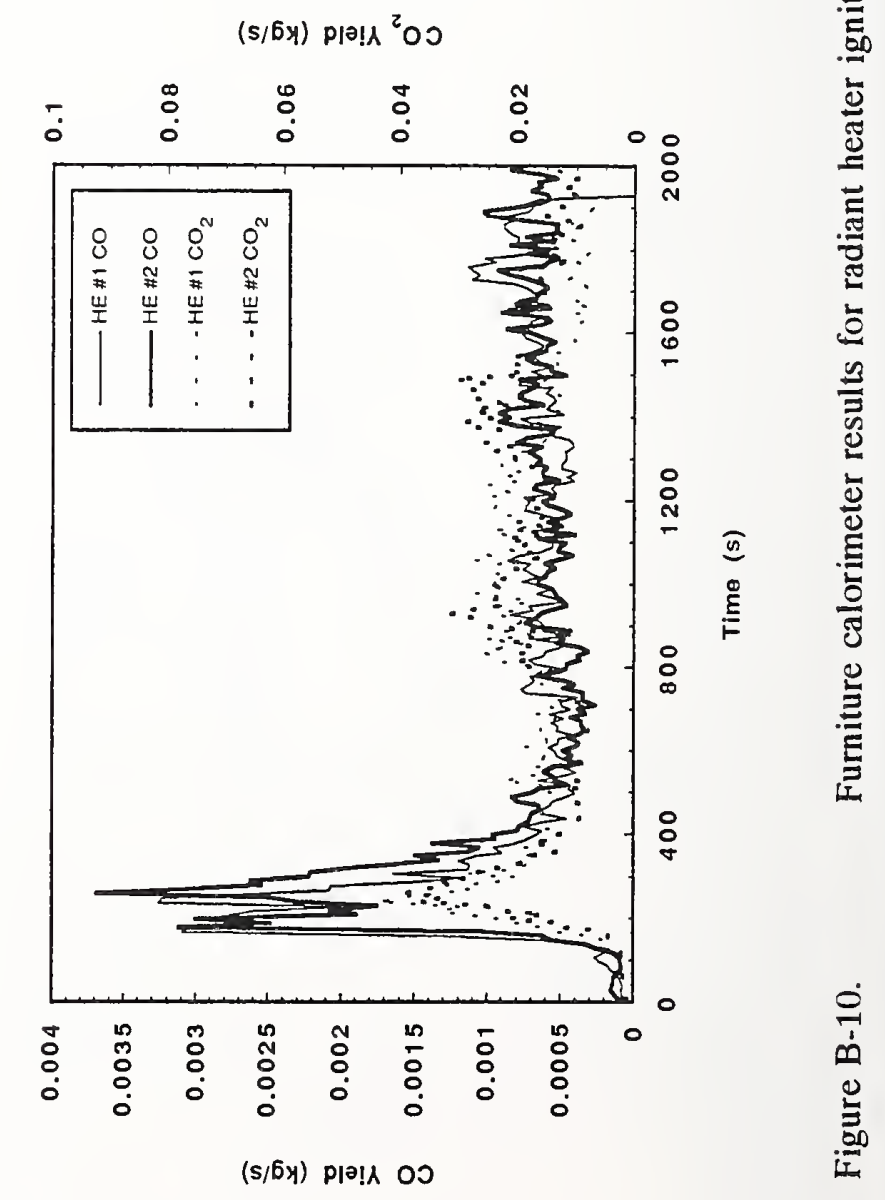



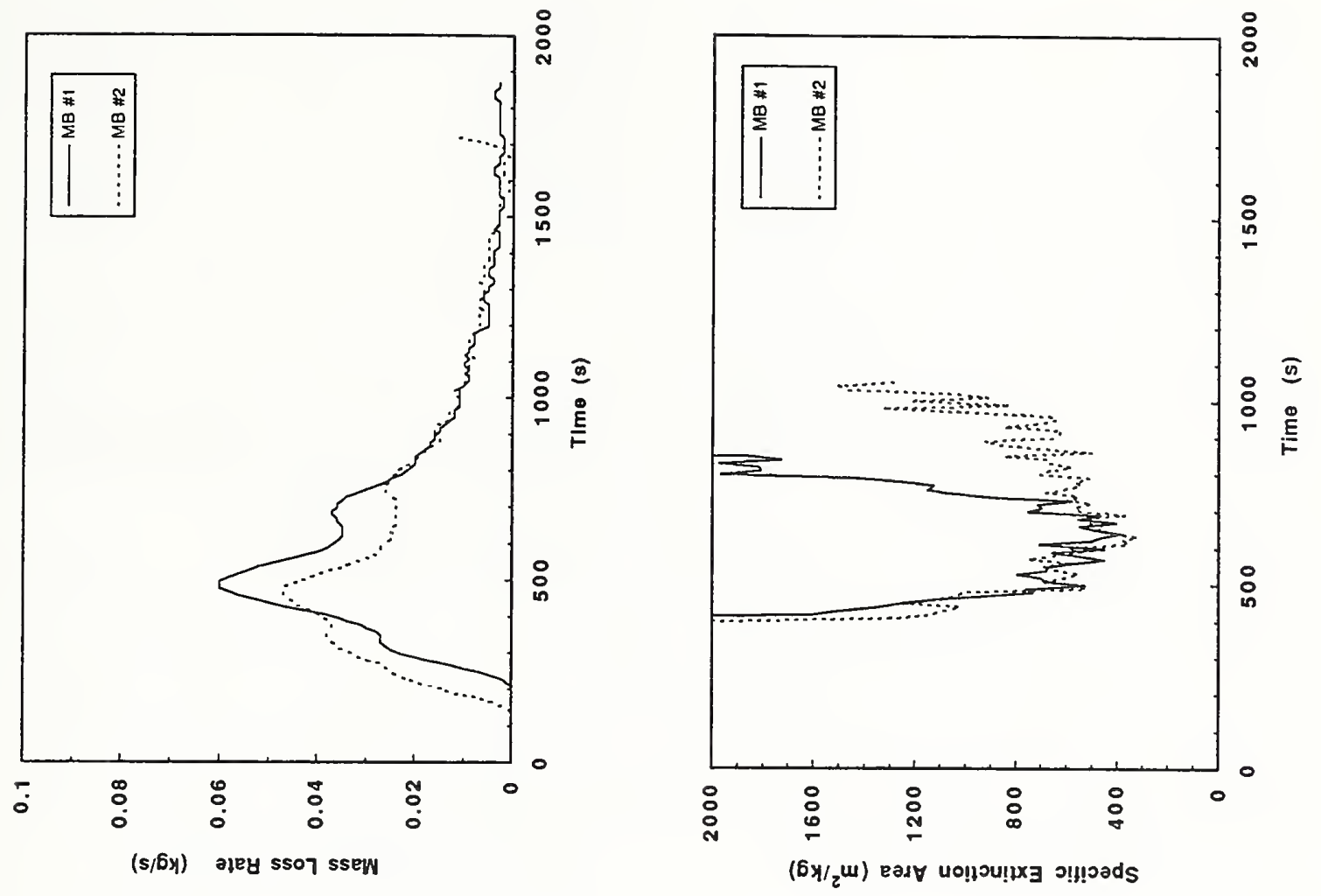

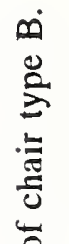



(Mx) өley eseejey jeeH

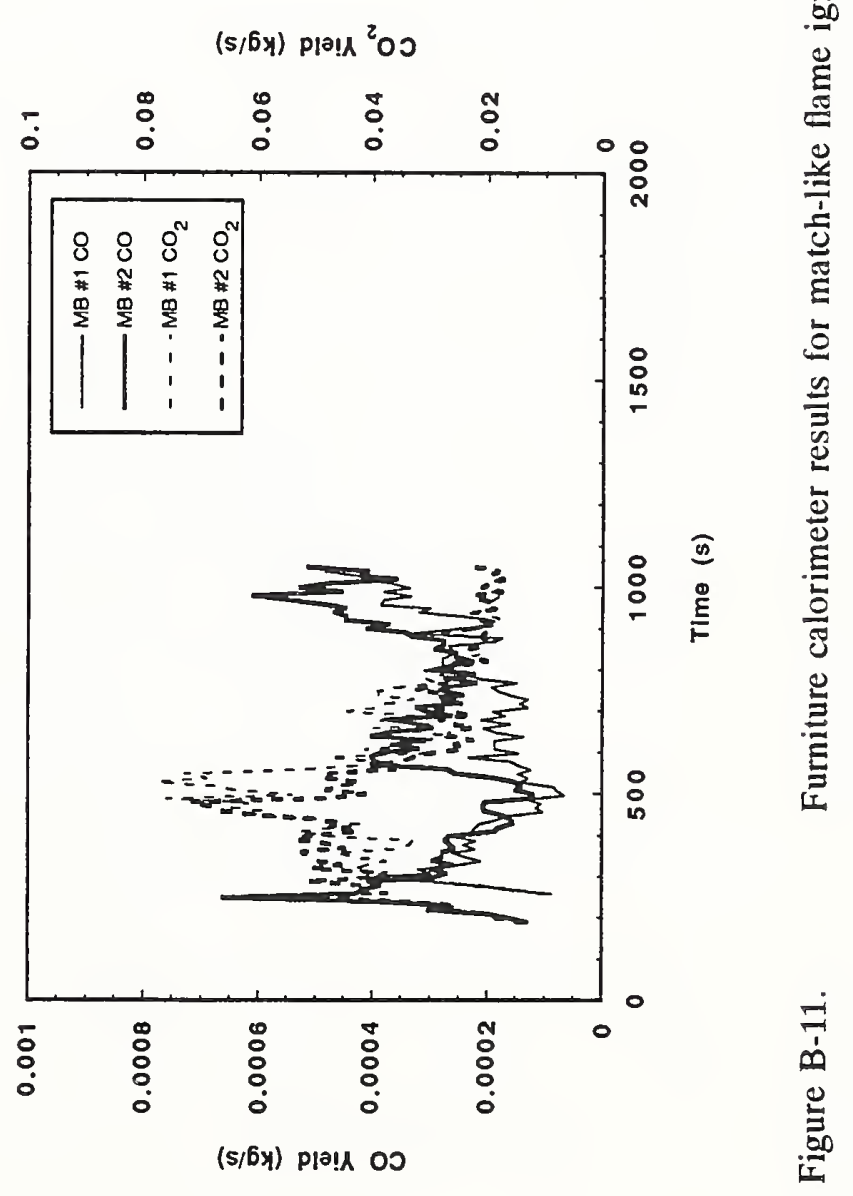



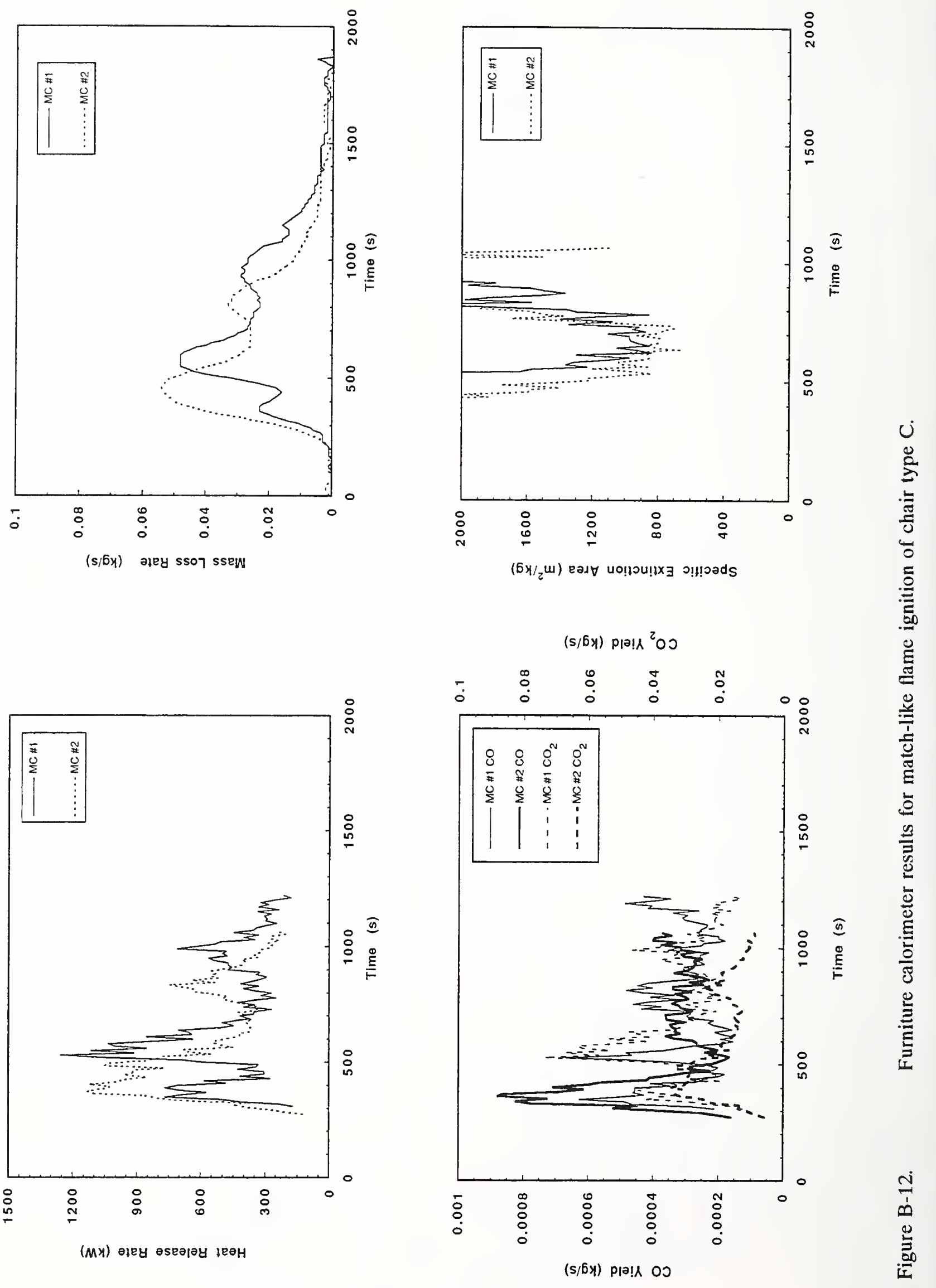

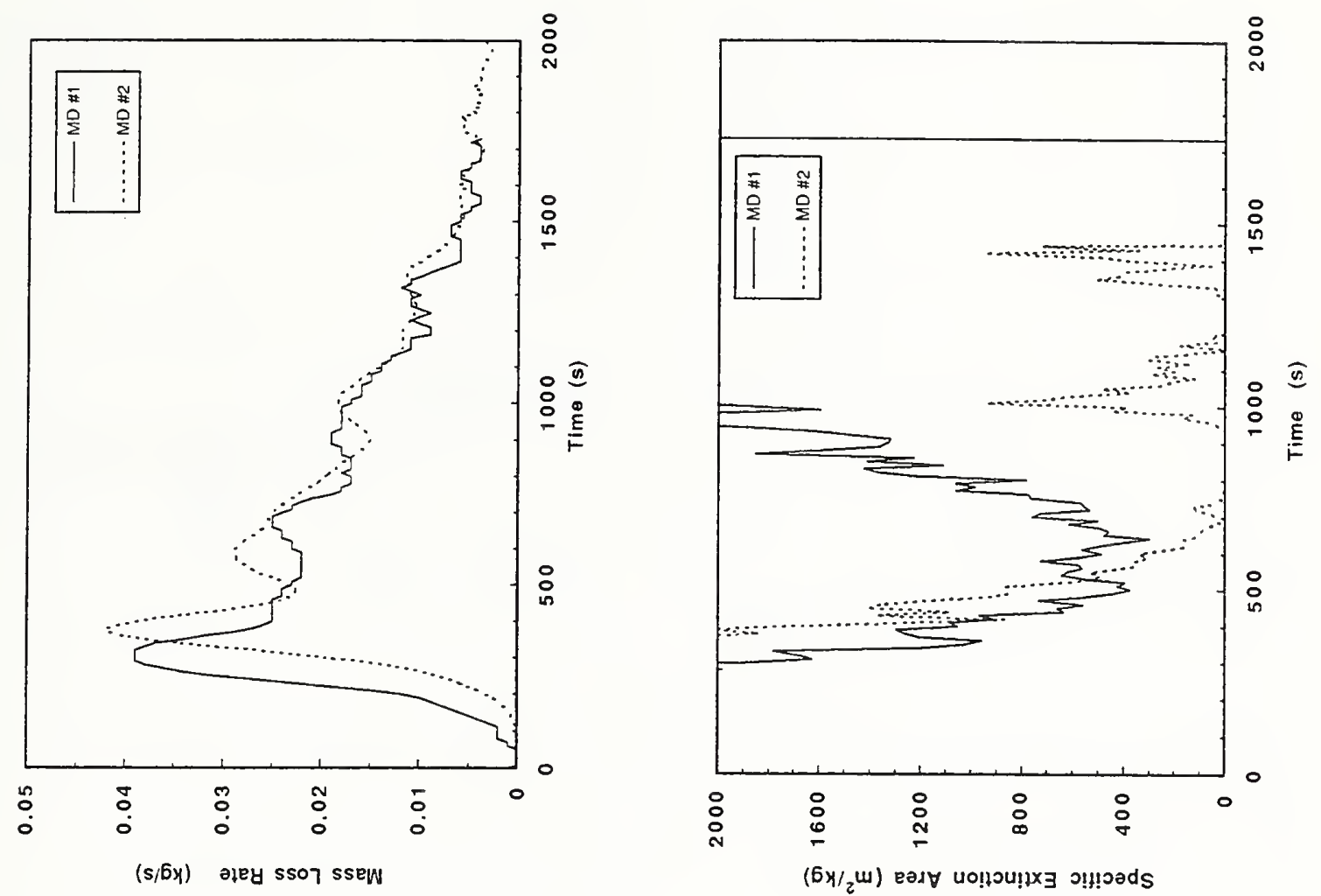

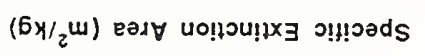

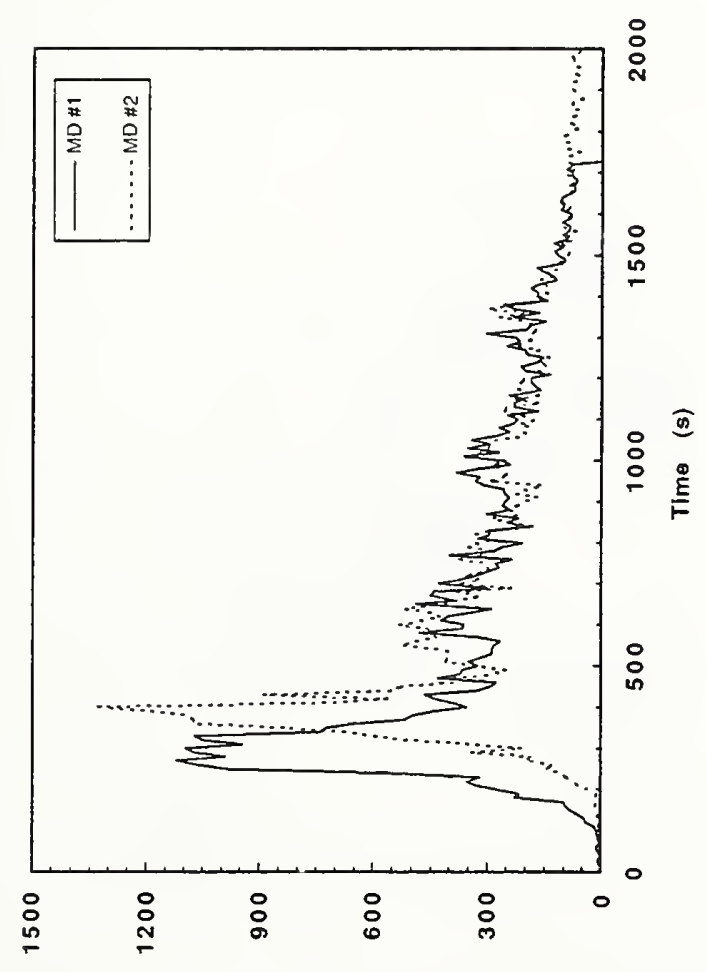

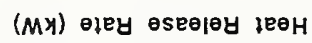

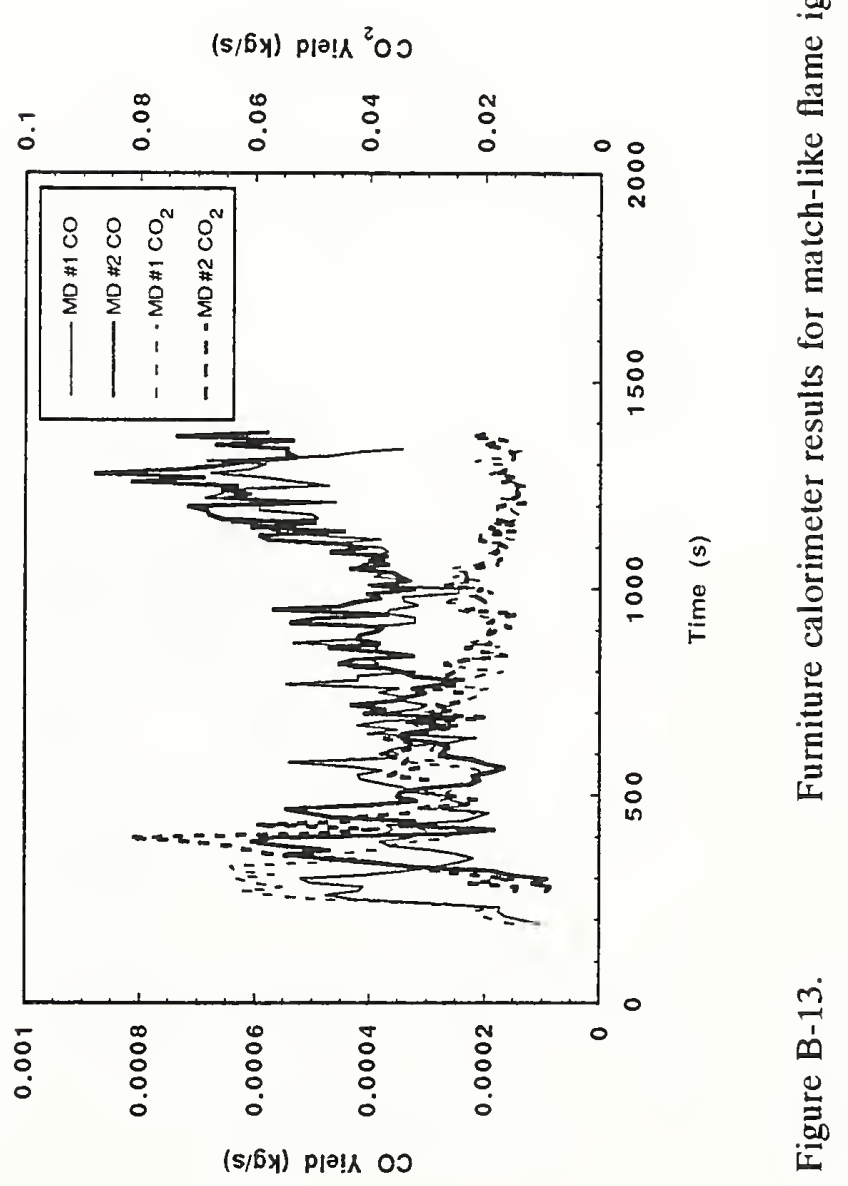



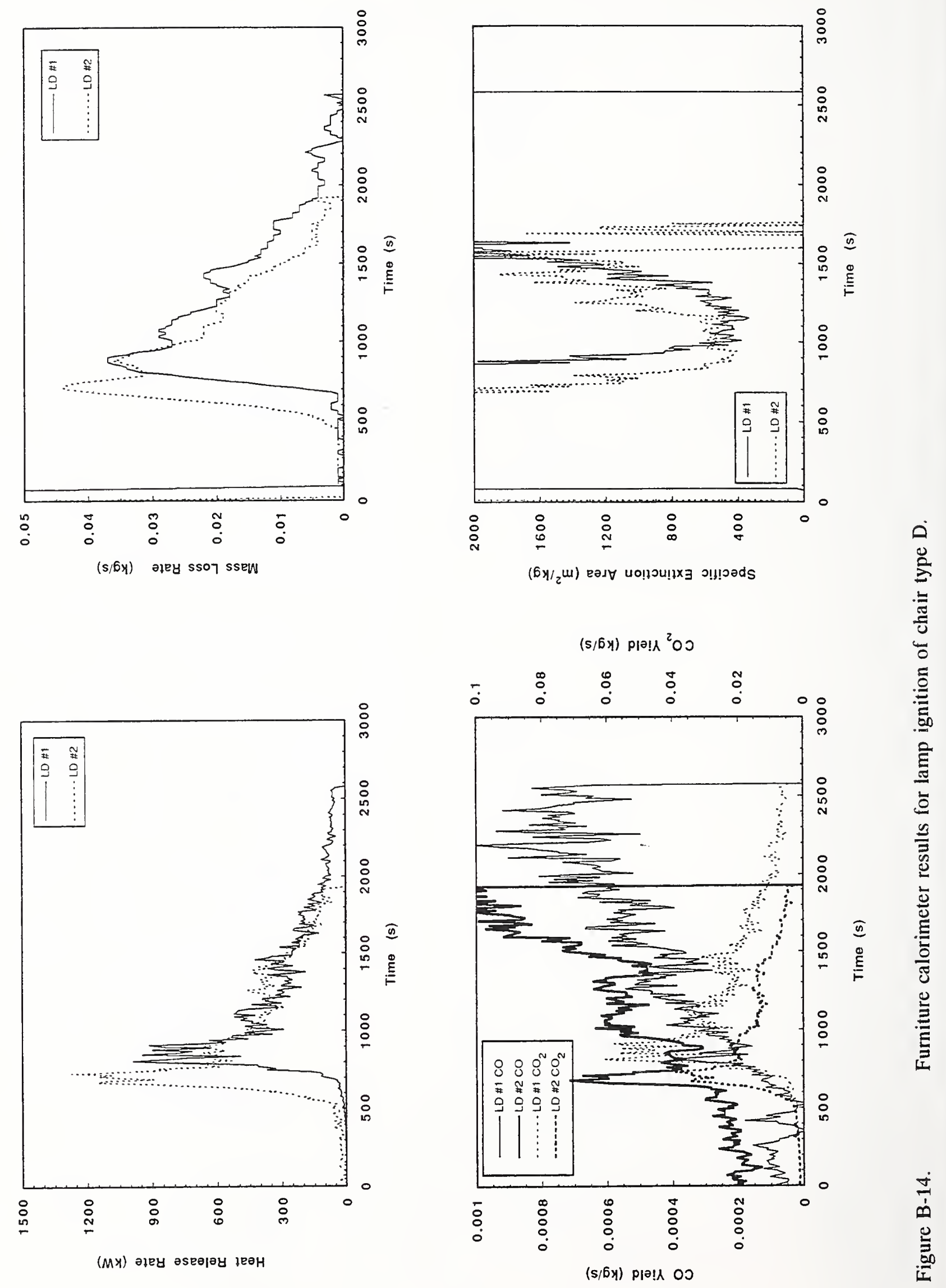



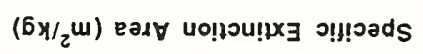

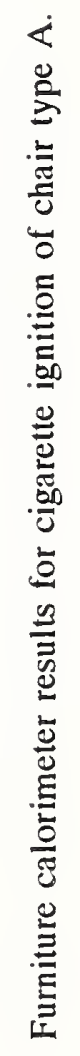
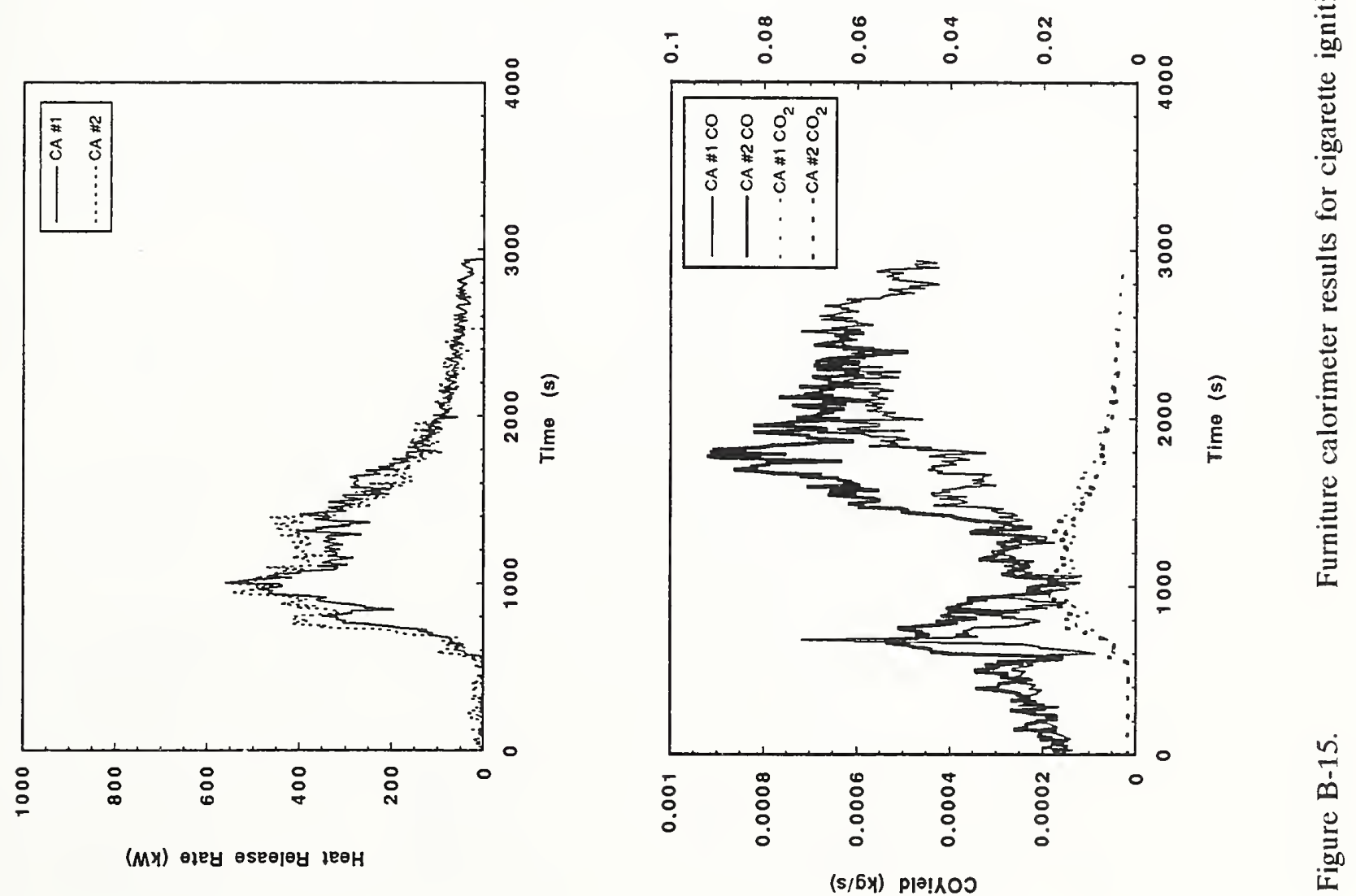


\section{APPENDIX C}

\section{Results from HAZARD I Simulations}

The status of the fire at time of occupant alert and at time occupant fate is decided based on HAZARD I simulations is shown both in tabular and graphical form. Time of occupant alert $\left(\mathrm{t}_{\text {alert }}\right)$ is the time from the start of the simulation to the time the first occupant is alerted to the fire. Time occupant fate is decided $\left(t_{\text {final }}\right)$ is the time at escape or time to incapacitation or entrapment in the building. The table gives these times and also the difference between these times. The table provides precise values for the fire status at these times. The graphs plot the fire status at these two times. They provide a quick visual comparison of: (a) the degree of agreement between the repeat burns of the same chair with the same ignition scenario (see pairs of bars denoted as 1 and 2), (b) the variation caused by chair materials, and (c) the effect of fire location (living room versus master bedroom). Under the table heading "Test" the first letter indicates the source (see page 6), and the second letter indicates the chair type (see page 4). 
Table C-1. Status of Fire at Time of Occupant Alert and at Time Occupant Fate is Decided; Based on HAZARD I Simulations

Test Location $\quad t_{\text {alert }} \quad \dot{Q} \quad$ THR of Chair

(s)

$(\mathrm{kW})(\mathrm{MJ})$

$\begin{array}{lllll}\mathrm{t}_{\text {final }} & \mathrm{Q} & \text { THR } & \Delta \mathrm{t} & \begin{array}{l}\text { Number } \\ (\mathrm{s})\end{array} \\ & (\mathrm{kW}) & (\mathrm{MJ}) & (\mathrm{s}) & \text { of deaths }\end{array}$

BA \#1 Living $\mathrm{Rm} . \quad 836$

BA \#2 Living Rm. 607

$162 \quad 33$

BA \#1

Bedroom $\quad 822$

$70 \quad 25$

BA \#2

Bedroom $\quad 574$

$149 \quad 31$

70 -

$\begin{array}{lllll}\mathrm{BB} \# 1 & \text { Living Rm. } & 109 & 687 & 38\end{array}$

BB \#2 Living Rm. $111 \quad 816 \quad 45$

$\begin{array}{lllll}\text { BB \#1 } & \text { Bedroom } & 60 & 379 & 11\end{array}$

$\mathrm{BB} \# 2$

Bedroom 77

$566 \quad 22$

BC \#1 Living Rm. $126 \quad 663 \quad 42$

BC \#2 Living Rm. $126 \quad 580 \quad 37$

$\begin{array}{lllll}B C \# 1 & \text { Bedroom } & 74 & 389 & 14\end{array}$

$\begin{array}{lllll}\mathrm{BC} \# 2 & \text { Bedroom } & 70 & 322 & 11\end{array}$

$\begin{array}{lllll}\text { BD \#1 Living Rm. } & 129 & 723 & 47\end{array}$

BD \#2 Living Rm. $72 \quad 274 \quad 18$

BD \#1 Bedroom $107 \quad 600$ -



BE \#1 Living Rm. $111 \quad 297 \quad 17$

$\mathrm{BE} \# 2$

Living $\mathrm{Rm} .116$

$291 \quad 17$

$\mathrm{BE} \# 1$

Bedroom $\quad 38$

1032

$\mathrm{BE} \# 2$

Bedroom 41

1032

$\begin{array}{lllll}\text { HA \#1 Living Rm. } & 1081 & 78 & 21\end{array}$

HA \#2 Living Rm. $506 \quad 188 \quad 27$

HA \#1

Bedroom $\quad 350$

7.51

HA \#2

Bedroom 288

$44 \quad 7$

$\mathrm{HB} \#$

Living Rm. 156

HB \#2

Living Rm.

$\begin{array}{ll}626 & 22\end{array}$

HB \#1

Living Rm.

$2078 \quad 744 \quad 46$

HB \#2

\section{Bedroom}

$91 \quad 51 \quad 2$

HC \#1 Living Rm. 307

$1989 \quad 70 \quad 4$

$\mathrm{HC} \# 2$

Living Rm.

$41 \quad 10$

$327 \quad 15$

$\mathrm{HC} \# 1$

Bedroom

156

$\mathrm{HC} \# 2$

Bedroom

212

$40 \quad 6$

$18 \quad .4$

HD \#1 Living Rm. $123 \quad 699 \quad 44$

HD \#2 Living Rm. $188 \quad 700 \quad 21$

HD \#1 $\quad$ Bedroom $\quad 76 \quad 436 \quad 17$

HD \#2 Bedroom 103

$24 \quad 1.5$

$\begin{array}{lllll}845 & 175 & 36 & 9 & 0 \\ 630 & 72 & 27 & 23 & 4 \\ 830 & 156 & 41 & 8 & 4 \\ 550 & 65 & 21 & - & 4 \\ & & & & \\ 120 & 757 & 44 & 11 & 4 \\ 120 & 882 & 53 & 9 & 4 \\ 81 & 568 & 25 & 21 & 0 \\ 90 & 662 & 30 & 23 & 4 \\ & & & & \\ 150 & 789 & 60 & 24 & 4 \\ 150 & 690 & 52 & 24 & 4 \\ 95 & 526 & 26 & 21 & 0 \\ 91 & 460 & 23 & 21 & 0 \\ & & & & \\ 140 & 785 & 55 & 11 & 4 \\ 83 & 286 & 23 & 11 & 0 \\ 100 & 561 & 28 & - & 4 \\ 43 & 259 & 12 & 13 & 0 \\ & & & & \\ 120 & 348 & 23 & 9 & 0 \\ 130 & 326 & 21 & 14 & 0 \\ 51 & 161 & 5 & 13 & 0 \\ 54 & 150 & 5 & 13 & 0 \\ & & & & \\ 1090 & 80 & 21 & 9 & 2 \\ 520 & 203 & 30 & 14 & 2 \\ 363 & 9 & 2 & 13 & 0 \\ 301 & 47 & 8 & 13 & 0 \\ & & & & \\ 166 & 726 & 29 & 10 & 4 \\ 2100 & 662 & 61 & 22 & 4 \\ 104 & 165 & 4 & 13 & 0 \\ 2002 & 87 & 4 & 13 & 0 \\ & & & & \\ 314 & 41 & 10 & 7 & 4 \\ 165 & 384 & 20 & 9 & 0 \\ 233 & 40 & 7 & 21 & 0 \\ 40 & 18 & .5 & 13 & 0 \\ & & & & \\ 130 & 738 & 49 & 7 & 4 \\ 200 & 863 & 30 & 12 & 2 \\ 100 & 570 & 29 & 24 & 2 \\ 116 & 29 & 2 & 13 & 0 \\ & & & & \end{array}$


Table C-1. Cont.

\begin{tabular}{|c|c|c|c|c|c|c|c|c|c|}
\hline Test & $\begin{array}{l}\text { Location } \\
\text { of Chair }\end{array}$ & $\begin{array}{l}\mathrm{t}_{\text {alert }} \\
\text { (s) }\end{array}$ & $\begin{array}{l}\dot{Q} \\
(k W)\end{array}$ & $\begin{array}{l}\text { THR } \\
\text { (MJ) }\end{array}$ & $\begin{array}{l}t_{\text {final }} \\
(\mathrm{s})\end{array}$ & $\begin{array}{l}\dot{Q} \\
(\mathrm{~kW})\end{array}$ & $\begin{array}{l}\text { THR } \\
\text { (MJ) }\end{array}$ & $\begin{array}{l}\Delta \mathrm{t} \\
(\mathrm{s})\end{array}$ & $\begin{array}{l}\text { Number } \\
\text { of deaths }\end{array}$ \\
\hline HE \#1 & Living $\mathrm{Rm}$. & 60 & 255 & 8 & 73 & 338 & 14 & 13 & 0 \\
\hline HE \#2 & Living $\mathrm{Rm}$. & 62 & 322 & 11 & 82 & 448 & 22 & 20 & 0 \\
\hline HE \#1 & Bedroom & 12 & 55 & .4 & 25 & 130 & 2 & 13 & 0 \\
\hline $\mathrm{HE} \# 2$ & Bedroom & 17 & 120 & 1.4 & 30 & 224 & 2 & 13 & 0 \\
\hline MB \#1 & Living Rm. & 124 & 465 & 30 & 130 & 486 & 33 & 6 & 4 \\
\hline MB \#2 & Living $\mathrm{Rm}$. & 104 & 586 & 33 & 110 & 599 & 36 & 6 & 2 \\
\hline MB \#1 & Bedroom & 74 & 288 & 12 & 95 & 362 & 18 & 21 & 2 \\
\hline $\mathrm{MB} \# 2$ & Bedroom & 53 & 319 & 9 & 74 & 435 & 17 & 21 & 0 \\
\hline MC \#1 & Living $\mathrm{Rm}$. & 68 & 703 & 24 & 82 & 828 & 34 & 14 & 2 \\
\hline $\mathrm{MC} \mathrm{\# 2}$ & Living Rm. & 134 & 438 & 16 & 141 & 555 & 24 & 7 & 0 \\
\hline MC \#1 & Bedroom & 26 & 269 & 3.5 & 39 & 404 & 8 & 13 & 0 \\
\hline $\mathrm{MC} \mathrm{\# 2}$ & Bedroom & 48 & 38 & 1.6 & 61 & 44 & 2.5 & 13 & 0 \\
\hline MD \#1 & Living Rm. & 181 & 617 & 37 & 200 & 762 & 50 & 19 & 4 \\
\hline $\mathrm{MD} \# 2$ & Living $\mathrm{Rm}$. & 185 & 556 & 25 & 190 & 604 & 28 & 5 & 2 \\
\hline MD \#1 & Bedroom & 112 & 198 & 12 & 133 & 304 & 18 & 21 & 0 \\
\hline $\mathrm{MD} \# 2$ & Bedroom & 81 & 78 & 3.4 & 94 & 95 & 5 & 13 & 0 \\
\hline LD \#1 & Living $R m$. & 265 & 503 & 36 & 270 & 522 & 38 & 5 & 4 \\
\hline LD \#2 & Living Rm. & 105 & 520 & 30 & 109 & 537 & 32 & 4 & 2 \\
\hline LD \#1 & Bedroom & 219 & 328 & 17 & 230 & 370 & 21 & 11 & 4 \\
\hline LD \#2 & Bedroom & 44 & 251 & 7 & 62 & 365 & 15 & 18 & 0 \\
\hline $\mathrm{CA} \# 1$ & Living $R m$. & 187 & 187 & 18 & 196 & 200 & 20 & 9 & 0 \\
\hline $\mathrm{CA} \# 2$ & Living $\mathrm{Rm}$. & 216 & 84 & 11 & 230 & 76 & 13 & 14 & 0 \\
\hline $\mathrm{CA} \# 1$ & Bedroom & 35 & 35 & .6 & 50 & 50 & 1.3 & 15 & 0 \\
\hline $\mathrm{CA} \# 2$ & Bedroom & 29 & 26 & .5 & 42 & 34 & 1.2 & 13 & 0 \\
\hline
\end{tabular}


(rw) pasealay leaн Іеł0」

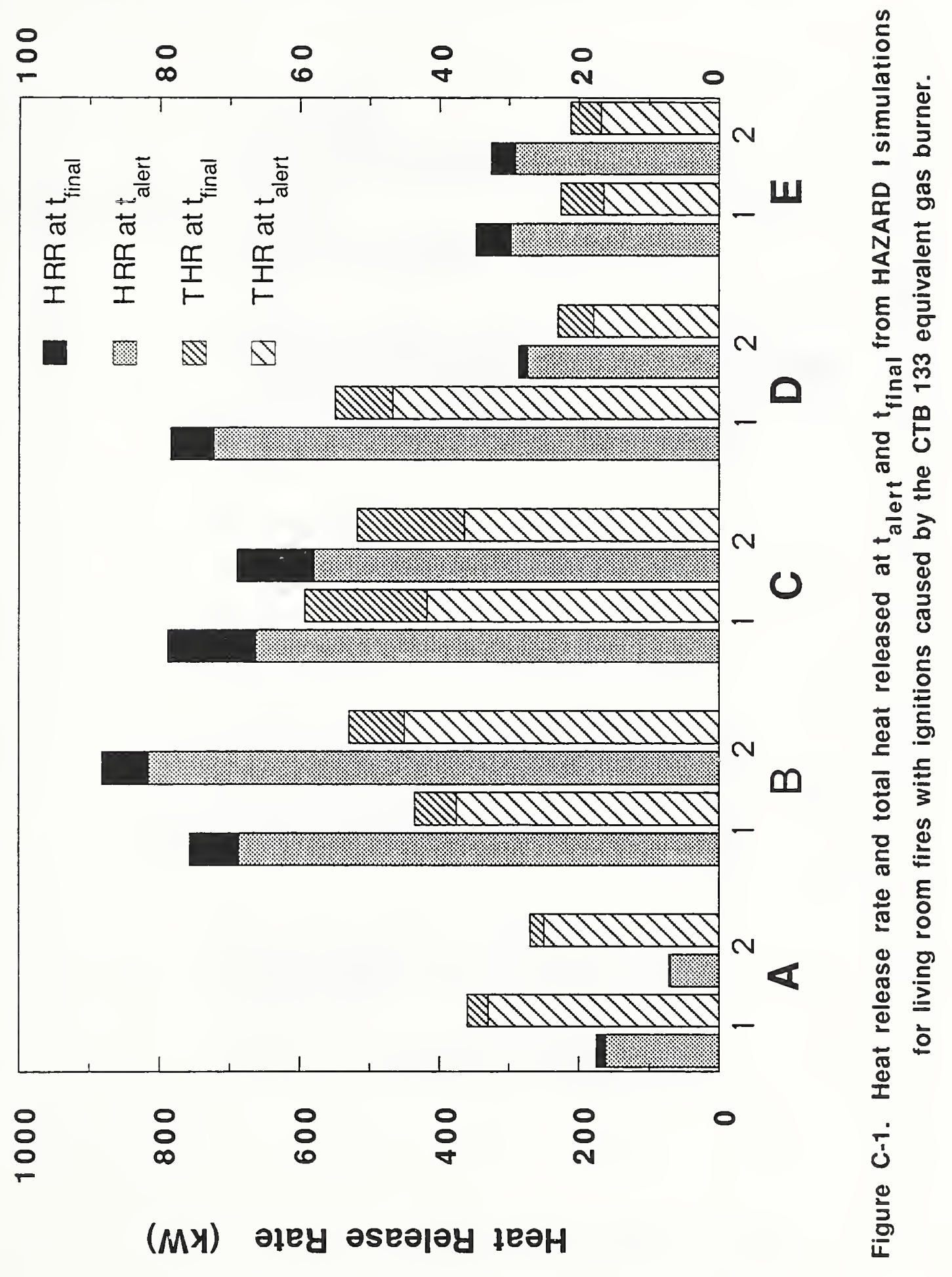




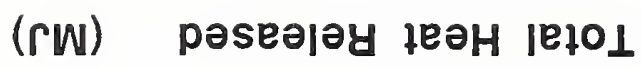

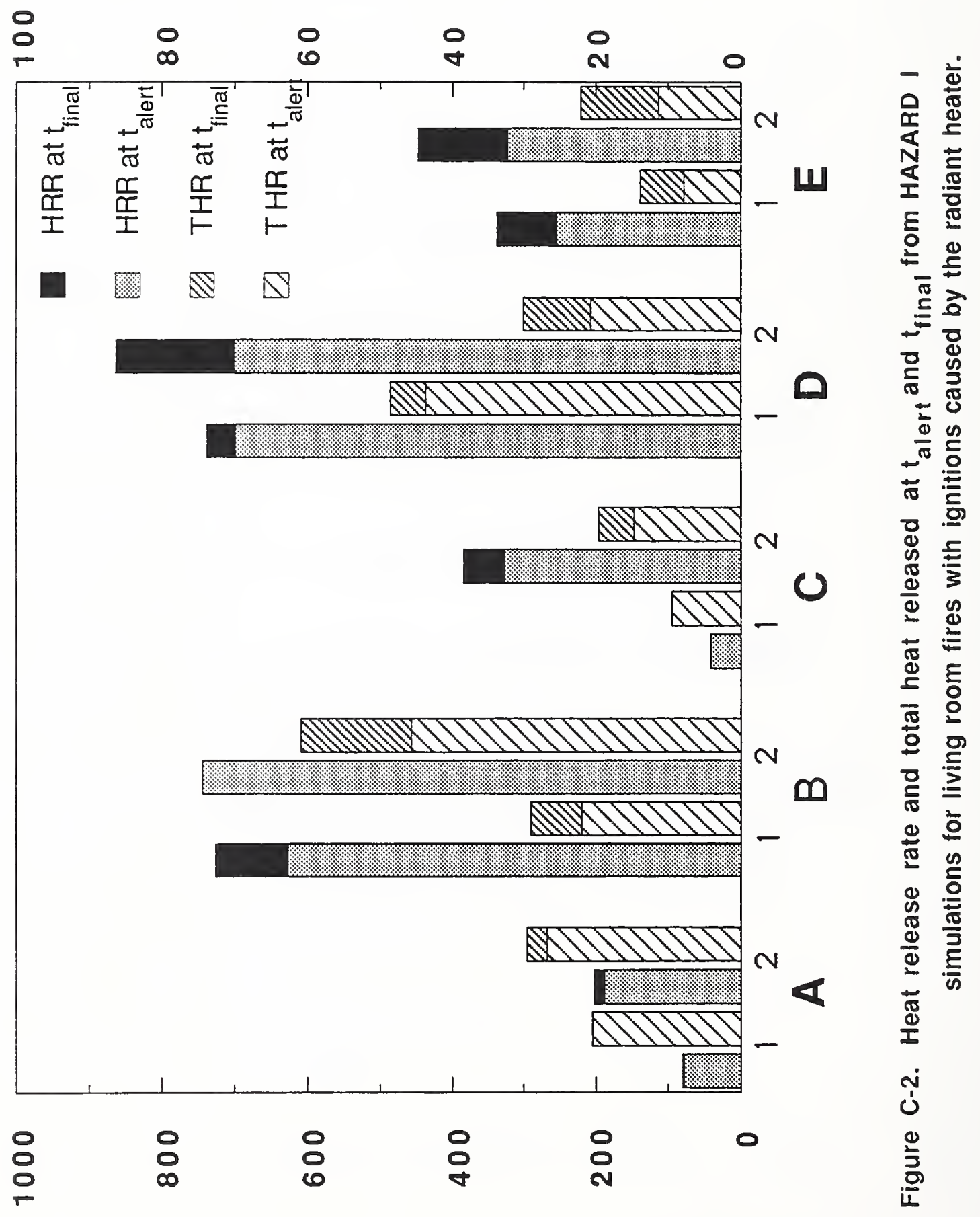

(MY) әңеч әsеәјәу цеән 


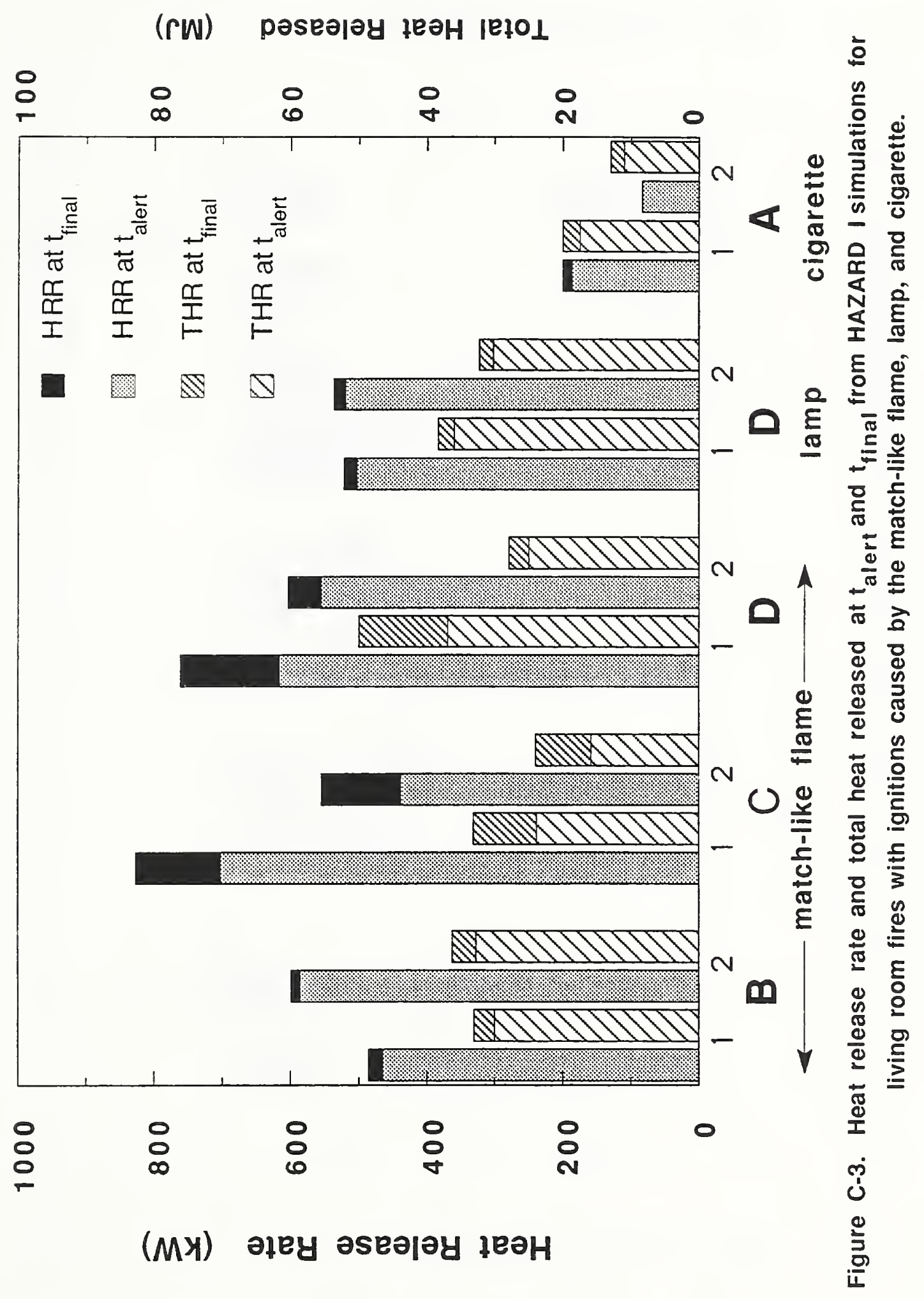




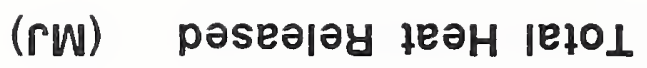

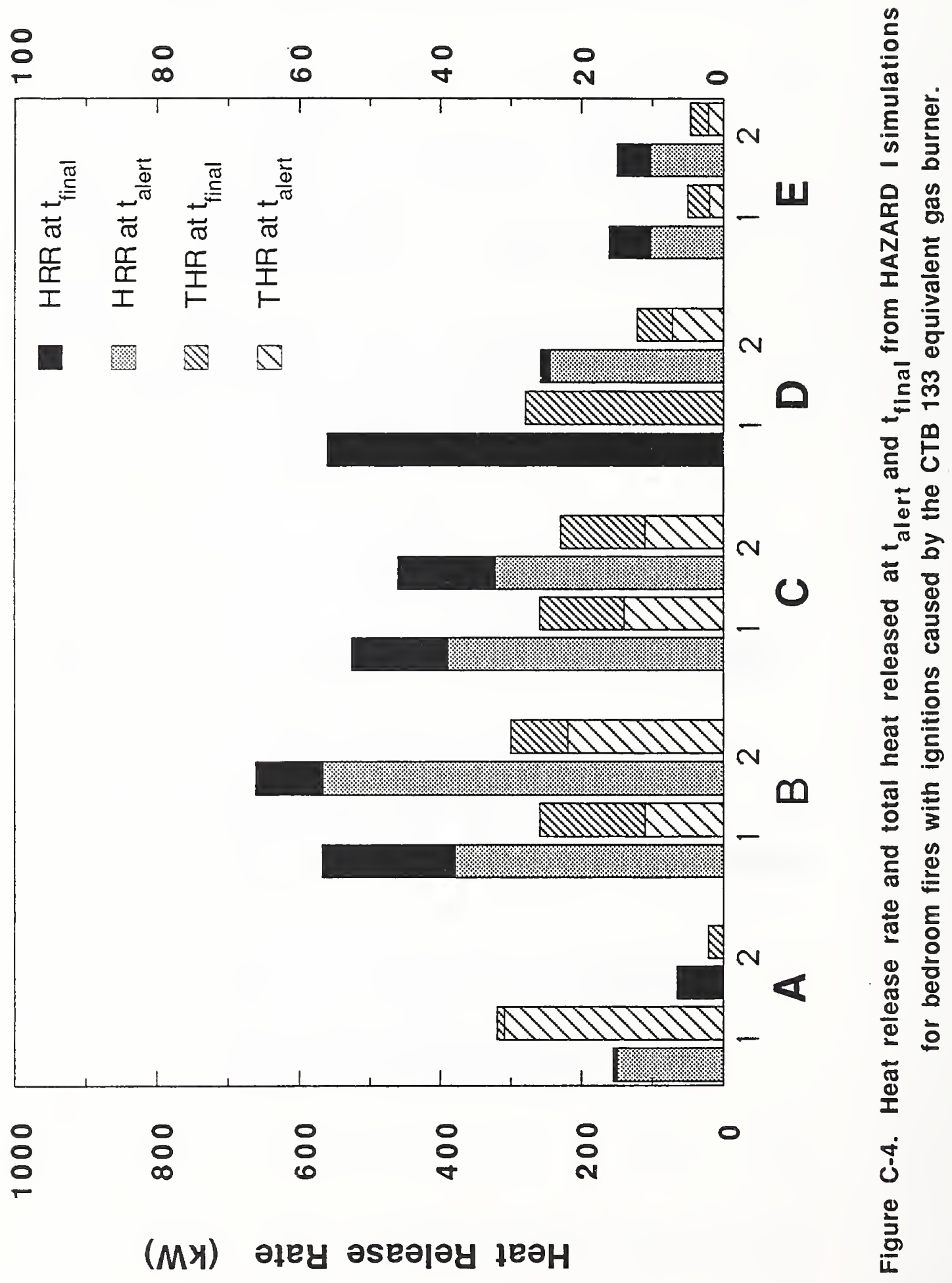




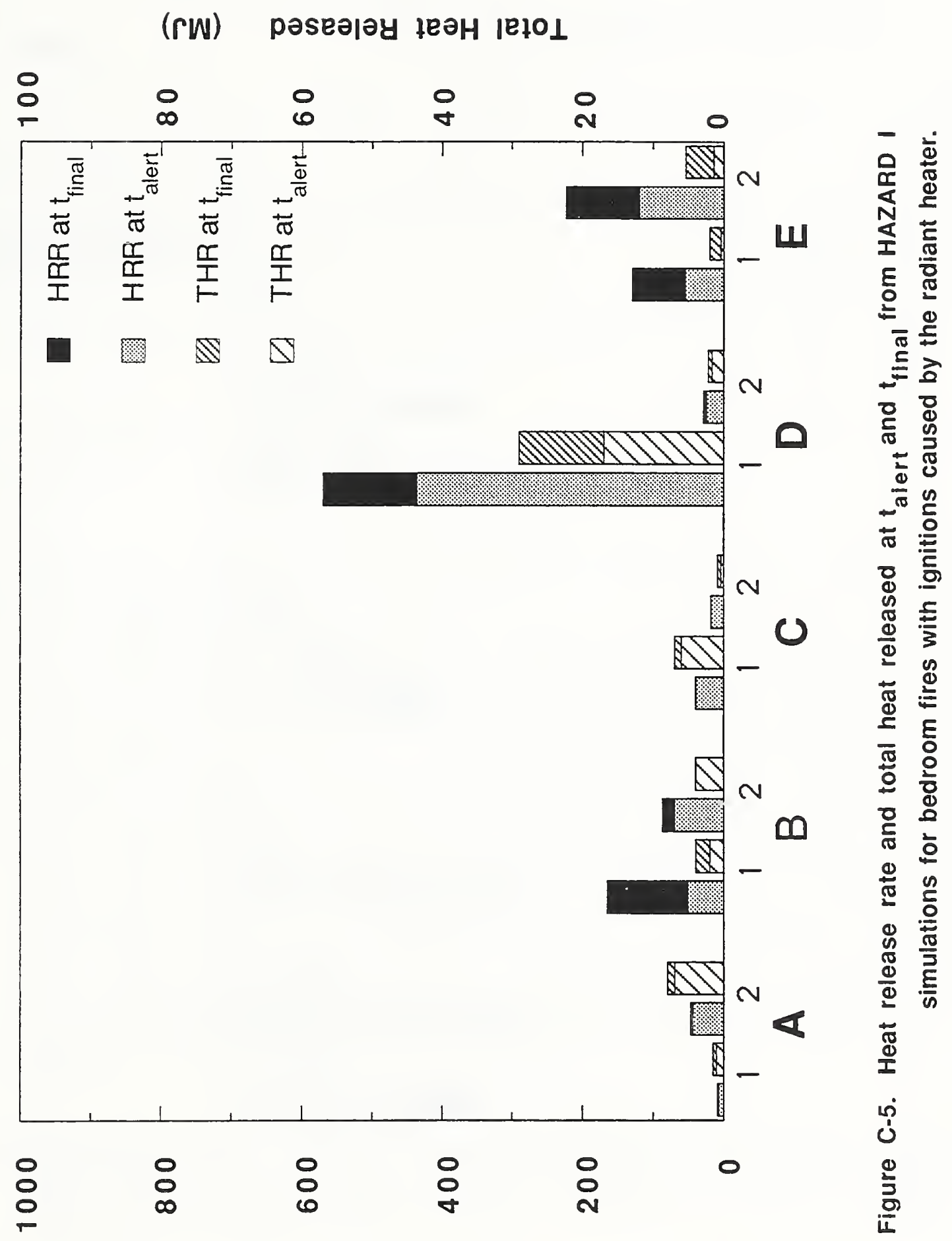

(Мя) әџеч әsеәәәу ұеән 


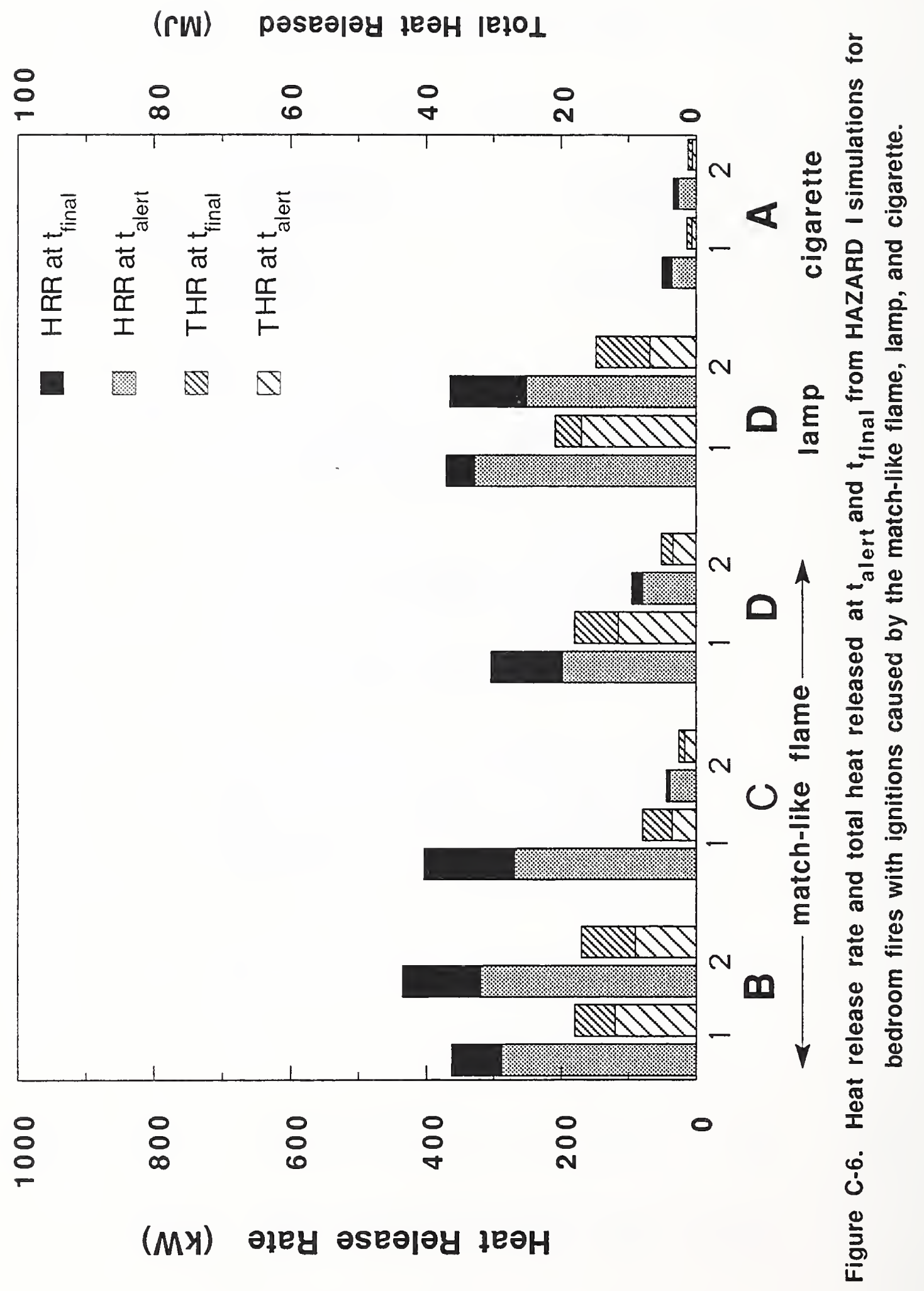




\begin{tabular}{|c|c|c|}
\hline \multirow[t]{3}{*}{$\begin{array}{l}\text { NIST-114A } \\
\text { (REV. 3-90) }\end{array}$} & \multirow{3}{*}{$\begin{array}{l}\text { U.S. DEPARTMENT OF COMMERCE } \\
\text { NATIONAL INSTITUTE OF STANDARDS AND TECHNOLOGY } \\
\text { BIBLIOGRAPHIC DATA SHEET }\end{array}$} & \begin{tabular}{|ll} 
1. & PUBLCATION OR REPORT NUMBER \\
& NISTIR 4847 \\
2. & PERFORMING ORGANIZATION REPORT NUMAER
\end{tabular} \\
\hline & & \\
\hline & & $\begin{array}{l}\text { 3. PUBLICATION DATE } \\
\text { June } 1992\end{array}$ \\
\hline
\end{tabular}

The Influence of Ignition Source on the Flaming Fire Hazard of Upholstered Furniture

5. AUUTHOR(S)

Thomas G. Cleary, Thomas J. Ohlemiller, and Kay M. Villa

6. PERFORMING ORGANIZATION (IF JOINT OR OTHER THAN MIST, SEE INSTRUCTIONS)

U.S. DEPARTMENT OF COMMERCE

MATIONAL INSTITUTE OF STANDARDS AND TECHNOLOGY

GANTHERSBURQ, MD 20899

7. CONTRACT/GRANT NUMBER

8. TYPE OF REPORT AND PERIOD COVERED

9. SPONSORING ORGANIZATION NAME AND COMPLETE ADDRESS (STREET, CITY, STATE, ZIP)

10. SUPPLEMENTARY NOTES

11. ABSTRACT (A 200-WORD OR LESS FACTUAL SUMMARY OF MOST SIGNIFICANT INFORMATION. IF DOCUMENT INCLUDES A SIGNIFICANT BIBLOGRAPHY OR LITERATURE SURVEY, MENTION IT MERE.)

A set of upholstered chairs constructed from five different fabric/foam combinations was subjected to a variety of ignition sources suggested by fire statistics. The sources included a cigarette, a small matchlike flame, an incandescent lamp, a space heater, and a large flame source (CTB 133 equivalent gas burner). The tests were performed in a furniture calorimeter where heat release rate and species production rates were obtained. For any chair type, the time to the peak heat release rate depended on the ignition sequence, but the magnitude of the peak did not, within the scatter of the data for any given chair. HAZARD I, the fire hazard assessment method developed at NIST, was used to quantify the hazard posed by the different ignition scenarios. No deaths were predicted when a working smoke detector was present. When a detector was not present, the results from the limited number of scenarios considered confirm the importance of a low peak heat release rate and a slow rate of rise to lessen the hazard of upholstered furniture fires. No one of the ignition scenarios examined consistently yielded the greatest potential hazard for all chair types tested when ignition and sustained burning was achieved. It is recommended that the hazards of upholstered furniture for residential use be assessed on the basis of resistance to small flame and cigarette ignition combined with peak heat release rate and time to peak subsequent to ignition by a strong source such as the CTB 133 equivalent gas burner.

12. KEY WORDS (6 TO 12 ENTRIES; ALPHABETICAL ORDER; CAPITAUZE ONLY PROPER NAMES; AND SEPARATE KEY WORDS BY SEMICOLONS) chairs; fabrics; fire statistics; fire hazard; furniture calorimeters; hazard analysis; home fires; ignition sources; upholstered furniture

FOR OFFICIAL DISTRIBUTION. DO NOT RELEASE TO MATIONAL TECHNICAL INFORMATION SERVICE (NTIS).

ORDER FROM SUPERINTENDENT OF DOCUMENTS, U.S. GOVERHMENT PRINTING OFFICE, WASHINGTON, DC 20402. 

